\title{
Effectiveness of Mealtime Interventions to Improve Nutritional Intake of Adult Patients in the Acute Care Setting: a Systematic Review.
}

\author{
Gail Whitelock \\ Master of Clinical Science \\ Joanna Briggs Institute \\ Faculty of Health Sciences \\ The University of Adelaide \\ Australia.
}

31st October 2012 


\section{Contents}

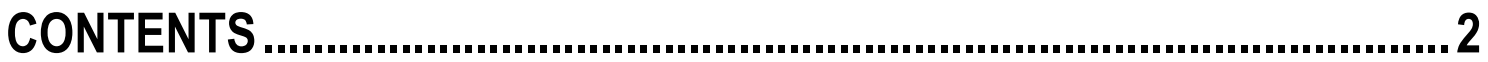

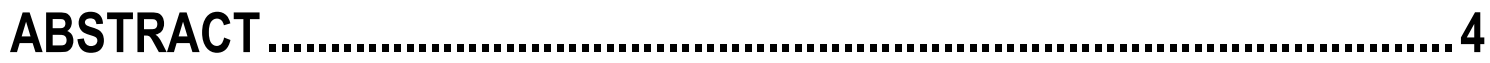

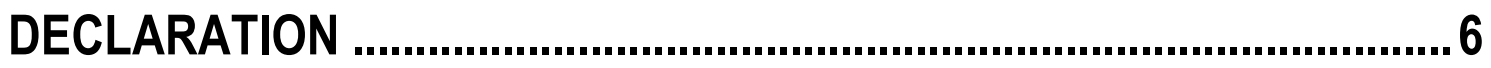

ACKNOWLEDGEMENTS ...................................................................

CHAPTER 1 INTRODUCTION ...........................................................

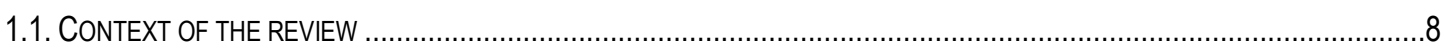

1.1.1. Defining malnutrition ............................................................................................................

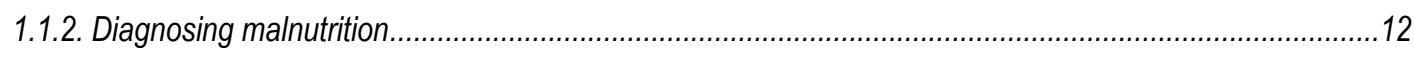

1.1.3. Prevalence of malnutrition......................................................................................................

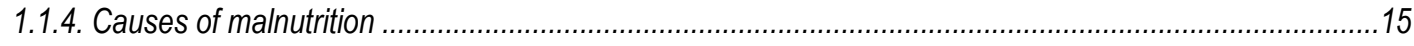

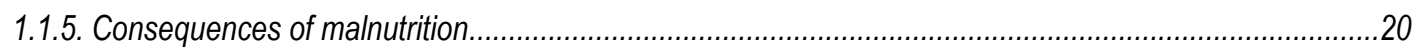

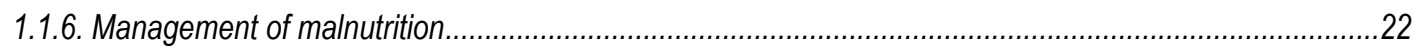

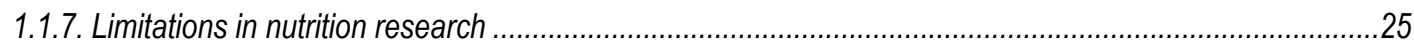

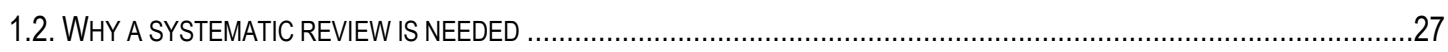

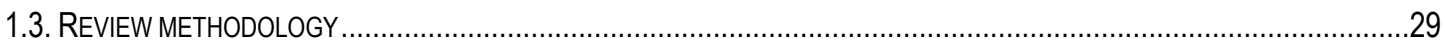



CHAPTER 2 SYSTEMATIC REVIEW........................................... 31

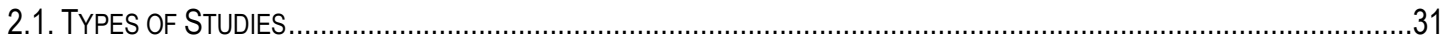

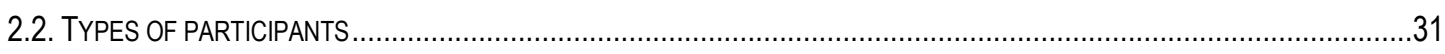

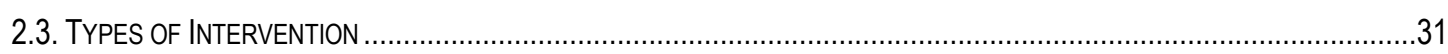

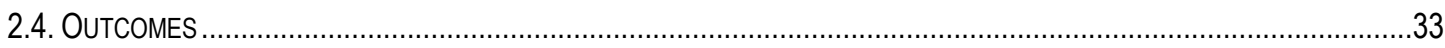

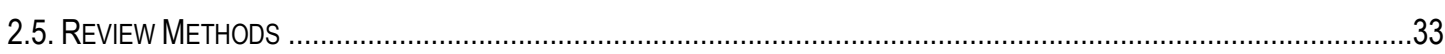

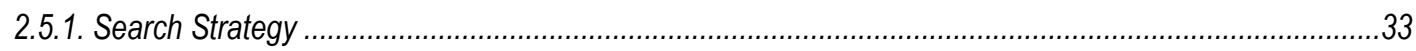

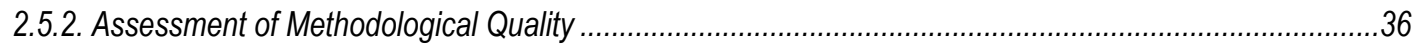

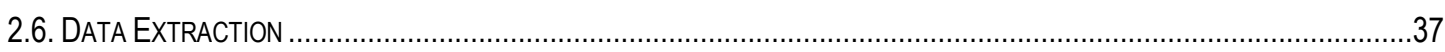

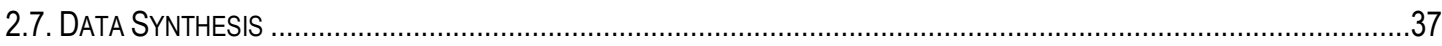

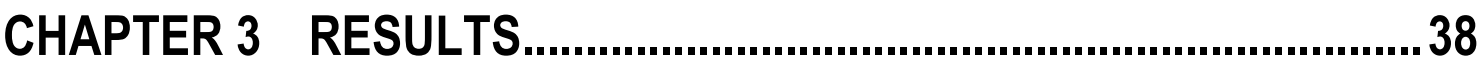

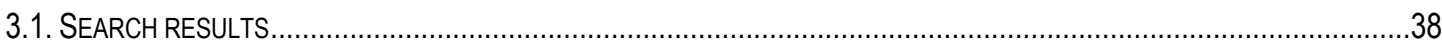

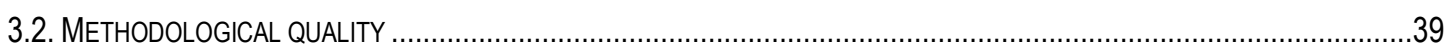

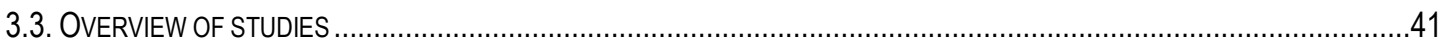

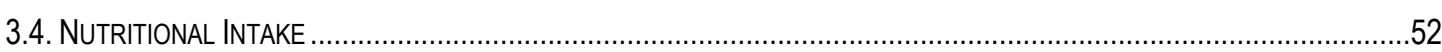




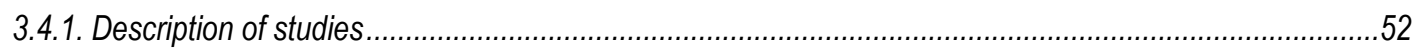

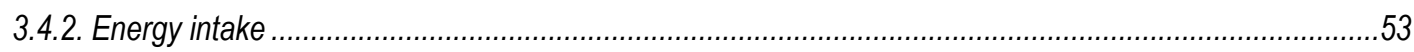

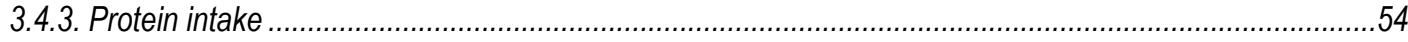

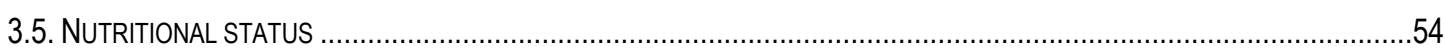

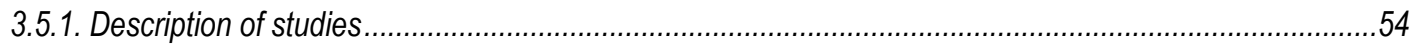

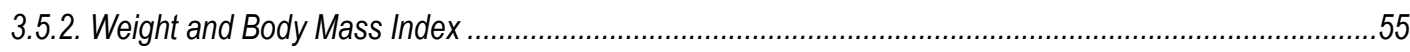

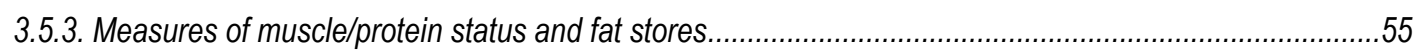

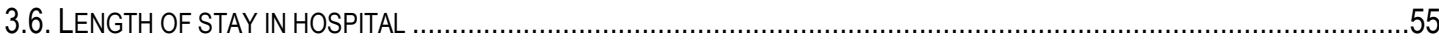

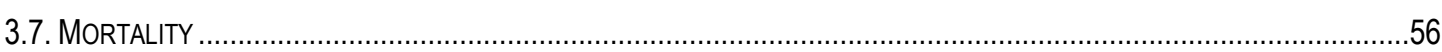

CHAPTER 4 DISCUSSION ............................................................57

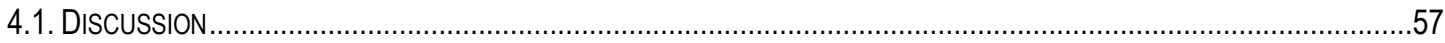

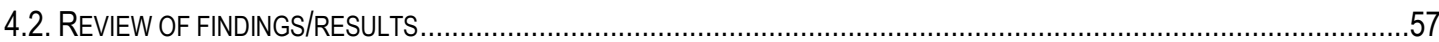

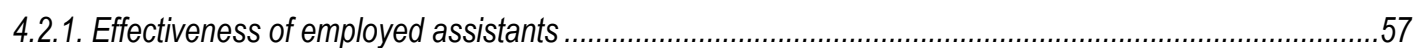

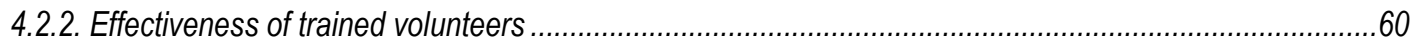

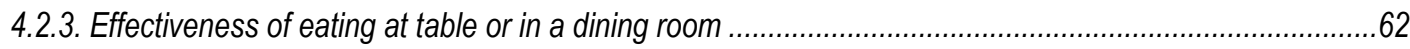

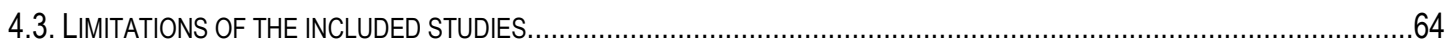

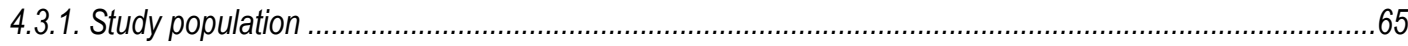

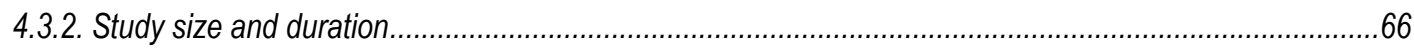

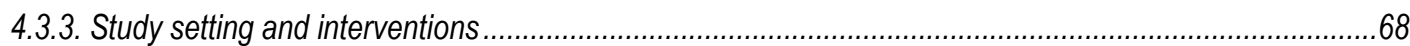

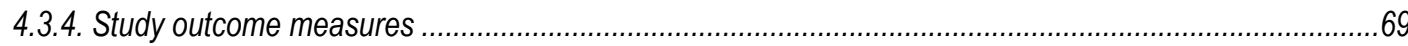

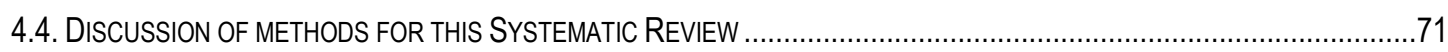

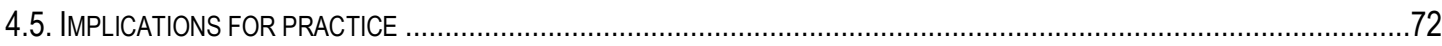

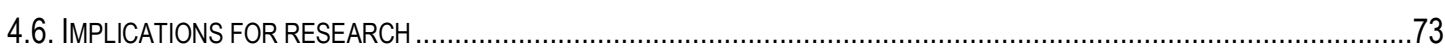

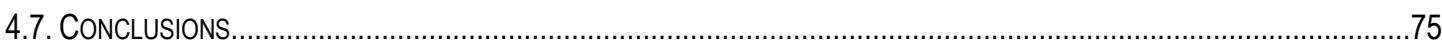

APPENDIX 1 SYSTEMATIC REVIEW PROTOCOL ..............................77

APPENDIX 2 SEARCH STRATEGY .............................................. 88

APPENDIX 3 CRITICAL APPRAISAL TOOL ......................................97

APPENDIX 4 DATA EXTRACTION TOOL ........................................102

APPENDIX 5 EXCLUDED STUDIES ...............................................105

APPENDIX 6 EXCLUDED STUDIES FOLLOWING CRITICAL

APPRAISAL ....................................................................................... 112

REFERENCES …...............................................................................113 


\section{Abstract}

Malnutrition affects $20-50 \%$ of patients in acute care hospitals. It is a problem that often goes unrecognised and untreated despite being associated with a number of adverse health consequences including delayed wound healing, increased infection rates, functional decline, increased length of stay in hospital and increased mortality. Lack of mealtime assistance has been suggested as a possible barrier to an adequate nutritional intake in patients. Mealtime intervention strategies focusing on either the mealtime environment or on the provision of support have been promoted by various organisations and advocacy groups as a means to improve nutritional intake. The objective of this systematic review was to identify, assess and synthesise the available evidence on the effectiveness of mealtime interventions to improve nutritional intake of adult patients in the acute care setting.

Published and unpublished studies in English language were searched for in PubMed/MEDLINE, CINAHL, EMBASE, Informit-health, Scopus and other citation databases. Three thousand four hundred and twelve citations were scanned to determine eligibility with 62 papers retrieved for full text examination. Nine papers matched the eligibility criteria for the review and were critically appraisal by two reviewers using the Joanna Briggs Institute - Meta Analysis of Statistics, Assessment \& Review Instrument. Six papers were ultimately included for data extraction and synthesis.

Six included studies involving 1071 patients evaluated the effectiveness of employed assistants, trained volunteers and eating around a table or in a dining room rather than by the bedside or in bed. Patient energy intake increased when employed assistants provided mealtime assistance, however this was only statistically significant for one of the two studies that investigated this mealtime intervention. Similarly, energy intake increased when trained volunteers supported patients at mealtimes; however this was only statistically significant in one of two relevant studies. Protein intake significantly increased in both studies where trained volunteers provided assistance at mealtimes. One study reported that energy intake significantly increased when patients ate around a table and another when patients ate in a dining room as compared with eating by or in their beds.

Mealtime interventions including the use of assistants, trained volunteers and eating at a table or in a dining room increases the energy intake of patients in acute care hospitals. Mealtime 
assistance provided by trained volunteers also increases protein intake in this patient group. Acute care providers should consider ways of implementing the aforementioned interventions throughout the day and prioritising mealtime care as a fundamental aspect of patient care. 


\section{Declaration}

I, Gail Whitelock, certify that this work contains no material that has been accepted for the award of any other degree or diploma in any university or any other tertiary institution, and, to the best of my knowledge and belief, contains no material previously published or written by any other person, except where due reference has been made in the text. In addition, I certify that no part of this work will, in the future, be used in a submission for any other degree or diploma in any university or other tertiary institution without the prior approval of the University of Adelaide and where applicable, any partner institution responsible for the joint-award of this degree.

I give consent to this copy of my thesis, when deposited in the University Library, being made available for loan and photocopying, subject to the provisions of the Copyright Act 1968.

I also give permission for the digital version of my thesis to be made available on the web, via the University's digital research repository, the Library catalogue, and also through web search engines, unless permission has been granted by the University to restrict access for a period of time.

Gail Whitelock

31st October 2012 


\section{Acknowledgements}

It would not have been possible for me to complete this thesis without the support of a number of significant people whom I would like to acknowledge and thank.

Firstly, I would like to thank my supervisors Dr Edoardo Aromataris, Associate Professor Michelle Miller and Dr Judith Gomersall for their ongoing advice and guidance. I would particularly like to thank Dr Edoardo Aromataris for his time, patience and encouragement which have enabled me to leave my comfort zone.

To my husband and children thank you for supporting me during this challenging time. I realise many things in our household have been sacrificed in order for me to complete this task.

In undertaking this thesis I have required a great deal of flexibility from my employer, which would not have been possible without the direct support of my manager Mrs Alison Shanks. Without her support and understanding I would not have been able to even entertain the thought of undertaking this thesis and I would like to thank her for this.

Finally, to the dietitians who conduct numerous small studies in the hospitals in which they work and who more often than not do not publish their work. What we do is meaningful and important, we need to publish and let the world know about what we do and improve patient care. 


\section{Chapter 1 Introduction}

\subsection{Context of the review}

Malnutrition is often identified as a condition that only affects people living in developing countries, however it is well documented that it is prevalent throughout the world in a variety of settings. (1) While it is viewed by many healthcare professionals as an important healthcare issue;(2) malnutrition remains largely unrecognised and untreated in the acute care hospitals $\mathbf{s}^{(1,3,4)}$ despite being associated with adverse clinical consequences, increased length of stay in hospital and increased healthcare costs.(1,5) Patients may be malnourished or at risk of malnutrition irrespective of their primary reason for admission to hospital and for many, their nutritional status will deteriorate further during the course of their stay in hospital. $(3,6-8)$

Malnutrition may be both a cause and consequence of disease. $(1,3)$ Table 1.1 . outlines the potential factors that may contribute to malnutrition. Malnutrition may also occur in the absence of disease, as seen in sarcopenia where there is a loss of both muscle mass and strength as part of the aging process. ${ }^{(9)}$ Weight loss may be observed in elderly patients as a result of this loss of muscle mass; which is caused in part by physiological changes in the stomach, changes in hormone levels, reduced intake of food and also reduced physical activity. $(9,10)$

Table1.1. Factors contributing to disease-related malnutrition.

\section{NOTE:}

This figure/table/image has been removed to comply with copyright regulations. It is included in the print copy of the thesis held by the University of Adelaide Library. 
(Adapted from Nutrition Support for Adults Oral Nutrition Support, Enteral Tube Feeding and Parenteral Nutrition. (11))

The last few decades have seen a growing interest in the subject of malnutrition in acute care hospitals. Accordingly, there has been an increased focus on identifying patients who are malnourished, or at risk of malnutrition, using nutrition screening and assessment tools. In Australia there has also been an increased interest in ensuring the correct diagnoses of malnutrition are made as in some instances these can lead to greater financial reimbursement for hospitals due to current case mix funding arrangements. (1, 12-14) Following the identification and documentation of the outcome of nutrition screening, action is required to ensure an adequate nutrition care plan is put into place and acted upon in an effort to ensure that individual patients have their nutritional needs met. Nutrition care plans need to take into account the individual patient's clinical condition and disease state. Whilst a good starting point, nutrition screening however does not guarantee that any action will be taken to ensure patients have adequate nutrition care plans implemented. A literature review by Weekes et al(15) indicated that screening alone may be insufficient to achieve benefits for malnourished patients and that more research is required to determine the most cost-effective interventions to manage malnutrition.

Patients may receive nutrition in hospital by various means, including orally, enterally or parenterally. Oral nutrition may be provided in the form of meals, snacks or oral nutritional supplements. For patients who are able consume food orally, the provision of nutrition falls largely to the hospital food service department who provide meals for the majority of hospitalised patients. Both the food service systems employed by hospitals and how the food is presented to patients can impact upon patient nutritional intake simply by influencing how appealing the food provided appears and how accessible it is to the patient.(16-18)

While oral nutrition in acute care hospitals may be available in a variety of forms as outlined above, it does not necessarily mean that patients will actually ingest this nutrition and receive the intended benefit of its provision. In 1859, Florence Nightingale stated "Every careful observer of the sick will agree in this that thousands of patients are annually starved in the midst of plenty, from want of attention to the ways which alone make it possible for them to take food." "(19) Over one hundred and fifty years later the problem highlighted persists; despite improvements in the 
identification of patients with malnutrition or at risk of malnutrition, improvements in palatability and nutritional adequacy of menus, oral nutritional supplements, enteral and parenteral feeding products, patients remain malnourished in hospital. Therefore it would seem apparent that there are other barriers to an adequate nutritional intake amongst patients in hospital. The circumstances of eating, including the mealtime environment and the lack of mealtime assistance for those who need it, have been cited as factors that can potentially influence patient nutritional intake in hospital. (20, 21) This has prompted organisations like Age UK (formerly Age Concern), the British Association for Parenteral and Enteral Nutrition (BAPEN) and the Council of Europe to call for eating environments that focus on the surroundings; food service systems that take into account individual patient preferences with regard to where they want to eat, consideration to be given to patients physical and mental status; suitably trained staff to assist patients with feeding difficulties; volunteers to assistant patients at mealtimes and also protected mealtimes. ${ }^{(22-25)}$

Pearson et al(26) report that nursing duties with regard to focusing on mealtimes and patient nutritional care in hospitals have diminished since the 1970's, compounding the problem of malnutrition. This change in practice has inadvertently led to a declining focus on the importance of nutrition and mealtimes in many hospitals. When asked, many nurses and doctors acknowledge nutrition as an important aspect of patient care, but few actively prioritise nutritional care in practice.(2) Kowanko et al(27) reported that although nurses considered nutritional care to be important many had difficulty in raising its priority above other nursing activities. Nurses report lack of time, competing priorities and taking their own meal breaks during patient mealtimes as reasons for not providing patients with the necessary assistance they need. $(2,27)$ Given the magnitude of the problem of malnutrition in hospital, the adverse clinical consequences associated with malnutrition and the lack of apparent action to assist patients at mealtimes, this systematic review will focus on the problem of malnutrition by examining the circumstances surrounding the provision of food and the mealtime environment in the acute care setting. This systematic review will seek to ascertain if there are any strategies that, when implemented, will effectively improve patient oral nutritional intake and/or nutritional status independently of the quantity or composition of the oral nutrition provided.

\subsubsection{Defining malnutrition}

Malnutrition literally means bad or faulty nutrition(5). Despite this literal meaning, there is confusion regarding the term and its use as numerous definitions exist in the literature with no internationally agreed interpretation existing amongst the experts in the field.(28-30) Among both lay people and many healthcare professionals, the meaning of malnutrition is commonly understood 
to encompass almost exclusively under-nutrition or underweight. In an attempt to remove this confusion regarding the definition of malnutrition various nutrition classification systems have been devised.(5) These classification systems have been broadly based on the following:

- which nutrients are involved;

- the number of nutrients involved;

- involvement of protein and other energy providing nutrients;

- lack of intake or excessive intake of nutrients based on what is considered to be a normal intake in the corresponding population group;

- clinical signs and symptoms of deficiency, for example vitamin C deficiency and the existence of scurvy or subjective clinical signs;

- initial cause of malnutrition, for example primary malnutrition due to poverty or secondary malnutrition as a consequence of illness or disease;

- increased demand for nutrients in usually healthy individuals, for example lactation; and

- the existence of other disease related factors such as malabsorption.

More recently, in a move to acknowledge the significance of inflammatory processes on nutritional status, Jensen (29) presided over an international guidelines development committee that proposed an 'aetiology-based' terminology to describe malnutrition in adults in the clinical setting. This terminology comprised of starvation-related malnutrition characterised by chronic starvation without inflammation, chronic disease-related malnutrition characterised by chronic inflammation which is of a mild to moderate degree, and acute disease or injury-related malnutrition. Following this, a study by Meijers(28) concluded that the definition of malnutrition should incorporate as a minimum the deficiencies of energy and protein and a decrease in fatfree mass. Function and inflammation were also considered to be important in defining malnutrition.(28) Defining malnutrition is fraught with complexity and requires the consideration of factors beyond simply insufficient consumption and absorption of nutrients but also the potential inflammatory processes that may occur in the presence of disease. For the purposes of this systematic review the term malnutrition will only refer to the state of protein-energy under-nutrition in patients who are being treated in acute care hospitals. This definition of malnutrition was used by Watterson et al(1) in the recent Australian Evidence based practice guidelines for the nutritional management of malnutrition in adult patients across the continuum of care. This definition best describes both the nutritional markers of interest in this systematic review, namely those of energy and protein intake and the clinical status of patients who are under-nourished. 


\subsubsection{Diagnosing malnutrition}

Unlike many other diseases there is no single diagnostic test for malnutrition. As a result of this lack of uniformity obtaining consistent and comparable data on informing diagnosis of malnutrition is often problematic. Historically, a range of measures have been used to determine if a patient is malnourished or not, including albumin, pre-albumin, haemoglobin, transferrin and total lymphocyte count. In addition to these measurements, clinical judgement has also been exercised to determine patient nutritional status by assessing patient fat and muscle stores. The International Classification of Diseases-10 (ICD-10) is the World Health Organisation's (WHO) standard diagnostic tool for epidemiological, health management and clinical purposes. This tool is used to classify and monitor the incidence and prevalence of diseases and other health problems in WHO member countries. Many member countries use this data to assist in the allocation of healthcare funds and in the development of healthcare policy.(31) The International Classification of Diseases and Related Health Problems Australian Modification (ICD-10-(AM)) states that "the degree of malnutrition is usually measured in terms of weight, expressed in standard deviations from the mean of the relevant reference population".(32) Codes E40 - 46 relate to various classifications for malnutrition as outlined in Table 1.2.

Table 1.2. World Health Organisation ICD-10.(1,32)

\begin{tabular}{|c|c|}
\hline WHO Code & Description \\
\hline E40 & $\begin{array}{l}\text { Kwashiorkor (severe malnutrition with nutritional oedema and with } \\
\text { dyspigmentation of skin and hair). }\end{array}$ \\
\hline E41 & Nutritional marasmus (severe malnutrition with marasmus). \\
\hline E42 & $\begin{array}{l}\text { Marasmic kwashiorkor (severe protein-energy malnutrition (as in E43): } \\
\text { intermediate form with signs of both kwashiorkor and marasmus). }\end{array}$ \\
\hline E43 & $\begin{array}{l}\text { Unspecified severe protein energy malnutrition (in adults, BMI }<18.5 \\
\mathrm{~kg} / \mathrm{m}^{2} \text { or unintentional loss of weight }(>10 \%) \text { with evidence of suboptimal } \\
\text { intake resulting in severe loss of subcutaneous fat and/or severe muscle } \\
\text { wasting). }\end{array}$ \\
\hline E44.0 & $\begin{array}{l}\text { Moderate protein-energy malnutrition (in adults, } \mathrm{BMI}<18.5 \mathrm{~kg} / \mathrm{m}^{2} \text { or } \\
\text { unintentional loss of weight }(5-9 \%) \text { with evidence of suboptimal intake } \\
\text { resulting in moderate loss of subcutaneous fat and/or moderate muscle } \\
\text { wasting). }\end{array}$ \\
\hline E44.1 & $\begin{array}{l}\text { Mild protein-energy malnutrition (in adults, } \mathrm{BMI}<18.5 \mathrm{~kg} / \mathrm{m}^{2} \text { or } \\
\text { unintentional loss of weight }(5-9 \%) \text { with evidence of suboptimal intake }\end{array}$ \\
\hline
\end{tabular}




\begin{tabular}{|l|l|}
\hline & resulting in mild loss of subcutaneous fat and/or mild muscle wasting). \\
\hline E45 & $\begin{array}{l}\text { Retarded development following protein-energy malnutrition (short } \\
\text { stature, stunting, physical retardation due to malnutrition). }\end{array}$ \\
\hline E46 & $\begin{array}{l}\text { Unspecified protein-energy malnutrition (malnutrition, protein-energy } \\
\text { imbalance). }\end{array}$ \\
\hline
\end{tabular}

Since 2008 dietitians in Australia have been diagnosing and coding for malnutrition in patient case mix summaries which are a standard component of patient medical records. The code definitions outlined in Table 1.2. refer to Body Mass Index (BMI), percentage weight loss, evidence of subcutaneous fat loss and muscle wasting. Body Mass Index is a measure of fat stores ${ }^{(33)}$ which can be calculated from an individual's weight and height using the following equation:

$$
\mathrm{BMI}=\frac{\text { Weight }(\mathrm{kg})}{\text { Height }(\mathrm{m})^{2}}
$$

Surrogate measures used to estimate height, including ulna length or demi-span, are commonly used in the acute care setting rather than actual height.(5, 33) It should be noted that different reference standards for BMl are used in different countries and different population groups. ${ }^{(5,34)}$ Accordingly, care needs to be taken when interpreting BMI in countries like Australia that have diverse ethnic populations including European, Asian and Aboriginal populations. Furthermore, difficulties may arise whilst attempting to obtain accurate measures of BMI in the acute care setting as recordings of weight may be confounded by patients experiencing fluid retention secondary to disease, where patients are too unwell to undertake such measurements and also, patients do not consent to have their height or weight measured.(5) Percentage of total body weight loss can give an indication of tissue mass and adequacy of patient energy intake. (33) An indication of subcutaneous fat can be obtained by measuring triceps skinfold (TSF) thickness; muscle mass by measuring mid-arm circumference (MAC) or subsequent calculation of mid-arm muscle circumference (MAMC) and muscle function is indicated by obtaining grip strength using hand grip dynamometry. ${ }^{(33)}$

Nutrition screening tools facilitate the identification of patients at risk of malnutrition, whereas nutrition assessment tools facilitate the diagnosis of malnutrition in patients in a variety of care settings. Table 1.3. outlines both the nutrition screening and assessment tools that have been validated for use in the acute care setting and which are commonly used. 
Table 1.3. Nutrition screening and assessment tools validated for use the acute care setting.

\begin{tabular}{|l|l|}
\hline Nutrition Screening Tools & Nutritional Assessment Tools \\
\hline Malnutrition Screening Tool (MST). & Subjective global assessment (SGA). \\
\hline $\begin{array}{l}\text { Malnutrition Universal Screening Tool } \\
\text { ('MUST'). }\end{array}$ & $\begin{array}{l}\text { Patient generated subjective Global } \\
\text { Assessment (PG-SGA). }\end{array}$ \\
\cline { 1 - 1 } $\begin{array}{l}\text { Mini Nutritional Assessment - Short Form } \\
\text { (MNA-SF). }\end{array}$ & $\begin{array}{l}\text { Mini-nutritional assessment (MNA) for older } \\
\text { adults. }\end{array}$ \\
\cline { 1 - 1 } $\begin{array}{l}\text { Nutritional Risk Screening (NRS -2002). } \\
\text { Sumplified Nutritional Assessment }\end{array}$ & \\
\hline
\end{tabular}

(Taken from Watterson et al(1) Evidence based practice guidelines for the nutritional management of malnutrition in adult patients across the continuum of care).

\subsubsection{Prevalence of malnutrition}

It has been acknowledged for decades in the literature that the problem of malnutrition in acute care hospitals routinely goes unrecognised, and as a result, often subsequently untreated. ${ }^{(1,3)}$ It is for this reason that much of the research in recent years on malnutrition has focused on the prevalence of both malnutrition and risk of malnutrition in the acute care and also other healthcare settings. To understand the magnitude of the problem of malnutrition in different settings it has been fundamental to obtain prevalence data. During this time there has also been a plethora of both nutrition screening and assessment tools developed to assist in identifying patients at risk of malnutrition and to diagnosis malnutrition.(35) Many of these tools have been validated, which has subsequently enabled clinicians to determine the prevalence of malnutrition or malnutrition risk in various healthcare settings with some degree of uniformity and consistency. In order to correct a problem it must first be acknowledged that a problem exists; data from these studies has enabled the problem of malnutrition to be acknowledged and enabled steps taken to address the problem.

Data from prevalence studies conducted in acute care settings in Australia, Europe and South America have shown that malnutrition is known to affect between $20-50 \%$ of patients depending

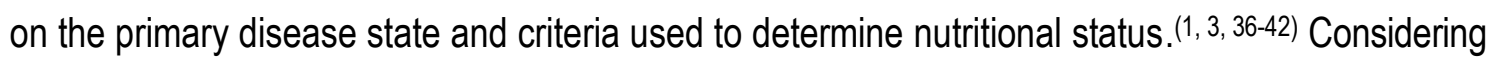
the primary disease state, these studies have shown that there is a greater incidence of malnutrition in certain population groups including the elderly, patients with cancer, critical illness, neurological disease, orthopaedic injury, respiratory disease, gastrointestinal disease, renal 
disease, cystic fibrosis, Human Immunodeficiency Virus (HIV) and Acquired Immunodeficiency Syndrome (AIDS). $(1,5,8,38,39)$ A number of other factors have also been found to increase risk of malnutrition including being female, polypharmacy, lower level of education and living alone. $(38,43)$ It should be noted however, that prevalence studies do not provide this complete picture regarding malnutrition as many of the measures used in these studies are not disease specific and there is still debate over the accuracy and suitability of some measures of nutritional status for example the use of BMI in Asian populations who have been found to have higher proportions of body fat than those from other population groups. (44) In addition to this, what is considered to be an ideal body weight has changed over time with adjustments made to BMI ranges and variation in anthropometric measures readily occurring between those undertaking such measurements. ${ }^{(5)}$

\subsubsection{Causes of malnutrition}

Worldwide the most common cause of malnutrition is famine or natural disaster.(5) These events make it near impossible for affected people to secure a hygienically safe supply of food and water. In developed countries with advanced food production systems and financial reserves, these events do not present the same devastating consequences. The most likely cause of malnutrition in developed countries is disease. $(5,8)$ Patients may already be malnourished or at risk of malnutrition on admission to hospital. $(36,45)$ This may be solely as a consequence of disease or due to other factors such as poverty, lack of access to suitable shops, lack of cooking facilities, skills or knowledge; reliance on others to provide food for example, in the case of children, elderly, people with mental or physical illness or disabilities or a combination of all of these factors. Eating disorders such as anorexia nervosa are also known to cause to malnutrition in developed countries. ${ }^{(5)}$

\section{Disease and symptoms of disease}

Many acute and chronic diseases have the potential to affect nutritional status. The mechanisms by which this occurs are complex and often multi-factorial. In some cases usual nutritional intake may be sufficient or insufficient to meet an individual patient's nutritional needs depending on the type and/or severity of disease. For patients with certain gastrointestinal diseases, burns or those who have wound healing issues, nutritional requirements may be elevated; in these patients experiencing physiological stress, their nutritional intake rapidly becomes inadequate. Resting energy expenditure is known to be elevated in conditions such as HIV and AIDS, pancreatic and lung cancers, chronic obstructive pulmonary disease and Crohns disease, however total energy 
expenditure may be less than in other disease due to reductions in physical activity while unwell. (5)

Disease or the specific symptoms of disease may affect a patient's nutritional intake by influencing their ability to eat or affecting the digestion or absorption of nutrients. $(5,6,46)$ Oral problems like poor dentition and dry or painful mouth may affect ability to chew and limit the types of foods eaten resulting in a diminished nutritional intake.(5, 6, 45, 47) Dysphagia, oesophageal strictures and respiratory problems can similarly impair eating, resulting in a reduced nutritional intake. $(5,6,45)$ Compromised motor skills can make it difficult for patients to manipulate food on a plate and bring it to their mouth to eat, move themselves into a suitable position to eat or reach food; all of which hinder self feeding and adversely impact on nutritional intake.(5, 6, 47) Psychosocial problems including depression and anxiety can suppress appetite whilst it is common for patients with dementia to forget how to eat.(5) Appetite can generally be affected by illness with many patients becoming apathetic about preparing and eating food.(6) Symptoms of disease such as diarrhoea and vomiting can lead to vitamin and mineral losses as well as fatigue which further compounds the problem. ${ }^{(6)}$

\section{Medical treatments and investigations}

The treatments and investigations employed in the management of diseases can adversely affect patient nutritional intake and/or status due to reasons including:

- missing meals due to medical and surgical procedures;

- delayed meals due to medical and surgical procedures;

- extended and/or inappropriate periods of fasting;

- treatments such as chemotherapy and radiotherapy leading to symptoms of nausea, vomiting, taste alterations, dry mouth, diarrhoea and constipation which can reduce nutritional intake; and

- medications impacting on nutritional status either from their effect on digestion and absorption of nutrients or the side effects they bring including taste alterations, sedation, nausea and vomiting. Antiobiotics, cytotoxic drugs, opiates, diuretics, antigout, antituberculosis, prokinetic agents and antidepressants are known to have an adverse impact on nutritional status and/or status. $(5,6,48)$

\section{Food service}

Hospitals throughout the world provide nutrition for patients in various forms, including food as meals and snacks, oral nutritional supplements, enteral and parenteral nutrition. It has been 
reported by Allison ${ }^{(49)}$ that $75 \%$ of patients rely solely on hospital food as their source of nutrition. The remaining patients may obtain their nutrition in part from hospital food but may also receive additional nutrition by means of oral nutritional supplements, enteral nutrition, parenteral nutrition, or a combination of all three. Some patients will not receive any nutrition in the form of food and will solely rely on these other sources of nutrition to meet their nutritional needs. Historically nursing staff provided patients with their meals, $(26,27)$ however today nurses rarely deliver meals to patients and the task is more likely to be undertaken by food service or ancillary staff(26) who are not trained in patient nutritional care. ${ }^{(50)}$

Hospital food service departments use a variety of systems to produce meals including cook-chill, cook-freeze and cook-fresh methods. Food may be delivered to patients as plated meals or as part of a bulk meal delivery system. A systematic review by Mahoney et al(16) indicated that a point of service meal delivery system such as a bulk system had the potential to increase patients energy intake. In addition to this other aspects of hospital food service systems can also contribute to patients not eating, including inflexible and prescriptive systems where meals are ordered hours or days in advance of being served to the patient and served at times determined by the hospital rather than the patient. Naithani et al(17) reported that patients often feel hungry but can have difficulty accessing food when they want it. Naithani et al(17) also reported that surgical patients, the elderly and patients with physical disabilities experience the greatest difficulty in accessing food. Today few hospitals have localised ward kitchens/pantries where nursing staff can access food at anytime of the day as patients require. This can further limit patient access to food, making it available only at the designated hospital mealtimes unless brought into hospital by visitors.

Meal ordering systems can be fraught with difficulty and can inadvertently exacerbate the problem of malnutrition in hospital as the descriptions of menu items may not accurately reflect the meal served. Furthermore, menus are often printed in one font size and in one language; limiting their utility amongst patients who are visually impaired, illiterate or do not read the language. These patients are more likely to require assistance to complete hospital menus in order to make suitable choices, or be offered a default meal if this assistance is not provided. Menus may offer a limited choice of food that does not take into account cultural or local taste preferences, textures or choice of portion sizes. Furthermore, many hospitals work on a limited cyclical menu of one or two weeks, if patients have been in hospital for extended periods across the menu cycle this can create menu fatigue which is also likely to limit nutritional intake. 
Studies on the provision of food in hospital have tended to involve patient questionnaires that focus on examining food preferences or satisfaction with the flavour of the food provided rather than address the nutritional adequacy of what is provided.(50) Many of these studies report that patients are generally happy with the food they are provided with(17) however despite this, studies have also shown that between $17-58 \%$ (by weight) of the food provided by hospitals is not eaten by patients and wasted. $(50,51)$ When Stanga et al(18) surveyed 317 patients in two Swiss hospitals, it was revealed that only $28 \%$ of patients reported that they consumed the full serve of their meal; while $50 \%$ of patients reported having a reduced appetite at some point during their admission to hospital. Although many hospitals report that their menus provide sufficient nutrition to meet patient needs, these wastage figures suggest that patients are not consuming adequate nutrition to meet their needs. (52-54) In reality, hospital menus may be nutritionally adequate but only for patients who require healthy eating choices like those admitted to hospital for routine procedures or lifestyle diseases and not for those who are acutely unwell and who require meal options with increased nutrient density. Food wastage in hospitals is greater than in other establishments like restaurants, schools or work place canteens. (55) Meals that are prepared, delivered and not eaten are both costly to the hospital and represent ineffective use of what is often a limited resource. ${ }^{55,}$ 56) These hospital food questionnaires also reveal that patients report that the temperature, appearance and aroma of the food they are presented with is particularly important. (18) The presentation of food can therefore potentially have an impact on how much patients will eat, or if they will eat at all. A study by Nijs et al(57) in patients in a nursing home found that nutritional intake was increased and incidence of malnutrition decreased when food was served on china crockery, with table cloths and appropriate cutlery. Evidently food that is presented in an inviting and appealing way is more likely to be consumed. Food in acute care hospitals however, is often presented on poor quality or plastic crockery with inadequate cutlery offered. Given that the temperature of the food is considered important by patients, any patients who require mealtime assistance to eat would need to receive such assistance in a timely manner before their meal becomes cold, in order to ensure the food is consumed.

Food services have largely been viewed by hospital management as part of hotel services rather than clinical services despite the aforementioned association of suboptimal nutritional intake with adverse clinical outcomes. Given this, Allison ${ }^{(50)}$ reported that food services in hospitals are often targeted to make cost saving in times of financial difficulties. The financial pressures placed on food services, together with current food hygiene requirements, has seen an increase in the use of individual portion control packs of foods and drinks in hospitals. This type of packaging can present difficulties for those patients with limited dexterity for whom opening these packages 
presents a challenge that potentially hinders their ability to readily access food and fluids. Naithani et al(17) noted in their qualitative study on hospital patients' experiences in accessing food, that problems in accessing food generally remain hidden because staff do not notice them and because patients are reluctant to ask for help.

\section{Ward and mealtime environment}

Apart from the problems associated with the provision of meals in hospital the following scenarios are common-place in the acute care setting and may further contribute to an inadequate nutritional intake:

- lack of routine to prepare patients for mealtimes;

- inappropriate positioning for eating, for example lying instead of sitting, meal being placed out of immediate reach;

- lack of assistance opening lids, food and fluid packages;

- lack of assistance cutting up food into bite sized pieces, putting in straws, buttering bread and seasoning food;

- dentures or glasses not in place prior to or during mealtimes;

- lack full feeding assistance;

- disturbances from noise and odours during mealtimes;

- interruptions by hospital staff; and

- lack of the necessary encouragement to eat.

\section{Hospital Staff}

The overall lack of recognition of malnutrition in acute care hospitals can in itself be a cause of the ongoing problem given that any adverse clinical condition if left unmanaged, is likely to worsen.(1,3) Despite the growing body of evidence, nutrition screening that can assist in the identification of patients at risk of malnutrition is not routinely performed by nurses in all hospitals. (4) Lack of recognition of malnutrition may also be evident in the documentation or lack of documentation of nutritional issues by nursing, medical and allied health staff in patient medical records. Using the Subjective Global Assessment, Gout et al(13) found in a study of 275 patients in an Australian acute care hospital that $23 \%$ were malnourished. Of the patients who were identified as being malnourished, only $15 \%$ of them had this indicated in their medical records. A dietitian was involved in $45 \%$ of the malnourished cases but had only documented the patient as being malnourished in $29 \%$ of the cases. (13) Communication difficulties do not exist exclusively in regard to medical records but also between hospital departments. Poorly defined communication 
pathways between food service, nursing, medical, dietetic and other allied health departments with regard to patients' nutritional needs can have an impact on a patient care.(2)

Nightingale and Reeves(58) examined malnutrition knowledge among different health professionals in a British acute care teaching hospital and found that nutritional knowledge was poor among nurses, doctors and pharmacists. The food service or ancillary staff who serve patients their meals are unlikely to have an understanding or knowledge of malnutrition or the importance of providing adequate nutritional care. ${ }^{(50)}$ Lack of procedures and policy from hospital management, poor communication between disciplines and departments, together with a lack of responsibility and a simple lack of acknowledgement further reinforces this adverse situation. $(2,50)$ For many patients who develop malnutrition or are at risk of developing malnutrition it is likely that a combination of the aforementioned factors may apply.

\subsubsection{Consequences of malnutrition}

An inadequate or absent nutritional intake over time with or without the presence of disease will result in weight loss due to the loss of fat stores and muscle mass. ${ }^{(59)}$ The rate at which this occurs varies between patients depending on their initial fat stores and muscle mass. ${ }^{(5)}$ Various studies have indicated that an unintentional weight loss of between $15-23 \%$ of body weight can bring about adverse physical and psychological changes. $(5,30)$ While an unintentional weight loss of $38-50 \%$ of body weight has been reported as being incompatible with life. ${ }^{(5)}$

\section{Muscle and fat loss}

Physically, a significant loss of fat stores and muscle mass can adversely affect respiratory and cardiac muscle function, ${ }^{(30,60)}$ as well as gastrointestinal absorption, renal function ${ }^{(60)}$ and impair the immune response making infections more difficult to detect and treat.(14) Thermoregulatory processes are also known to be affected by weight loss. ${ }^{(30)}$ Muscle function can become impaired in response to an inadequate nutritional intake well before any losses in muscle mass are detected.(59) This reduced muscle function quickly returns when nutritional intake improves. Muscle function is commonly assessed by hand grip dynamometry. $(5,6,33)$ Given that both cardiac muscle mass and function can be reduced in malnutrition, cardiac failure has been suggested as a final cause of death in malnourished patients.(5) Deaths attributable to malnutrition are still being reported in acute care hospitals in the United Kingdom and Australia.(14,61) Psychological changes including fatigue, apathy and depression can occur in response to malnutrition which make it more difficult for patients to find the motivation to eat in order to facilitate their recovery. ${ }^{6}$, 60) 


\section{Complications}

Malnutrition has been shown to increase the risk of developing pressure sores, post operative complications, delay wound healing, decrease intestinal absorption of nutrients, impair mobility and as previously mentioned, increase infection rates. $(5,6,11,14,30,60)$ Furthermore malnourished females are at risk of developing menstrual irregularities.(11) Surgeons have reported since the 1930s that malnourished patients are three to four times more likely than well nourished patients to develop post surgical complications. ${ }^{(59)}$ Malnourished patients are also more likely to require assistance from healthcare professionals at home post discharge from hospital and to have more readmissions to hospital.(5)

\section{Financial consequences}

Aside from the individual physical and psychological consequences of malnutrition for the patient, there are major economic consequences incurred by both the patient and healthcare provider. In Australia an estimated $\$ 46.3$ billion was spent on hospitals in $2009-10$ or $3.7 \%$ of the country's gross domestic product. In the period from 2005 to 2010 spending on Australian hospitals increased at a rate that was higher than the rate of inflation. (62) Presentations to Australian hospital emergency departments have increased by $4.9 \%$ per year over the last 5 years and admissions to hospitals have increased by $3.6 \%$ per year.(63) Given this increase in demand for acute care hospital beds and an aging population,(64) it is likely that healthcare costs will continue to escalate. The BAPEN advisory group on malnutrition reported an estimated public expenditure in excess of $£ 13$ billion (approximately $A \$ 21$ billion per exchange rate October 2012) on diseaserelated malnutrition in the United Kingdom in 2007.(65) Also within the United Kingdom, the National Institute for Health and Clinical Excellence identified better nutritional care as the fourth largest potential source of cost saving to the National Health Service in the United Kingdom. (11) The treatment costs for patients who are malnourished or at risk of malnutrition in hospital are reported to be $20-60 \%$ greater than for patients who are not malnourished or at risk of malnutrition. ${ }^{(42,66-68)}$ The increased cost of treating a malnourished patient comes as a result of the consequences of malnutrition including the higher incidence of infections and pressure sores and reduced mobility and functionality, which leads to an increased need for medications, procedures, nursing and other supportive care.(14)

In Australia, a diagnosis of malnutrition documented in the medical records as a co-morbidity or complication has the ability to influence the Australian National - Diagnosis Related Group which can bring about financial reimbursement for the treating hospital. $(1,14)$ Therefore, if malnutrition is not appropriately documented in the medical records it can result in a financial shortfall for the 
treating hospital. $(12,13)$ With finite resources it is prudent that healthcare providers recognise any inefficiencies or potential ways of reducing healthcare costs in order to effectively manage this healthcare issue.

\section{Length of stay in hospital}

It has been widely reported in the literature that malnutrition is associated with an increased length of stay in hospital. $(7,8,14,66)$ Norman et al(8) reviewed eight studies investigating length of stay in hospital and found that patients who were moderately or severely malnourished had lengths of stay $40-70 \%$ greater than well nourished patients. A study by Smith et al(69) in 19 hospitals in the United States examining the cost saving associated with the level of nutritional care provided in hospital found that patients at risk of malnutrition who received nutritional interventions by day three of admission including additional nutritional provision from larger meal serves, additional snacks, oral nutritional supplements, enteral or parenteral nutrition; feeding assistance and nutritional screening, assessment or monitoring occurring at least every 4 days had shorter lengths of stay in hospital than patients who did not received this level of nutritional care. ${ }^{(69)}$

\subsubsection{Management of malnutrition}

In 1999, the Council of Europe reviewed current hospital nutritional practices in Europe with the aim of highlighting problems and creating management guidelines. ${ }^{(70)}$ This subsequently led to Resolution ResAP (2003)3(23) on food and nutritional care in hospitals that made numerous recommendations in relation to the management of patients with malnutrition and those at risk of malnutrition in hospitals. The main aims of the Council of Europe are to reinforce democracy, human rights and the rule of law, and to develop common responses to political, social, cultural and legal challenges, based on the 1948 Declaration of Human Rights; proper nutritional care in hospital is considered to be a basic human rights. ${ }^{(71)}$

The key points raised by Resolution $\operatorname{ResAP}(2003) 3^{(23)}$ in relation to the management of malnutrition for patients able to ingest food orally are outlined below and suggest that:

- patients should be screened on admission to hospital and weekly thereafter, using an appropriately validated nutritional screening tool, in order to identify patients who are malnourished or at risk of malnutrition;

- identification of patients at nutritional risk should be followed by a thorough nutritional assessment, nutritional care plan including dietary goals, monitoring of food intake and 
body weight, and adjustment of care plan as indicated. Food intake should be documented and assessed with special attention to the collection of meal trays;

- fasting should not be part of routine care and the literature should be reviewed in order to determine which procedures may require fasting and for what period of time;

- patients requiring nutritional support should receive it at the earliest opportunity during their hospital stay, with food being the first choice to correct or prevent malnutrition. Oral nutritional supplements should not be used as a substitute for the adequate provision of food. Enteral and/or parenteral nutrition should only be commenced when the use of ordinary food fails or is inappropriate. This support should be individualised;

- patients medical records should contain information about their nutritional status, and physical and mental condition in relation to food intake;

- health authorities and hospital management should acknowledge their responsibility with regard to nutritional care and support, and food service systems;

- hospital management, physicians, pharmacists, nurses, dieticians and food service staff should work together in providing nutritional care and participate in a continuous education programmes on the management of malnutrition;

- hospitals should develop appropriate standards for nutritional care and adhere to any national accreditation standards;

- the food service system should be adjusted to the patients needs taking into consideration their physical and mental condition;

- the eating environment should focus on surroundings and the presence of trained staff to assist patients with feeding difficulties, be free from unpleasant smell or odours and patients should have the opportunity to choose their eating environment including sitting around a table when eating for meals;

- $\quad$ proper feeding-aids should be available to patient when required to facilitate independent feeding;

- the provision of meals should be flexible and individualised with patients able to order food at any time including having snacks and oral nutritional supplements offered between meals when appropriate;

- a range of dishes enriched in energy and protein should be available in every hospital aimed at malnourished patients and those at risk of malnutrition.

- interruption of patients mealtimes by ward rounds, teaching and diagnostic procedures should be minimised; and

- relatives should be encouraged to be involved at mealtimes when appropriate. 
These recommendations have been supported by organisations including the British National Health Service, European Society for Parenteral and Enteral Nutrition and BAPEN; as well as being endorsed by the Royal College of Nursing, British Dietetic Association, British Medical Association and Hospital Caterers Association in the United Kingdom. $(22,71,72)$ In addition to the Council for Europe's recommendations, and in an effort to further highlight the problems faced by older people in hospital, Age Concern's 2006 report Hungry to be heard - The scandal of malnourished older people in hospital and Age UK's (formerly Age Concern) 2010 report Still Hungry to be Heard outlined seven steps to end the scandal of malnutrition in hospital as follows: $(24,25)$

- hospital staff must listen to older people, their relatives and carers;

- all ward staff must become 'food aware';

- hospital staff must follow their own professional codes and guidance from other bodies;

- older people should be assessed for the signs or danger of malnourishment on admission and at regular intervals during their stay;

- protected mealtimes should be introduced (a system of protecting mealtimes from unnecessary and avoidable interruptions, providing an environment conducive to eating and enabling staff to provide patients with support and assistance with meals);

- a red tray system should be implemented and steps taken to ensure that it works in practice (patients who have previously been identified as requiring mealtime assistance have their meals delivered to them on a red tray in order to distinguish them from patients who do not have any mealtime assistance requirements); and

- use volunteers to assist at mealtimes where appropriate.

Despite these detailed recommendations and endorsements there is evidence that in many hospitals in Europe and throughout the world these nutritional standards are not met. The BAPEN report Malnutrition Matters - Meeting Quality Standards in Nutritional Care: A Toolkit for Commissioners and Providers in England declared that malnourished individuals or those at risk of developing malnutrition, should be identified and treated and that nutritional care is a matter of quality. (73) The 2010 Australasian Nutrition Care Day Survey of 370 wards in 56 acute care hospitals revealed that $64 \%$ of wards performed some sort of nutrition screening. ${ }^{(41)}$ A survey by Schindler et al(74) in 2007/2008 of 325 hospitals in Europe and Israel found on average 52\% of units were performing nutrition screening. These studies $(41,74)$ show that while recommendations support the use of nutrition screening it only being conducted in just over half of the healthcare facilities studied. Kondrup et al(75) investigated why patients do not necessarily receive the nutritional care as recommended within nutrition standards in a study of 750 patients across three 
Danish hospitals. Similarly to the two previously mentioned studies, these authors reported that although nutritional screening had been implemented in wards studied, only $60 \%$ of patients had been screened. (75) Of those patients identified as being at risk of malnutrition, $47 \%$ had a nutrition care plan and just 30\% appeared to be receiving nutritional monitoring. Nurses involved in this study were subsequently interviewed in order to gain insight as to why aspects of the nutrition standards were not being implemented. Management's lack of instruction on how to deal with the problem of malnutrition, lack of basic knowledge of dietary requirements and the practical aspects of the hospital's food service were reported as being the main reasons for the inconsistency in nutritional care provided by the nursing staff. ${ }^{(75)}$ In terms of nutritional screening practices many hospitals do not comply with existing evidence based guidelines. $(41,74)$

In 1997, the Association of Community Health Councils for England and Wales report, Hungry in Hospital, highlighted that even patients with good appetites were not receiving sufficient nutrition due to inadequate assistance at mealtimes. (20) In 2006 in a study by Xia and McCutcheon(21) conducted in two medical wards in an Australian teaching hospital, found that $57 \%$ of patients required some form of mealtime assistance in order to eat their meal, with $49 \%$ of patients receiving assistance from nursing staff at meal commencement. Similarly, in an observational study undertaken in 2008 by Tsang(76) in a geriatric ward of an Australian teaching hospital, $70 \%$ of patients were found to require some form of mealtime assistance in order to eat their meal. This interest in the need for mealtime assistance has led to a number of acute care hospitals employing nutrition/dietetic assistants to undertake this function and to the creation of designated dining rooms or areas for patients to eat in order to facilitate optimal nutritional intake at mealtimes.

\subsubsection{Limitations in nutrition research}

Nutrition research is fraught with difficulties primarily arising from ethical and logistical considerations. Ethically there are many complex issues around the provision of nutrition with respect for patient autonomy, religious and legal rights, which all require careful consideration. In many countries differentiation is made between nutrition provided by oral means as compared with that provided by enteral and parenteral means. The provision of oral nutrition and assistance with eating is generally considered to be a basic human right, while nutrition provided by enteral and parenteral means is considered to be medical therapy.(77) For this reason, randomising patients capable of oral consumption of food in a study where they could potentially be denied sufficient oral nutrition would be unethical. Blinding patients to what they are eating or the environment in which they are eating in an attempt to reduce the risk of bias can be extremely 
difficult if not impossible. Likewise, blinding researchers in these circumstances can be problematic. The management of nutrition for patients in any healthcare setting usually involves the combined efforts of multiple groups of people working in different and distinct departments within the healthcare setting; these include nurses, dietitians, doctors, pharmacists, food service staff and others. These departments are likely to have different and competing priorities making organising nutritional research studies complex.

Nutritional provision and interventions can be affected by other aspects of patient care making it difficult to separate out the true effect of the intervention. Concurrent treatments, appetite, food or cultural preferences may all have an impact on patient nutritional intake regardless of what nutrition intervention is initiated. Although many of the nutrition screening and assessment tools used in the acute care setting are validated, some tools used may not have undergone such validation processes. This means, there is likely to be an element of subjectivity involved in the use of tools that have not been validated. Given the ethical and logistical issues in the field of nutrition research there are limited randomised control trials (RCT) conducted, with quasiexperimental studies being more commonly employed despite being at a lower level in the hierarchy of evidence. $(78,79)$

Studies on malnutrition would normally require some form of data collection with regard to patient nutritional intake. Nutritional intake in the acute care setting is usually determined from plate waste. Plate waste is the amount of served food that remains uneaten by patients after the mealtime has ended.(55) Although generally used to determine the effectiveness of menus( ${ }^{(80)}$ plate waste is also used to obtain data on the individual food intake of a patient which can then be analysed to determine the patient's nutritional intake. Plate waste may be determined in a number of ways, with weighed plates waste considered to be the most accurate method of obtaining this data. $(80,81)$ Weighed plate wastes can be achieved by either pre- and post-meal weighing of food or by comparing post meal weight of food, with known standardised serves. The former, if done with due care, will bring about the most accurate result but practically weighed plate wastes are time consuming, labour intensive and require a great deal of space to hold the discarded meal trays making it difficult to manage large numbers of patients. ${ }^{(80)}$ Additionally, weighing food after the patient has finished with their meal is problematic as different foods can be mixed together making it difficult to analyse the exact amount of each food consumed by the patient. Given the difficulties in obtaining weighed plate wastes, semi-quantitative visual estimations of plate waste using point scales are commonly used to obtain data on the amounts of food consumed by patients in the acute care setting. ${ }^{(55)} \mathrm{A}$ study by Sherwin et al(82) in an aged care residential home 
found visual estimations of plate waste to be valid when compared to weighed plate wastes. In addition to this, visual estimations of plate waste are more practical as they are less time consuming and less likely disrupt other ward and food service activities. ${ }^{(80)}$

Food record charts may also be commonly used to obtain data on the amount of food eaten by patients in the acute care setting. Food record charts require accurate documentation with regard to both the item of food consumed and portion size. The accuracy of this documentation is therefore dependent on the person completing the chart. In addition to this, there is no way of knowing for sure if an item of food or fluid consumed has been omitted from the documentation or merely not consumed. Data on the amount of each food item consumed can then be analysed using food composition tables or dietary analysis software to calculate the corresponding amount of energy or nutrients consumed.

\subsection{Why a systematic review is needed}

Previous systematic reviews regarding nutrition in the acute care setting $(83,84)$ have focused on the provision of additional nutrition from either oral nutritional supplements, enteral nutrition or modified menus. These reviews have not examined other non-nutritional factors that may influence patient nutritional intake, status, length of stay or mortality. The following systematic reviews were identified prior to conducting the current systematic review:

- Joanna Briggs Institute Systematic Review by Vanderkroft et al(83) entitled Minimising under nutrition in the older person. This review was undertaken in the acute care setting and set out to identify best practices to minimise under-nutrition in patients aged 65 years and older. The review included 29 identified studies from 1980 to 2005. The interventions in the included studies related to additional nutritional provision from modified menus, oral nutrition supplementation or enteral feeds. Although conducted in the same setting as the current systematic review, the review by Vanderkroft et al(83) was specific to elderly patients and focused on nutritional provision interventions.

- Joanna Briggs Institute Systematic Review The effectiveness of interventions to reduce under-nutrition and promote eating in older adults with dementia: a systematic review by Jackson et al(85) was registered in 2009 and published in 2011 in the Joanna Briggs library of systematic reviews during the search phase of this current systematic review. This systematic review included 11 identified studies from 1999 to 2009 that included adults aged 60 years and over, diagnosed with dementia and who were living in any care setting. This review examined both direct nutritional provision and related nursing, food 
service, dietetic and feeding practices. Although these related practices were also the intended focus of this current systematic review the population group is different with only patients with dementia being included and not patients in the acute care setting. The interventions identified in the review by Jackson et al(85) were contrast tableware, eating in small dining rooms, serving meals from a bulk trolley, serving one course at a time, staggering mealtimes, introducing an aquarium in the dining area, offering oral nutritional supplements, increasing the number of meal choices, educating carers and including dietetic nutritional assessment.

- Cochrane review by Milne et al(84) entitled Protein and energy supplementation in elderly people at risk from malnutrition. This review examined 62 randomised and quasirandomised controlled trials conducted with elderly patients who were provided with additional energy and protein primarily from oral nutritional supplements. This review by Milne et al(84) did not examine environmental or supportive nutritional practices and its focus was on elderly patients.

With increasing demands on the providers of acute care beds and the cost of treating a malnourished patient being greater than that of a non-malnourished patient, it is important that any intervention that could potentially reduce length of stay in hospital and healthcare costs is investigated, as this could have major implications for future healthcare spending and policy. As previously stated in section 1.1.6., the Council for Europe, Age UK (formerly Age Concern) and BAPEN have called for strategies to improve the mealtime environment to be implemented as a way of managing malnutrition and malnutrition risk. Before implementing any new strategy, it is prudent to examine the evidence for doing so. With many hospitals having already implemented or looking to implement initiatives which may influence mealtime environments such as protected mealtimes, red tray systems, employing dietetic/nutrition assistants or mealtime volunteer assistant programs there is a need to examine the available evidence. Implementation of these schemes is likely to have financial and operational implications either directly through staff salaries or purchase of equipment or indirectly through additional workload for existing staff or reorganisation of staff roles and functions. Any healthcare initiative needs to demonstrate benefit to both the patient in terms of improved recovery from illness and healthcare provider in terms of representing value for money.

Given this recent interest in these supportive nutritional practices that relate to the environment and circumstances of eating, this systematic review proposes to examine those aforementioned interventions that endeavour to promote optimal eating and feeding for adult patients in the acute 
care setting. Interventions of interest are those that are not solely nutritional screening or interventions based on the provision of additional nutrition. This review will assist in formulating some guidance with regard to future directions for environmental and supportive nutritional practices in the acute care setting. Clinical nutritional studies are often small when considering the numbers of patients involved and a systematic review provides the opportunity to examine these small studies collectively and bring about greater understanding.

\subsection{Review methodology}

This systematic review examined the effectiveness of mealtime interventions in adult patients in the acute care setting using Joanna Briggs Institute methods for a systematic review assessing the effectiveness of an intervention. This review considered RCTs in the first instance, however given the aforementioned difficulties in section 1.1.7. with collecting nutritional data, randomising and blinding in nutritional studies, it was envisaged that few RCTs would be found so quasiexperimental study designs have also been included in this review. Although characterised by lower validity than true RCTs, quasi-experimental study designs ${ }^{(78,79)}$ are important in the clinical setting and are commonly used when ethical considerations preclude randomisation in experimental research designs. There have been numerous papers published discussing the problems of malnutrition and patient mealtimes in acute care hospitals, however as these are discussion and opinion papers they were not considered for inclusion in this systematic review.

\subsection{Review question and objectives}

The purpose of this systematic review was to identify, critically appraise, synthesise and present the best available evidence on the effectiveness of mealtime interventions that improve nutritional intake of adult patients in the acute care setting. Interventions were sought that relate to mealtimes and not how food or fluids were offered or ordered, for or by the patient, but rather included interventions that evaluated or altered the environment and/or circumstances of patient mealtimes.

The specific review question was as follows:

What are the effects of identified mealtime interventions in improving nutritional intake of adult patients in the acute care setting?

As previously stated, for the purposes of this systematic review the term malnutrition only referred to the state of protein-energy under-nutrition in patients who are being treated in acute care 
settings. Acute care setting referred to services occurring within an acute care hospital.(1) This systematic review included patients in acute care hospitals regardless of whether they had acute or maintenance care status. Mealtime assistance was taken to mean assistance or facilitation from another person to be able to eat.(86) 


\section{Chapter 2 Systematic Review}

Chapter 2 outlines the systematic review methods, including an overview of the eligibility criteria, search strategy and description of the processes utilised for critical appraisal, data extraction and data synthesis. The a priori protocol is presented in Appendix 1.

\subsection{Types of Studies}

In the first instance this systematic review considered experimental studies including RCTs. In the absence of these studies or in the event of insufficient data being available the review would extend to other quasi-experimental study designs. A limited number of RCTs were found and consequently quasi-experimental study designs were included in this systematic review. Although considered to be of a lower internal validity these study designs were included as they were regarded as making a contribution to the systematic review as the best available evidence on this subject. $(78,79)$

\subsection{Types of participants}

Consideration was given to studies that included adults, aged 18 years and over, from any ethnic background, who were inpatients in acute care hospital with any diagnosis. Patients in intensive care or high dependency units, those obtaining their nutrition exclusively by enteral or parenteral means, those receiving palliative care or considered to be at end of life were excluded from this systematic review. Patients in other healthcare settings such as rehabilitation, transitional care and residential aged care facilities were also excluded from this systematic review.

\subsection{Types of Intervention}

The current review considered studies that evaluated mealtime assistance interventions such as:

- organisational practices;

- food service practices;

- nursing practices;

- medical practices;

- dietetic practices;

- dietetic/healthcare assistant practices;

- volunteer practices; and

- family/carer practices. 
The types of mealtime interventions likely to have the potential to influence nutritional intake and/or status and therefore considered likely to have been studied and unearthed in this review were as follows:

- Set up or pre-mealtime practices that prepare patients for mealtimes. These practices may include washing hands, toileting, ensuring patients are wearing dentures and glasses if required, ensuring space is available for the meal tray to be positioned on the overway table, the overway table is cleared of any non-meal related items such as dressings, urine bottles, newspapers and magazines; the overway table is positioned at the correct height and within reach of the patient and the patient is in the correct sitting position for eating. Medications that are required to be taken before or with meals are prepared by nursing staff in advance of mealtimes.

- Feeding assistance practices where patients are provided with feeding assistance by nurses, dietetic/healthcare assistants or volunteers. Specific staff or volunteers may be allocated to look after patient mealtime assistance requirements. Meal delivery systems or targeted feeding assistance practices for example the red tray system where patients previously identified as requiring mealtime assistance have their meal delivered on a red (or other specified colour) tray that acts as a visual cue to nursing staff indicating that the patient requires mealtime assistance.(87) Mealtime assistance may take the form of opening up food packets, taking lids off plates, buttering bread, cutting up food or providing the patient with full feeding assistance.(87)

- Protected mealtimes where patients are able to eat undisturbed at mealtimes and do not have any unnecessary or avoidable interruptions during this time. Hospital staff, either clinical or non-clinical support staff who are not involved with mealtime tasks are asked to vacate the ward during this time enabling the remaining staff to focus their full attention on providing patients with mealtime assistance and maintain an environment conducive to eating. (88-90).

- Dining rooms or areas where patients can eat in a designated room or area specifically designed for mealtimes rather than from a tray by or in their bedside. The room or area should be free from other ward distractions including unwanted noise and smells. Dining rooms may have a nurse or dietetic/healthcare assistant on hand to assist patients during mealtimes.

- Ward kitchens/pantries that contain supplies of food and fluids including nutritionally dense snacks and nourishing fluids thus allowing patients access to suitable food and fluids, 24 hours a day. 
- Nutrition support teams or committees who consider more than just the foods or fluids prescribed for the patient. These teams may also consider the delivery of the above practices at a wider level and may make recommendations on the most appropriate environment or circumstances in which patient eats and drinks.

Interventions that were solely related to the actual food or fluid offered or ordered, for or by the patient, were not considered in this systematic review. Strategies that promote the identification of malnutrition, for example nutrition screening or assessment were excluded from this systematic review.

\subsection{Outcomes}

The primary outcome measures of interest in this systematic review were measures of patient nutritional intake and/or nutritional status. Measures of nutritional intake may include weighed or semi-quantitative visual estimates of plate waste or subjective documented food intakes. Furthermore, intakes of energy and protein were of primary interest as they are the nutritional factors which will influence weight, BMI, muscle mass and fat stores. Measures of nutritional status including weight, BMI, anthropometric measures and nutritional status as determined by nutrition screening or assessment tools validated for the acute care setting were considered in this systematic review. Secondary outcome measures of length of stay in hospital and all-cause mortality were also considered in this review.

\subsection{Review Methods}

\subsubsection{Search Strategy}

The review methods employed in this systematic review followed Joanna Briggs Institute standard methods. Prior to developing the search strategy for this systematic review, an initial scoping search of the Joanna Briggs Institute Database of Systematic Reviews and protocols and the Cochrane Database of Systematic Reviews and Database of Abstracts of Reviews of Effects was conducted to ascertain the suitability of the proposed review topic and determine if this or a similar systematic review had already been undertaken, furthermore to ensure that there would be value in undertaking this current systematic review. No other systematic review evaluating the effectiveness of mealtime interventions in adult patients in the acute care setting was located. Since the completion of the protocol for this systematic review two further systematic reviews were identified that relate to the subject matter of this current systematic review: 
- Qualitative systematic review published in 2011 in the Journal of Clinical Nursing by Jefferies et al(91) entitled Nurturing and nourishing: the nurses' role in nutritional care. The aim of this systematic review was to describe what nurses could do to reduce the incidence of malnutrition in patients in acute care and long term care hospitals. The review examined what nurses could do to facilitate access to food, support the mealtime environment and prevent prolonged and repeated periods of fasting. The review identified 73 papers from 1998 to 2008 and used Joanna Briggs Institute appraisal instruments to evaluate the literature. The outcome of this review was used to produce eight nursing standards to form the basis of a hospital policy. This review examined patients in both acute and long term care and was only concerned with exploring the nurses' role and not that of other staff members.

- In 2011 Green et al(92) published $A$ systematic review of the use of volunteers to improve mealtime care of adult patients or residents in institutional settings. This review identified ten studies, four of which were conducted in acute care settings. These four studies(93-96) were also identified in the search for this current systematic review. Green et al(92) only considered the intervention of volunteer assistants and not other possible environmental or supportive interventions. The review by Green et al(92) also considered a variety of care settings and did not focus on the acute care setting, specifically.

The search strategy employed in this systematic review was designed to find published and unpublished studies reported in English language using a three step search strategy. No date restrictions were applied to search strategy. An initial search of PubMed/MEDLINE and CINAHL was undertaken followed by analysis of the text words contained in the titles, abstracts and the index terms used to describe the identified citations. A second search was undertaken in which all identified keywords and index terms were applied across the databases outlined in Table 2.1. Appendix 2 provides further details on the search strategies employed for each of the listed databases. The process of identifying and reviewing titles and abstracts was facilitated by the use of Endnote X3 (Thomson Reuters) reference management software. Full papers were retrieved for those citations that appeared to meet the inclusion criteria upon scanning of the citation details returned from the database search. Thirdly, the reference lists of all the retrieved papers were searched to locate any additional, relevant studies. Finally, as the Journal of Nutrition and Dietetics featured a number of relevant citations from the first, second and third searches a hand search of this journal was performed from its inception in January 1988 to December 2011, in order to locate any additional relevant studies. 
Table 2.1. Databases searched and the date of each search performed.

\begin{tabular}{|l|l|}
\hline Database & Date searched \\
\hline PubMed/MEDLINE & $28 / 9 / 11$ \\
\hline CINAHL & $29 / 9 / 11$ \\
\hline EMBASE & $6 / 10 / 11$ \\
\hline Informit - Health & $9 / 10 / 11$ \\
\hline Cochrane Central Trials Register & $14 / 10 / 11$ \\
\hline Scopus & $13 / 10 / 11$ \\
\hline Australian Digital Theses Program (TROVE) & $16 / 10 / 11$ \\
\hline Index to Theses & $18 / 10 / 11$ \\
\hline Proquest Dissertations \& Theses & $15 / 10 / 11$ \\
\hline
\end{tabular}

In addition to the citation databases outlined in Table 2.1., details of the government and healthcare organisation websites searched in order to locate eligible studies are outlined in Table 2.2 .

Table 2.2. Government and organisational websites searched for eligible studies, web address and date search performed.

\begin{tabular}{|l|l|l|}
\hline Organisation & Website URL & $\begin{array}{l}\text { Date } \\
\text { searched }\end{array}$ \\
\hline Australian federal government (health) & $\underline{\text { www.health.gov.au }}$ & $19 / 10 / 11$ \\
\hline Aged Care Australia & $\underline{\text { www.agedcareaustralia.gov.au }}$ & $19 / 10 / 11$ \\
\hline South Australia Health & $\underline{\text { www.health.sa.gov.au }}$ & $19 / 10 / 11$ \\
\hline $\begin{array}{l}\text { Australian Capital Territory Government } \\
\text { Health }\end{array}$ & $\underline{\text { www.health.act.gov.au }}$ & $20 / 10 / 11$ \\
\hline $\begin{array}{l}\text { Department of Health and Human Services, } \\
\text { Tasmania }\end{array}$ & $\underline{\text { www.dhhs.tas.gov.au }}$ & \\
\hline $\begin{array}{l}\text { Department of Health of the Northern } \\
\text { Territory }\end{array}$ & $\underline{\text { www.health.nt.gov.au }}$ & $20 / 10 / 11$ \\
\hline Western Australian Health Department & $\underline{\text { www.health.wa.gov.au }}$ & $20 / 10 / 11$ \\
\hline Queensland Health & $\underline{\text { www.health.qld.gov.au }}$ & \\
\hline New South Wales Ministry of Health & $\underline{\text { www.health.nsw.gov.au }}$ & $20 / 10 / 11$ \\
\hline Department of Health, Victoria & $\underline{\text { www.health.vic.gov.au }}$ & $24 / 10 / 11$ \\
\hline National Health Service & $\underline{\text { www.nhs.uk }}$ & $24 / 10 / 11$ \\
\hline
\end{tabular}




\begin{tabular}{|c|c|c|}
\hline Age UK (formally Age Concern) & www.ageuk.org.uk & $14 / 11 / 11$ \\
\hline Dietitians Association of Australia & www.daa.asn.au & $14 / 11 / 11$ \\
\hline British Dietetic Association & www.bda.uk.com & $14 / 11 / 11$ \\
\hline American Dietetic Association & www.eatright.org & $14 / 11 / 11$ \\
\hline Dietitians of Canada & www.dietitians.ca & $14 / 11 / 11$ \\
\hline $\begin{array}{l}\text { Australasian Society of Parenteral and } \\
\text { Enteral Nutrition }\end{array}$ & www.auspen.org.au & $14 / 11 / 11$ \\
\hline $\begin{array}{l}\text { British Association of Parenteral and Enteral } \\
\text { Nutrition }\end{array}$ & www.bapen.org.uk & $14 / 11 / 11$ \\
\hline $\begin{array}{l}\text { European Society of Parenteral and Enteral } \\
\text { Nutrition }\end{array}$ & www.espen.org & $14 / 11 / 11$ \\
\hline Australian Nurses Federation & www.anf.org.au & $14 / 11 / 11$ \\
\hline Royal College of Nursing Australia & www.rcna.org.au & $14 / 11 / 11$ \\
\hline Royal College of Nursing & www.ren.org.uk & $14 / 11 / 11$ \\
\hline American Nurses Association & www.nursingworld.org & $14 / 11 / 11$ \\
\hline Canadian Nurses Association & www.cna-aiic.ca/cna/default_e.aspx & $14 / 11 / 11$ \\
\hline
\end{tabular}

\subsubsection{Assessment of Methodological Quality}

Papers that were deemed to meet the review criteria on full text examination accordingly progressed to the appraisal stage in the review process. These selected papers were appraised by two independent reviewers for methodological validity using standard critical appraisal instruments from the Joanna Briggs Institute Meta Analysis Statistics Assessment and Review Instrument (JBI-MAStARI) (Appendix 3). Consistency between the two reviewers was obtained by adhering to the descriptors stated in the critical appraisal tool, which outlined the criteria required to obtain the answer for each question (Appendix 3). The critical appraisal tool comprised of ten questions to assist in assessing the validity of the selected studies. Each question was scored as either being "yes", "no" or "unclear" from the information provided in the published paper. "Yes" answers were allocated to appraisal questions if the paper answered the question as per the predetermined criteria (Appendix 3) and "no" if it did not. Responses were allocated as "unclear" if it was determined that insufficient information had been reported by the study author(s) to make a conclusive decision. In addition to this, following each reviewer's independent appraisal, any discrepancies in terms of the application and interpretation of the questions in the critical appraisal tool were identified by the primary reviewer (Gail Whitelock) and were subsequently discussed by both reviewers. If consensus could not be obtained from these discussions a third 
reviewer would be employed, however this was not necessary as both the primary and secondary reviewers agreed on which studies should progress to the synthesis stage of the systematic review.

Given the limited number of RCTs conducted in the area of clinical nutrition it was expected that few of the included studies would obtain "yes" answers to questions one, two, three and five which related to randomisation of the treatment groups and the blinding of the allocator, patient and assessor (Appendix 3). An overall cut off of a minimum of five "yes" answers was set for the ten critical appraisal questions in order for data to be extracted from the study and subsequently included in the final synthesis of this systematic review. Studies that scored between zero and four were considered not to be of sufficient quality to warrant inclusion in the review synthesis given the risk of bias and were consequently excluded from the systematic review. Studies that scored between five and seven were considered as being of medium quality and those that scored between eight and ten of high quality.

\subsection{Data Extraction}

The JBI-MAStARI data extraction tool was used to extract data for the included studies (Appendix 4). The tool included specific details about the interventions, population, study methods and outcome measures of relevance to the systematic review question. Data extraction was solely performed by the primary reviewer (Gail Whitelock).

\subsection{Data Synthesis}

The interventions employed, outcome measures reported and statistical analysis of each of the included studies was considered and compared. The limited number of studies located investigating and reporting on the same intervention and resultant lack of homogeneity between these studies prevented any meta-analysis or statistical combination of extracted outcome data from being conducted in this systematic review. Consequently, the results from the review were presented as a narrative summary. 


\section{Chapter 3 Results}

\subsection{Search results}

Figure 3.1 illustrates the number of citations identified from the database searches, the number of full text papers retrieved following review of the titles and abstracts of the initial identified citations, the number of papers critically appraised and finally the number of studies included in the final analysis. Appendices 5 and 6 provide details of the excluded papers and reasons for their exclusion.

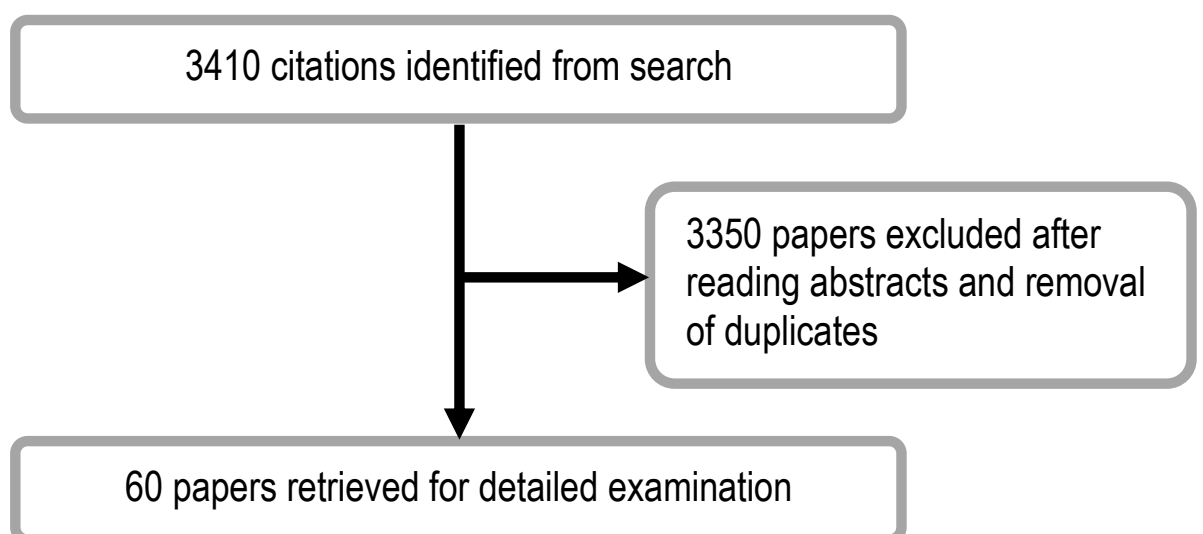

2 papers identified from third search. No papers identified from hand search of the Journal of Human Nutrition \& Dietetics 1988 - 2011

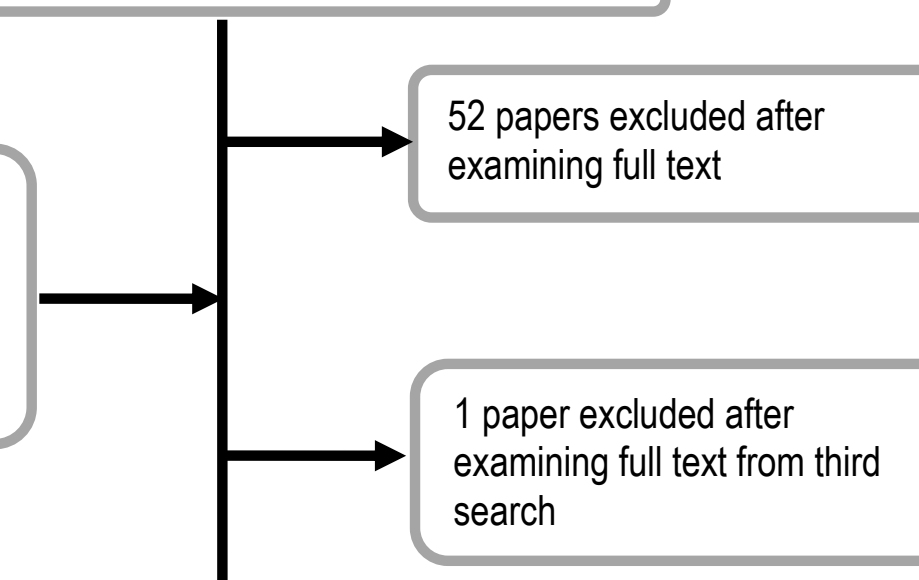

9 studies appraised for methodological quality

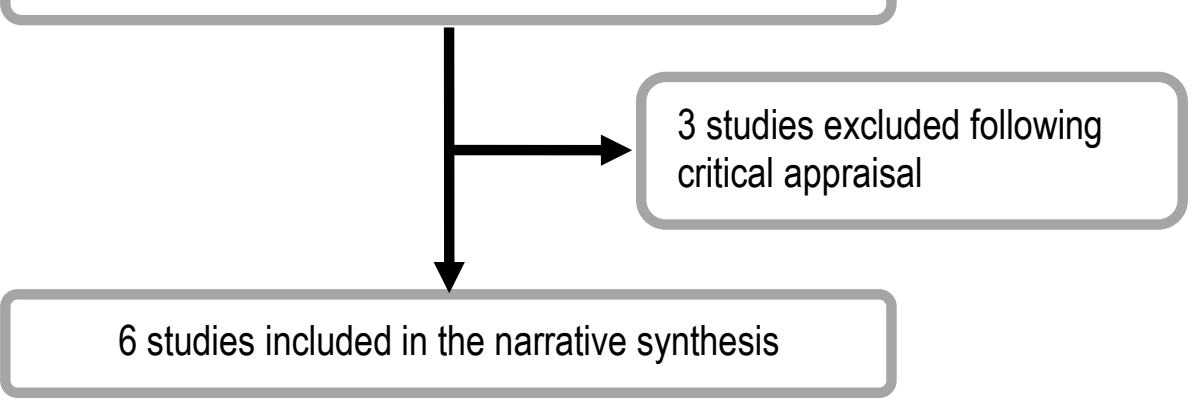

Figure 3.1. Flow diagram of search results and subsequent process of review. 


\subsection{Methodological quality}

Studies included in the final synthesis scored between five and nine when assessed against the ten critical appraisal questions. Table 3.1. outlines the critical appraisal scores for each of the nine appraised studies. The two identified RCTs ${ }^{(97,98)}$ had the highest scores with seven and nine out of ten respectively, with the four remaining included studies(93, 99-101) scoring five out of ten following critical appraisal. The RCTs received higher scores primarily due to the study design which supported "yes" answers to questions relating to randomisation and blinding. The other four included studies(93, 99-101) employed quasi-experimental study designs. Like RCTs, quasiexperimental study designs aim to evaluate interventions; however they do not involve any randomisation and are often used when it is not ethical or logical to undertake an RCT.(102)

The three remaining appraised studies $(95,103,104)$ scored three or less. Scoring in these studies indicated that randomisation had not occurred, there was no blinding of patients, withdrawals were not described and it was "unclear" if allocators had been blinded. Furthermore, it was "unclear" if assessors were blinded, or groups treated in the same manner with the exception of the stated intervention. Given this, these studies were assessed to be at high risk of bias and as such were considered to be of poor quality and subsequently excluded following appraisal by both reviewers (Appendix 6).

Some differences were found between individual appraisal answers allocated by the primary and secondary reviewers. Nevertheless, both reviewers agreed upon the same six papers to be included in the final synthesis and therefore a third reviewer was not referred to. 
Table 3.1. Critical Appraisal Scores for studies that met eligibility criteria for the review. (For questions see Appendix 3).

\begin{tabular}{|c|c|c|c|c|c|c|c|c|c|c|c|}
\hline Paper & Q1 & Q2 & Q3 & Q4 & Q5 & Q6 & Q7 & Q8 & Q9 & Q10 & Total \\
\hline Duncan et al.(98) & Yes & No & Yes & Yes & Yes & Yes & Yes & Yes & Yes & Yes & 9 \\
\hline Hickson et al.(97) & Yes & No & Unclear & Yes & No & Yes & Yes & Yes & Yes & Yes & 7 \\
\hline Walton et al.(99) & No & No & Unclear & No & Unclear & Yes & Yes & Yes & Yes & Yes & 5 \\
\hline Wright et al.(93) & No & No & No & Yes & No & Yes & Yes & Unclear & Yes & Yes & 5 \\
\hline Wright et al.(100) & No & No & No & No & No & Yes & Yes & Yes & Yes & Yes & 5 \\
\hline Edwards et al.(101) & No & Unclear & Unclear & No & Unclear & Yes & Yes & Yes & Yes & Yes & 5 \\
\hline Hickson et al.(103) & No & No & Unclear & No & Unclear & Unclear & Unclear & Yes & Yes & Yes & 3 \\
\hline Wilson et al.(104) & No & No & No & No & Unclear & Unclear & Unclear & Yes & Yes & Yes & 3 \\
\hline Robinson et al.(95) & No & No & No & No & Unclear & Yes & Unclear & Unclear & Unclear & Unclear & 1 \\
\hline
\end{tabular}

Studies that scored four out of ten or less were rated as being at high risk of bias and were excluded from data extraction and synthesis. Further details can be found in Appendix 6. 


\subsection{Overview of studies}

The six included studies examined the effectiveness of three different mealtime interventions. The interventions investigated included:

- employed assistants to facilitate patients eating and feeding at mealtimes; $(97,98)$

- trained volunteers to provided mealtime assistance; $(93,99)$ and

- eating location at mealtimes. $(100,101)$

Table 3.2. provides a summary of the characteristics of the included studies with Table 3.3. summarising the statistically significant results. All six studies ${ }^{(93,97-101)}$ examined the effect of the described intervention on energy intake with four $(93,97,99,100)$ of the included studies also examining the effect on protein intake. Nutritional status was measured in three of the studies ${ }^{(97}$, 98, 100) using a variety of anthropometric measures, including weight(97, 98, 100), $\operatorname{MAC}(97,98)$, MAMC,(97) hand grip dynamometry(97, 98) and TSF thickness. $(97,98)$ Length of stay in hospital was considered in the two studies $(97,98)$ that examined the effectiveness of employed assistants; with the study by Duncan et al(98) also considering mortality as an outcome measure.

One study on protected mealtimes by Hickson et al(103) was identified and subsequent excluded from this systematic review following appraisal (Appendix 6). 
Table 3.2. Summary of included studies.

\begin{tabular}{|c|c|c|c|c|c|c|}
\hline Study & Methods & $\begin{array}{l}\text { Participants, } \\
\text { setting }\end{array}$ & Intervention & Outcome measures & Results & Notes \\
\hline Duncan et al.(98) & $\begin{array}{l}\text { Study design: } \\
\text { RCT. } \\
\text { Duration of study: } \\
3 \text { years. } \\
\text { Randomisation: } \\
\text { Sequentially } \\
\text { numbered in blocks } \\
\text { of } 10 \text { using sealed } \\
\text { envelopes prepared } \\
\text { by unrelated staff } \\
\text { member. }\end{array}$ & $\begin{array}{l}\text { Participants } \\
\text { Total } n=363 \text {. } \\
\text { Intervention } n=165 \text {. } \\
\text { Control } n=153 \text {. } \\
\text { Setting: } \\
\text { Acute trauma ward, } \\
\text { University Hospital of } \\
\text { Wales, Cardiff, UK. } \\
\text { Inclusion criteria: } \\
\text { Females > } 65 \text { years } \\
\text { with acute } \\
\text { nonpathological hip } \\
\text { fracture. }\end{array}$ & $\begin{array}{l}\text { Intervention group: } \\
\text { Additional assistance } \\
\text { from trained dietetic } \\
\text { assistants for } 6 \\
\text { hours per day, } 7 \\
\text { days per week for } \\
\text { positioning, feeding, } \\
\text { food preferences, } \\
\text { co-ordinating meal } \\
\text { orders, provision of } \\
\text { feeding aids and } \\
\text { encouragement at } \\
\text { mealtimes. } \\
\text { Control group: } \\
\text { Conventional nurse/ } \\
\text { dietitian led care. }\end{array}$ & $\begin{array}{l}\text { Food intake: } \\
\text { Obtained using } \\
\text { semi-quantitative } \\
\text { food intake records. } \\
\text { A three day weighed } \\
\text { food intake on days } \\
3-6 \text { post surgery } \\
\text { conducted in a } \\
\text { subset of } 27 \text { patients } \\
\text { and further weighed } \\
\text { food intakes } \\
\text { obtained on } 24 \\
\text { patients in the } \\
\text { second year for } \\
\text { validation of portion } \\
\text { sizes. }\end{array}$ & $\begin{array}{l}\text { Intervention group } \\
\text { showed significantly } \\
\text { greater energy } \\
\text { intake (1446kJ ( } 349 \\
\text { kcal)/24 hours; } p= \\
<0.001 \text { ) than control } \\
\text { group. } \\
\text { Increased energy } \\
\text { intake from food was } \\
\text { non-significantly } \\
\text { greater in the } \\
\text { intervention group } \\
\text { but significantly } \\
\text { greater from oral } \\
\text { nutritional } \\
\text { supplements }\end{array}$ & $\begin{array}{l}\text { Dietetic assistant } \\
\text { role solely related to } \\
\text { nutrition and } \\
\text { mealtime assistance. } \\
\text { Participants and } \\
\text { providers not } \\
\text { blinded. } \\
\text { Assessor blinded }\end{array}$ \\
\hline
\end{tabular}




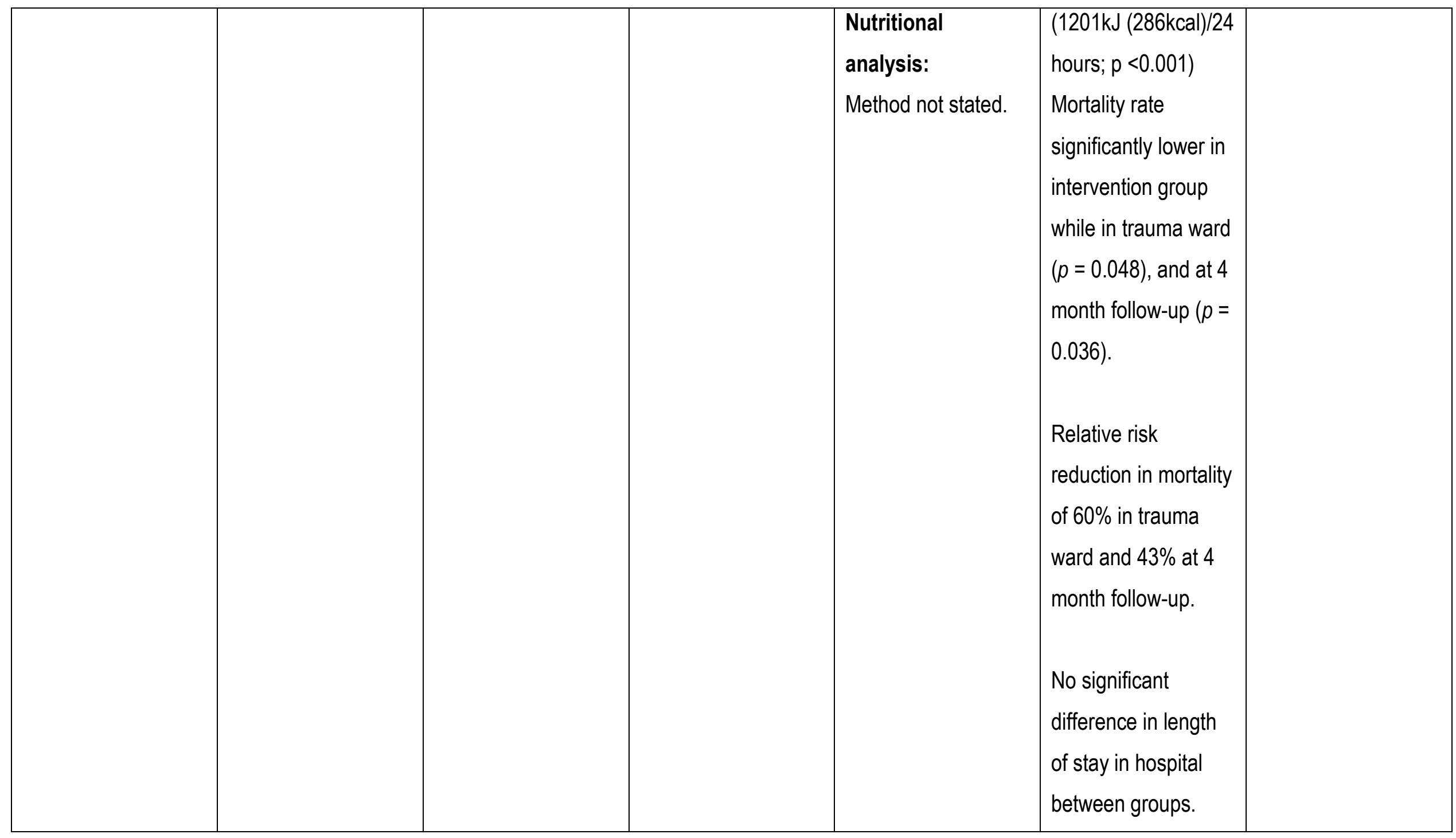




\begin{tabular}{|c|c|c|c|c|c|c|}
\hline Hickson et al.(97) & $\begin{array}{l}\text { Study design: } \\
\text { RCT. } \\
\text { Duration of study: } \\
20 \text { months. } \\
\text { Randomisation: } \\
\text { Computer generated } \\
\text { allocation using } \\
\text { random tables and } \\
\text { sealed envelopes } \\
\text { prepared by an } \\
\text { independent group. }\end{array}$ & $\begin{array}{l}\text { Participants } \\
\text { Total } n=592 . \\
\text { Intervention } n=300 \text {. } \\
\text { Control } n=292 . \\
\text { Setting: } \\
\text { Acute medicine for } \\
\text { the elderly wards, } \\
\text { Hammersmith } \\
\text { Hospital, London, } \\
\text { UK. } \\
\text { Inclusion criteria: } \\
\text { Aged } \geq 65 \text { years. } \\
\text { Exclusion criteria: } \\
\text { Patients unable to } \\
\text { take food orally, not } \\
\text { expected to survive } \\
\text { admission, discharge } \\
\text { planned within } 4\end{array}$ & $\begin{array}{l}\text { Intervention group: } \\
\text { Trained healthcare } \\
\text { assistants were } \\
\text { available for } 5 \text { days } \\
\text { per week for } 2 \text { meals } \\
\text { per day to provide } \\
\text { additional assistance } \\
\text { at meal times. } \\
\text { Activities undertaken } \\
\text { by healthcare } \\
\text { assistants included } \\
\text { assisting patients } \\
\text { with seating position, } \\
\text { meal tray set up, } \\
\text { opening packets and } \\
\text { lids, cutting up food, } \\
\text { feeding, dentures, } \\
\text { putting glasses on } \\
\text { ensuring correct } \\
\text { meal received, menu }\end{array}$ & $\begin{array}{l}\text { Food intake: } \\
\text { Obtained for } 6 \% \text { of } \\
\text { patients using } \\
\text { combination of } \\
\text { weighed food intake } \\
\text { for main meals and } \\
\text { food records for } \\
\text { breakfast and } \\
\text { snacks. } \\
\text { Nutritional } \\
\text { analysis: } \\
\text { Dietplan5 }{ }^{\mathrm{TM}} \text {. } \\
\text { Weights: } \\
\text { Obtained by trained } \\
\text { personnel using } \\
\text { electronic scales. }\end{array}$ & $\begin{array}{l}\text { Non-significant } \\
\text { increase in energy } \\
(370 \mathrm{~kJ}(88 \mathrm{kcal}) / 24 \\
\text { hours; } p=0.53) \text { and } \\
\text { protein ( } 3 \mathrm{~g} / \mathrm{day} ; p= \\
0.62) \text { intake in } \\
\text { intervention group. } \\
\text { No differences } \\
\text { between groups in } \\
\text { BMl. } \\
\text { No differences in } \\
\text { length of stay or } \\
\text { anthropometric } \\
\text { measures at } \\
\text { discharge between } \\
\text { the groups. }\end{array}$ & $\begin{array}{l}\text { Lower than expected } \\
\text { numbers of patients } \\
\text { recruited to the } \\
\text { study. } \\
\text { Healthcare } \\
\text { assistants performed } \\
\text { other assistant roles } \\
\text { in the ward over and } \\
\text { above providing } \\
\text { mealtime assistance. } \\
\text { Participants, } \\
\text { providers and } \\
\text { assessors not } \\
\text { blinded. }\end{array}$ \\
\hline
\end{tabular}




\begin{tabular}{|c|c|c|c|c|c|c|}
\hline & & $\begin{array}{l}\text { days and those who } \\
\text { were readmitted and } \\
\text { had already } \\
\text { participated in the } \\
\text { study. }\end{array}$ & $\begin{array}{l}\text { completion and } \\
\text { encouragement. } \\
\text { Control group: } \\
\text { Usual ward care. }\end{array}$ & & & \\
\hline Walton et al.(99) & $\begin{array}{l}\text { Study design: } \\
\text { Single group pilot } \\
\text { study. } \\
\text { Duration of study: } \\
\text { One month } \\
\text { Randomisation: } \\
\text { convenience sample }\end{array}$ & $\begin{array}{l}\text { Participants: } \\
\text { Total } n=9 \text { (patients } \\
\text { acted as their own } \\
\text { controls for other } \\
\text { meals). } \\
\text { Setting: } \\
\text { Aged care ward, } \\
\text { Sutherland Hospital, } \\
\text { Sydney, Australia }\end{array}$ & $\begin{array}{l}\text { Intervention group: } \\
\text { Patients referred for } \\
\text { volunteer feeding } \\
\text { assistance by senior } \\
\text { nursing staff } \\
\text { received additional } \\
\text { assistance from } \\
\text { trained volunteers for } \\
\text { meal tray set up, } \\
\text { opening packets, } \\
\text { feeding, } \\
\text { encouragement and } \\
\text { conversation for } \\
\text { weekday lunches. }\end{array}$ & $\begin{array}{l}\text { Food intake: } \\
\text { Obtained for } 3 \text { main } \\
\text { meals by weighed } \\
\text { plate waste with } \\
\text { duplicate samples of } \\
\text { meals used for } \\
\text { standard serve size } \\
\text { comparison. } \\
\text { Electronic scales } \\
\text { used to weigh plate } \\
\text { waste. } \\
\text { Nutritional } \\
\text { analysis: } \\
\text { FoodWorks }\end{array}$ & $\begin{array}{l}\text { Non-significant } \\
\text { increase in energy } \\
\text { intake in the } \\
\text { intervention group } \\
\text { for weekday lunch } \\
\text { meal } \\
439 \mathrm{~kJ}(104 \mathrm{kcal}) ; p= \\
0.072) \text {. } \\
\text { No significant } \\
\text { difference in total } \\
\text { daily energy intake. } \\
\text { Significantly more } \\
\text { protein (10.1g; } p\end{array}$ & $\begin{array}{l}\text { Pilot study with small } \\
\text { numbers. } \\
\text { Volunteers' role } \\
\text { limited. } \\
\text { Participants and } \\
\text { providers not } \\
\text { blinded. } \\
\text { Unclear if assessor } \\
\text { blinded. }\end{array}$ \\
\hline
\end{tabular}




\begin{tabular}{|c|c|c|c|c|c|c|}
\hline & & & $\begin{array}{l}\text { Control group: } \\
\text { Received usual ward } \\
\text { care. }\end{array}$ & $\begin{array}{l}\text { (Professional } \\
\text { Edition, Version 4). }\end{array}$ & $\begin{array}{l}<0.05) \text { consumed at } \\
\text { weekday lunch meal. } \\
\text { Total daily protein } \\
\text { intake was } \\
\text { significantly greater } \\
(10.7 g ; p<0.05) \text { on } \\
\text { the days volunteers } \\
\text { assisted at lunch. }\end{array}$ & \\
\hline Wright et al.(93) & $\begin{array}{l}\text { Study design: } \\
\text { Quasi-experimental. } \\
\text { Study duration: } \\
4 \text { months. } \\
\text { Randomisation: } \\
\text { Convenience sample }\end{array}$ & $\begin{array}{l}\text { Participants: } \\
\text { Total } n=46 . \\
\text { Intervention } n=16 \text {. } \\
\text { Control } n=30 . \\
\text { Setting: } \\
\text { Charing Cross } \\
\text { Hospital, London, } \\
\text { UK. }\end{array}$ & $\begin{array}{l}\text { Intervention group: } \\
\text { Additional assistance } \\
\text { from trained } \\
\text { volunteers from } \\
\text { 08:00 - 16:00 with } \\
\text { seating position, } \\
\text { opening packets, } \\
\text { ensuring meal within } \\
\text { reach, removing lids, } \\
\text { dentures, cutting up } \\
\text { food, checking }\end{array}$ & $\begin{array}{l}\text { Food intake: } \\
\text { Obtained for } \\
\text { breakfast, lunch and } \\
\text { between meal } \\
\text { snacks and } \\
\text { supplements in the } \\
\text { intervention group } \\
\text { for } 3 \text { days using food } \\
\text { intake record } \\
\text { completed by } \\
\text { volunteers. A one }\end{array}$ & $\begin{array}{l}\text { Intervention group } \\
\text { had significantly } \\
\text { greater daily intake } \\
\text { of energy and } \\
\text { protein compared } \\
\text { with the control } \\
\text { group. } \\
\text { Energy (1336 kJ } \\
\text { (318kcal); } p=0.002) \\
\text { and protein }(15 \mathrm{~g} ; p=\end{array}$ & $\begin{array}{l}\text { Adjusted method } \\
\text { used for food intake } \\
\text { data collection in } \\
\text { control group. } \\
\text { Small numbers in } \\
\text { study. } \\
\text { Intervention provided } \\
\text { for } 3 \text { days for each } \\
\text { patient. }\end{array}$ \\
\hline
\end{tabular}




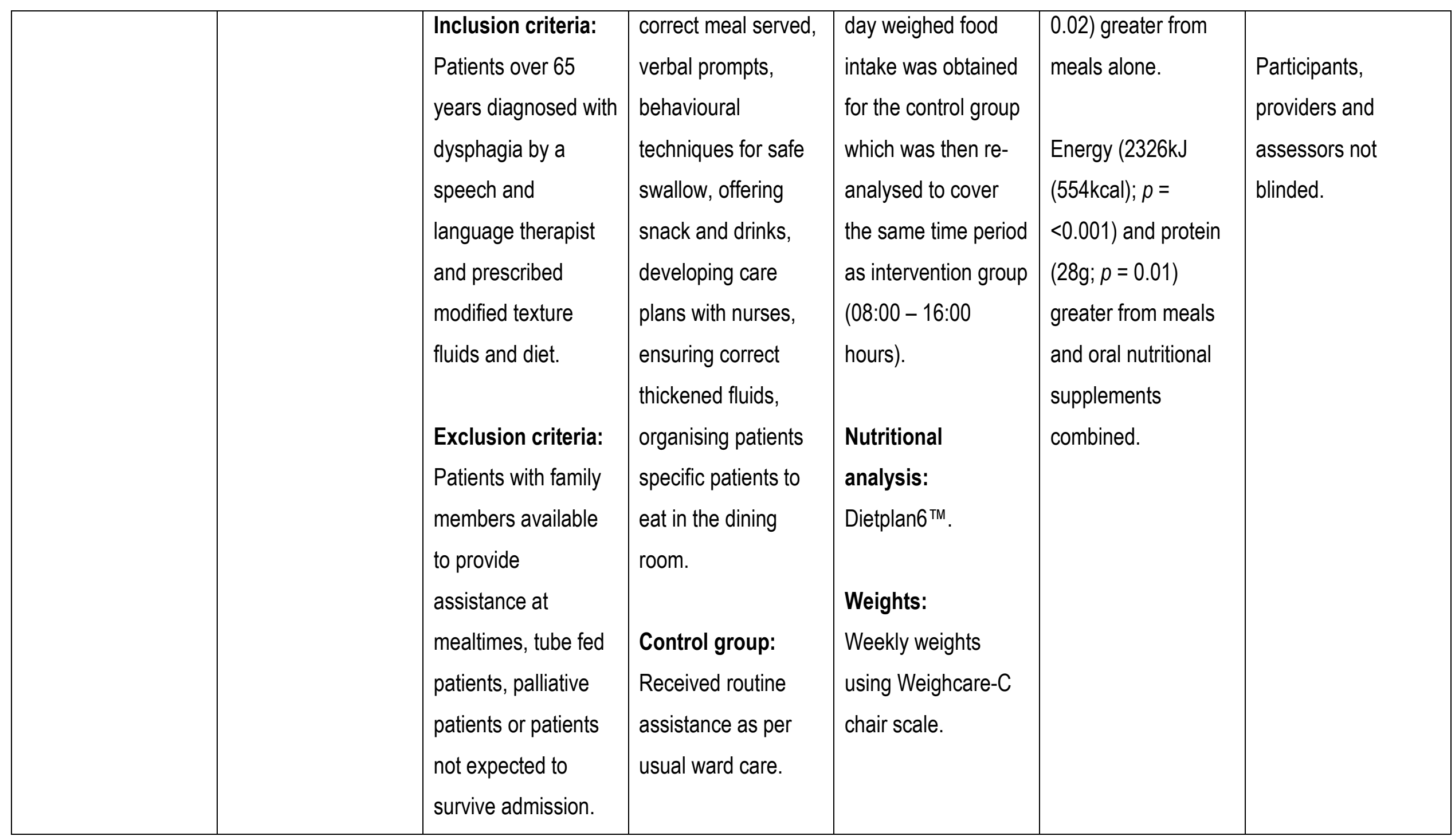




\begin{tabular}{|c|c|c|c|c|c|c|}
\hline Wright et al.(100) & $\begin{array}{l}\text { Study design: } \\
\text { Quasi-experimental. } \\
\text { Study duration: } \\
6 \text { weeks. } \\
\text { Randomisation: } \\
\text { Convenient sample. }\end{array}$ & $\begin{array}{l}\text { Participants: } \\
\text { Total } n=48 . \\
\text { Intervention } n=30 . \\
\text { Control } n=18 . \\
\text { Median age } 84 \\
\text { years. } \\
\text { Setting: } \\
\text { Acute medicine for } \\
\text { the elderly wards, } \\
\text { Charing Cross } \\
\text { Hospital, London. } \\
\text { Inclusion criteria: } \\
\text { All patients admitted } \\
\text { to the two wards } \\
\text { were considered for } \\
\text { inclusion. }\end{array}$ & $\begin{array}{l}\text { Intervention group: } \\
\text { Patients deemed } \\
\text { suitable by nursing } \\
\text { and physiotherapy } \\
\text { staff based on } \\
\text { medical condition } \\
\text { and rehabilitation } \\
\text { potential were } \\
\text { encouraged to } \\
\text { attend a dining room } \\
\text { to eat lunch. The } \\
\text { dining room was } \\
\text { supervised by a } \\
\text { trained nursing } \\
\text { assistant who } \\
\text { offered support and } \\
\text { encouragement with } \\
\text { meals as required. }\end{array}$ & $\begin{array}{l}\text { Food intake: } \\
\text { Mean protein and } \\
\text { energy intake for a } \\
\text { minimum of } 3 \text { lunch } \\
\text { meals for each } \\
\text { patient recorded } \\
\text { using food record } \\
\text { charts completed by } \\
\text { researchers. Mean } \\
\text { of the first, median } \\
\text { and final days intake } \\
\text { used for patients } \\
\text { with more than } 3 \\
\text { days intake } \\
\text { recorded. } \\
\text { Nutritional } \\
\text { analysis: } \\
\text { Dietplan } 5^{\mathrm{TM}} \text {. }\end{array}$ & $\begin{array}{l}\text { Intervention group } \\
\text { had significantly } \\
\text { higher intakes of } \\
\text { energy ( } 542 \mathrm{~kJ} \\
(129 \mathrm{kcal}) ; p=< \\
0.013) \text { than control } \\
\text { group for the lunch } \\
\text { meal. } \\
\text { No significant } \\
\text { difference in protein } \\
\text { intake between } \\
\text { groups ( } p=0.63 \text { ). } \\
\text { No significant } \\
\text { difference in weight } \\
\text { gain between groups } \\
(p=0.6) \text {. }\end{array}$ & $\begin{array}{l}\text { Nursing staff aware } \\
\text { ware researchers } \\
\text { were measuring food } \\
\text { intake. } \\
\text { Small numbers in } \\
\text { study. } \\
\text { Patients attended } \\
\text { the dining room a } \\
\text { median of four times. } \\
\text { Participants, } \\
\text { providers and } \\
\text { assessors not } \\
\text { blinded. }\end{array}$ \\
\hline
\end{tabular}




\begin{tabular}{|c|c|c|c|c|c|c|}
\hline & & & $\begin{array}{l}\text { Control group: } \\
\text { Patients ate meals } \\
\text { by their bedside with } \\
\text { nursing assistants } \\
\text { available for } \\
\text { assistance as part of } \\
\text { usual ward routine. }\end{array}$ & $\begin{array}{l}\text { Weights: } \\
\text { Weekly weights } \\
\text { obtained using } \\
\text { Weighcare-C chair } \\
\text { scale. }\end{array}$ & & \\
\hline Edwards et al.(101) & $\begin{array}{l}\text { Study design: } \\
\text { Quasi-experimental. } \\
\text { Study duration: } \\
3 \times 24 \text { hour periods. } \\
\text { Randomisation: } \\
\text { Convenience } \\
\text { sample. }\end{array}$ & $\begin{array}{l}\text { Participants: } \\
\text { Total } n=13 . \\
\text { Intervention } n=4 . \\
\text { Control } 1 n=5 . \\
\text { Control } 2 n=4 . \\
\text { Setting: } \\
\text { Ambulant patients in } \\
\text { Women's Health } \\
\text { unit, National Health } \\
\text { Service Hospital, } \\
\text { UK. }\end{array}$ & $\begin{array}{l}\text { Intervention group: } \\
\text { Patients ate meals at } \\
\text { dining table. } \\
\text { Control groups: } \\
\text { Group 1- ate meals } \\
\text { from trays sitting by } \\
\text { their bed. } \\
\text { Group } 2 \text { - ate meals } \\
\text { from trays while in } \\
\text { their bed. }\end{array}$ & $\begin{array}{l}\text { Food intake: } \\
\text { Breakfast, lunch and } \\
\text { dinner meals were } \\
\text { obtained for } 3 \text { x } 24 \\
\text { hours periods by } \\
\text { means of weighed } \\
\text { plate waste. } \\
\text { Digital scales were } \\
\text { used to weigh plate } \\
\text { waste. }\end{array}$ & $\begin{array}{l}\text { Mean daily energy } \\
\text { intake was } \\
\text { significantly greater } \\
\text { eating around a table } \\
(p<0.05) \text {. } \\
\text { Energy } 1193 \mathrm{~kJ} \\
(284 \mathrm{kcal}) / 24 \text { hours } \\
\text { greater when } \\
\text { compared with } \\
\text { eating from tray by } \\
\text { bed and } \\
1130 \mathrm{~kJ}(269 \mathrm{kcal}) / 24\end{array}$ & $\begin{array}{l}\text { Small numbers in } \\
\text { study. } \\
\text { Snacks and between } \\
\text { meal oral nutritional } \\
\text { supplements were } \\
\text { not reported. } \\
\text { Providers and } \\
\text { assessors unblinded. } \\
\text { Unclear if } \\
\text { participants blinded. }\end{array}$ \\
\hline
\end{tabular}




\begin{tabular}{|l|l|l|l|l|}
\hline & & & Nutritional & $\begin{array}{l}\text { hours greater } \\
\text { compared with } \\
\text { analysis: } \\
\text { performed using } \\
\text { Microdiet. }\end{array}$ \\
\hline
\end{tabular}

$\mathrm{RCT}=$ Randomised control trial; $\mathrm{BMI}=$ Body Mass Index; $n=$ number; $\mathrm{g}=$ grams; $\mathrm{kJ}=$ kilojoule; $\mathrm{kcal}=$ kilocalorie 
Table 3.3 Summary of statistically significance results.

\begin{tabular}{|c|c|c|c|c|c|}
\hline Study & $\begin{array}{l}\text { Energy intake } \\
\text { (kJ/kcals) }\end{array}$ & Protein intake $(\mathrm{g})$ & $\begin{array}{l}\text { Measures of nutritional } \\
\text { status }\end{array}$ & $\begin{array}{l}\text { Length of stay in } \\
\text { hospital (days) }\end{array}$ & Mortality (number) \\
\hline \multirow[t]{2}{*}{ Duncan et al.(98) } & \multirow[t]{2}{*}{ Significant increase } & \multirow[t]{2}{*}{ Not measured } & $\begin{array}{l}\text { Non-significant increase } \\
\text { in grip strength (Kgf). }\end{array}$ & \multirow[t]{2}{*}{ No difference } & \multirow{2}{*}{$\begin{array}{l}\text { Significant decrease in } \\
\text { hospital and at } 4 \text { months } \\
\text { post discharge }\end{array}$} \\
\hline & & & $\begin{array}{l}\text { Significantly less } \\
\text { reduction in MAC (cm) }\end{array}$ & & \\
\hline Hickson et al.(97) & Non-significant increase & Non-significant increase & No difference & No difference & Not measured \\
\hline Walton et al.(99) & Non-significant increase & Significant increase & Not measured & Not measured & Not measured \\
\hline Wright et al.(93) & Significant increase & Significant increase & Not measured & Not measured & Not measured \\
\hline Wright et al.(100) & Significant increase & No difference & $\begin{array}{l}\text { Non-significant increase } \\
\text { in the number of patients } \\
\text { that gained weight }(\mathrm{kg})\end{array}$ & Not measured & Not measured \\
\hline Edwards et al.(101) & Significant increase & $\begin{array}{l}\text { Measured but not } \\
\text { reported }\end{array}$ & Not measured & Not measured & Not measured \\
\hline
\end{tabular}

MAC = Mid Arm Circumference; Kgf =kilogram force; $\mathrm{cm}=$ centimetres; $\mathrm{kg}=$ kilograms; $\mathrm{kJ}=$ Kiljoules; $\mathrm{kcals}=$ kilocalories; $\mathrm{g}=\mathrm{grams}$.

Statistical significance of $p \leq 0.05$ in all studies. 


\subsection{Nutritional Intake}

\subsubsection{Description of studies}

Various methods were used to determine nutritional intake and subsequently analyse energy and protein intake in the included studies. Hickson et al(97) reported nutritional intake data for $6 \%$ of the study participants using a combination of weighed food intakes for lunch and dinner and food record charts for breakfast, snacks and drinks. Protein and energy intakes were analysed using Dietplan5 $^{\mathrm{TM}}$ (Forestfield Software Ltd, Horsham, UK). Duncan et al(98) recorded data on patient nutritional intakes on the $3^{\text {rd }}$ post operative day using semi-quantitative food intake charts that included descriptions of portion sizes. These charts were completed by the dietetic assistants in the case of the intervention arm and by nurses in the control arm of the study. Food portions were validated by means of a weighed intake on day's 3-6 post operatively for 27 consecutive patients. Energy intakes were assessed to the nearest 50kcal(210kJ) for $275(91 \%)$ of patients. The nutritional analysis tool used to determine energy intake was not stated in this study.

In the studies assessing the use of volunteers Walton et al(99) used electronic scales to weigh plate waste for the lunch-time meal including both food and drinks. Nutritional intake was then determined by comparing the amount consumed with the hospital standard serves. The standard serves were obtained from information provided by the hospital food service department, food manufacturer's packaging labels and by obtaining duplicate samples of meals in order to determine the baseline standard serve. Nutritional analysis was performed using FoodWorks ((Professional Edition) Version 4, 1998-2003 (Xyris Software Pty Ltd, Highgate Hill, Australia)). In the volunteer study of volunteers by Wright et al(93) nutritional intake data were collected by means of the standardised hospital food intake charts, which were completed by the volunteer assistants in the intervention arm of the study. Nutritional intake data were recorded from 08:00 16:00 hours for three days and the mean included for each patient. Analysis was performed by a registered dietitian using Dietplan6 ${ }^{\mathrm{TM}}$ (Forestfield Software Ltd, Horsham, UK). Nutritional intake data for the intervention group was compared with data from an earlier study by Wright ${ }^{(105)}$ which recorded the nutritional intake of patients in the same hospital with similar demographics and diagnoses, and on modified textured diets. This study originally recorded dietary intake for this control group for 24 hours which was subsequently adjusted to include only the nutritional intake between 08:00 - 16:00 hours in order to match the intervention group. The nutritional intake data were obtained by means of a one day weighed plate waste where food was weighed before it was served and the uneaten residual food weighed to determine the amounts of food consumed by the patient. Analysis was performed using Dietplan $5^{\mathrm{TM}}$. The patients in the study by Wright et 
al ${ }^{(100)}$ ate in a supervised dining room and were compared with patients who ate by their bedside. Nutritional intake data were collected by means of standardised hospital food intake charts that were completed by the researchers. Nutritional data were collected for a minimum of three lunches with the mean intake determined for each patient. For patients who had their intake recorded for more than 3 days the mean was obtained from the first, median and last days that food intake charts were completed. Analysis was performed by a registered dietitian using Dietplan $5^{\mathrm{TM}}$. Similarly in the study by Edwards et al,(101) patients consumed meals either sitting around a table with other patients, by their bedsides or in their beds. Meals were weighed before and after being served to patients using digital scales (Hanson) in order to determine the amount of food consumed by the patient. Nutritional analysis was undertaken using Microdiet (Salford University, UK). Nutritional data were collected for three consecutive, 24 hour periods.

\subsubsection{Energy intake}

All six included studies(93, 97-101) examined the effect of the described mealtime intervention on patient energy intake. Four of the included studies $(93,98,100,101)$ showed a statistically significant increase in energy intake in the interventions groups when compared to their respective control groups. The study by Duncan et al(98) demonstrated an increased mean energy intake of $349 \mathrm{kcal}(1465.8 \mathrm{~kJ})$ per 24 hours in the group that had dietetic assistants available to facilitate at mealtimes compared with the control group who did not received assistance $(p=<0.001)$. The increased energy intake was derived from both hospital food and oral nutritional supplements in this study. When compared separately, there was only a non-significant increase in energy intake derived from hospital food intake whilst there was significantly greater energy intake attributable to intake of oral nutritional supplements. Oral nutritional supplements were available to both the intervention and control groups throughout the day in this study(98).

Patients who received mealtime assistance from volunteers in the study by Wright et al(93) consumed significantly more energy $554 \mathrm{kcal}(2327 \mathrm{~kJ})$ from both food and oral nutritional supplements than the control group did from the hours of 08:00 - 16:00 $(p=0.002)$. In the study by Wright et al (100) comparing eating locations, the mean energy intake at lunch was found to be $129 \mathrm{kcal}(541.8 \mathrm{~kJ})$ greater for patients who ate in a dining room when compared to those who ate by their bedside which was statistically significant $(p<0.013)$. Similarly, Edwards et al $(101)$ demonstrated that the mean daily energy intake was $269 \mathrm{kcal}(1129.8 \mathrm{~kJ})$ greater for patients who ate around a table compared to those who ate in bed and $284 \mathrm{kcal}(1192.8 \mathrm{~kJ})$ greater when compared to those who ate by their bedsides $(p<0.05)$. 
Hickson et al(97) showed a non significant increase in energy intake of $370 \mathrm{~kJ}(98 \mathrm{kcal})$ per day when trained healthcare assistants facilitated patients eating $(p=0.53)$. Similarly, in the study by Walton et al(99) evaluating trained volunteers, a greater but non-significant increase in energy intake of $439 \mathrm{~kJ}(104 \mathrm{kcal})$ at lunch was found in the intervention group $(p=0.072)$.

\subsubsection{Protein intake}

Five of the included studies $(93,97,99-101)$ reported on the effects of the described intervention on patient protein intake. In the study by Hickson et al(97) there was a non significant increase in protein intake of $3 g$ per day reported when healthcare assistants were available to assist patients $(p=0.62)$. Walton et al(99) found patients mean protein intake was increased significantly by $10.1 \mathrm{~g}$ $(p<0.05)$ for lunch-time meals where trained volunteers provided support. Despite this, no significant change in patient protein intake was reported by the authors when changes in protein intake were analysed over the entire day. The other remaining study ${ }^{(93)}$ investigating the use of trained volunteers found patients who had access to volunteers from 08:00-16:00 hours consumed a mean of $28 \mathrm{~g}$ more protein from food and oral nutritional supplements that the control group ( $p=0.02)$. Unlike the study by Wright et al(100) evaluating a supervised dining room, which found a non significant increase in protein intake of $1.2 \mathrm{~g}$ for the lunch-time meal between patients who ate in a supervised dining room compared to those who ate by their bedside $(p=0.63)$. The study by Edwards et al(101) reported an increased mean daily protein intake for patients who ate at the dining table however did not provide the relevant values to reflect this reported difference.

\subsection{Nutritional status}

\subsubsection{Description of studies}

Nutritional status was measured by means of anthropometric measures in three of the included studies, $(97,98,100)$ however only Duncan et al(98) demonstrated any significant result with less reduction in MAC demonstrated in patients in the intervention arm of study. Although statistically significant this result does not demonstrate an improvement in patient nutritional status but merely less deterioration. No other statistically significant differences in anthropometric measures were found between the groups in these studies, $(97,98,100)$ although non-significant differences were reported. Hickson et al(97) obtained patient anthropometric measures on admission and discharge from hospital. Body Mass Index was calculated from surrogate height measurements using demi-span, whilst weight was recorded using calibrated electronic scales operated by trained personnel. Descriptions of how MAC, MAMC, TSF thickness and grip strength were obtained were not described by the authors. The study by Duncan et al(98) evaluating the 
effectiveness of employed assistants also obtained anthropometric measures on admission and discharge from hospital. Surrogate height measurements were obtained from supine total arm length and although patient's weights were recorded, no details were provided regarding how these were measured. The methods by which MAC, TSF thickness and grip strength were obtained were not described. Wright et al(100) obtained weekly weights for patients using a Weighcare-C chair scale (Advanced Weighing, Newhaven, UK).

\subsubsection{Weight and Body Mass Index}

The study by Hickson et al(97) found no statistically significant difference in median weight $(p=0.42)$ or BMI ( $p=0.41)$ with comparison between patients assisted by healthcare assistants and those receiving usual care. Body Mass Index was not reported in the study by Duncan et al(98) despite both weight and height being recorded. It was however reported by the authors that mean weight fell in both groups of patients $(p=0.16)$. ${ }^{(98)}$ Wright et al(100) found no significant difference in weight gain between patients who ate in a dining room compared to those who ate from by their bedside or in bed $(p=0.6)$. Although non-significant, a greater number of patients who ate in the dining room demonstrated a weight gain, with three patients losing weight and 14 patients gaining weight, in comparison to patients who ate by their bedside, where seven patients lost weight and nine patients gained weight $(p=0.12)$.

\subsubsection{Measures of muscle/protein status and fat stores}

The study by Hickson et al(97) found no difference in median MAC ( $p=0.39)$, TSF thickness $(p=0.45)$, MAMC $(p=0.06)$ or grip strength $(p=0.17)$ in patients assisted by healthcare assistants compared to those who received usual care. The study by Duncan et al(98) found mean MAC fell in both groups of patients but to a statistically significant lesser degree $(p=0.002)$ in the group that received support from the dietetic assistants. The authors measured TSF thickness and grip strength in both patient groups on admission and four months post discharge from hospital. Triceps skinfold thickness fell $(p=0.087)$ in both groups while mean handgrip strength increased in both groups. ${ }^{(98)}$ Although not statistically significant, a greater gain in handgrip strength was demonstrated in group assisted by dietetic assistants $(p=0.32) .{ }^{(98)}$

\subsection{Length of stay in hospital}

Two studies $(97,98)$ reported on patient length of stay in hospital, both of which evaluated the effectiveness of employed assistants. Hickson et al(97) found no difference in length of stay in hospital $(p=0.45)$ between patient groups. Likewise, Duncan et al(98) also found no statistical 
difference in length of stay in hospital between the group of patients assisted by dietetic assistants as compared to the control group of patients $(p=0.81)$.

\subsection{Mortality}

Duncan et al(98) reported on mortality as an outcome measure and demonstrated a significantly lower mortality rate when patients received mealtime assistance from dietetic assistants while they were in the acute trauma unit $(p=0.048)$ and four months post discharge $(p=0.036)$. 


\section{Chapter 4 Discussion}

\subsection{Discussion}

This chapter discusses the effect of each mealtime intervention on outcome measures, as well as providing a more detailed discussion of each of the included studies. The strengths and limitations of this systematic review are also discussed as well as the implications for future practice and research.

The results of this systematic review demonstrate that energy intake can be increased in patients in the acute care setting when either employed assistants or volunteers are present to provide mealtime support or when patients eat around a table or in a supervised dining room. The increase in the four studies $(93,97,98,101)$ that reported on patient energy intake ranged from $370 \mathrm{~kJ}(88 \mathrm{kcal})$ to $1466 \mathrm{~kJ}(349 \mathrm{kcal})$ per day. The two studies $(99,100)$ that measured energy intake specifically for the lunch-time meal demonstrated increases in energy intake of between $439 \mathrm{~kJ}(104 \mathrm{kcal})$ and $542 \mathrm{~kJ}(129 \mathrm{kcal})$ for that meal. In addition to this, protein intake was increased by 10.1 - 15g per meal when trained volunteers were present to provide mealtime support to patients. Based on a typical patient who may commonly occupy an acute care hospital bed for example a 65 year old patient weighing $60 \mathrm{~kg}$ with daily nutritional requirements of approximately $7560 \mathrm{~kJ}(1800 \mathrm{kcal})$ and $60 \mathrm{~g}$ of protein, the increases demonstrated would represent $5-19 \%$ of their daily energy requirement and $16-25 \%$ of their daily protein requirement. Conversely, this review reveals non-significant improvements in nutritional status and no improvements in length of stay in hospital. Only one study(98) demonstrated improved mortality in hospital and at 4 months post discharge when dietetic assistants were available to provide mealtime assistance.

\subsection{Review of findings/results}

\subsubsection{Effectiveness of employed assistants}

The studies examining the effectiveness of employed assistants $(97,98)$ used different titles to describe this role, one of healthcare assistant and the other of dietetic assistant, however the role and functions of these assistants appeared similar. The role of dietetic assistant was first established in the 1990s as means of assisting in the management of malnutrition in hospitals. ${ }^{(106)}$ A study by Le Cornu et al(107) in the UK found that while dietetic assistants were not formal trained; $61 \%$ of dietitians and $53 \%$ of dietetic assistants supported the development of a recognised mandatory qualification. Assistants utilised by Hickson et al(97) and Duncan et al(98) were provided with training prior to commencing their role. In the study by Hickson et al(97) 
healthcare assistants were provided with 15 hours of training on nutrition and related topics and had their skills and knowledge assessed before and after training and again six months into the study. The assistants were employed specifically for the study so it is unclear if they had any previous relevant experience. Similarly, in the study by Duncan et al(98) the dietetic assistants were provided with 14 days orientation and training including spending time with a specialist dietitian. The dietetic assistants had no previous formal nutrition education but had experience working within the hospital environment. Although these assistants had relevant hospital experience and received a lengthier training program which may suggest they were better equipped for their role, it was not stipulated whether their knowledge and skills had been assessed or if they were considered to be competent.(98) Hickson et al(97) reported that the mean skill scores for the three assistants was $53 \%$ at the start of the training program rising to $76 \%$ post training and knowledge scores were $41 \%$ prior to training and $75 \%$ post training. Skills and knowledge were reportedly maintained when assessed six months into the 20 month study. The skills and knowledge scores were not individually reported so it is unclear if all of the assistants functioned at a similar level. Assistants with good knowledge and skills are likely to have engaged well with both patients they were assisting and nursing staff. This may have provided patients with an enhanced level of service that could potentially have improved their nutritional intake. Conversely, assistants with less developed knowledge and skills may have had difficulties engaging with patients and nursing staff making them less effective their role.

The assistants in the study by Hickson et al(97) worked shifts across five days per week and provided patients with mealtime assistance for two meals per day. Although the number of hours was not stated it is estimated that approximately 25 hours per week of assistance would have been provided. In the study by Duncan et al(98) the assistants were available for 6 hours per day 7 days per week equating to 42 hours of assistance per week. The greater level of assistant hours in the study by Duncan et al(98) may explain the greater observed effect of assistants reported by these authors.

The roles and functions of the assistants in each of the studies $(97,98)$ were similar and are detailed in Table 4.1. In both studies(97, 98) the presence of assistants at mealtimes improved patient energy intake, however this was only statistically significant in the study by Duncan et al.(98) Protein intake was reported by Hickson et al(97) which showed a non-significant increase in the intervention group. Duncan et al(98) did not analyse the protein intake or that of any other nutrient from the nutritional data collected stating that the values would be too imprecise and furthermore 
did not provide an explanation for this imprecision. Assistance from employed assistants had no effect on patient length of stay in hospital.

Table 4.1. Comparison of the role and function of employed assistants in Hickson et al(97) and Duncan et al. ${ }^{(98)}$

\begin{tabular}{|c|c|c|}
\hline Role and function & Hickson et al.(97) & Duncan et al.(98) \\
\hline Food choice & $\begin{array}{l}\text { Providing help to ensure patients } \\
\text { completed their menu. }\end{array}$ & $\begin{array}{l}\text { Checking patients personal and } \\
\text { cultural food preferences, } \\
\text { assisting with food choices and } \\
\text { portion sizes and co-ordinating } \\
\text { meal orders with catering staff. }\end{array}$ \\
\hline Oral supplements & $\begin{array}{l}\text { Providing additional milky drinks } \\
\text { throughout the day and } \\
\text { distributing prescribed oral } \\
\text { nutritional supplements to } \\
\text { patients. }\end{array}$ & $\begin{array}{l}\text { Ordering any oral nutritional } \\
\text { supplements if necessary. } \\
\text { Ensuring nutrition support is } \\
\text { offered regularly. }\end{array}$ \\
\hline Mealtime assistance & $\begin{array}{l}\text { Ensuring patients are sitting in the } \\
\text { best possible position to eat and } \\
\text { can reach their meal tray, opening } \\
\text { food packets and removing lids. } \\
\text { Cutting up patients food, checking } \\
\text { the correct meal has been served, } \\
\text { cleaning, putting on patients } \\
\text { glasses and cleaning and putting } \\
\text { in patients dentures prior to } \\
\text { mealtimes }\end{array}$ & $\begin{array}{l}\text { Ensuring patients are sitting in the } \\
\text { best possible position to eat. }\end{array}$ \\
\hline Feeding & Enabling feeding. & $\begin{array}{l}\text { Feeding the frailest patients. } \\
\text { Supporting patients to feed } \\
\text { themselves. }\end{array}$ \\
\hline $\begin{array}{l}\text { Interacting and } \\
\text { encouragement }\end{array}$ & $\begin{array}{l}\text { Encouraging and enabling feeding } \\
\text { of patients and supporting ward } \\
\text { staff in this role. }\end{array}$ & $\begin{array}{l}\text { Sitting with patients and } \\
\text { encouraging them to eat. }\end{array}$ \\
\hline $\begin{array}{l}\text { Data collection and } \\
\text { documentation }\end{array}$ & $\begin{array}{l}\text { Identifying patients who have a } \\
\text { reduced food intake and other risk }\end{array}$ & $\begin{array}{l}\text { Identifying patients with nutritional } \\
\text { issues, assisting in resolving }\end{array}$ \\
\hline
\end{tabular}




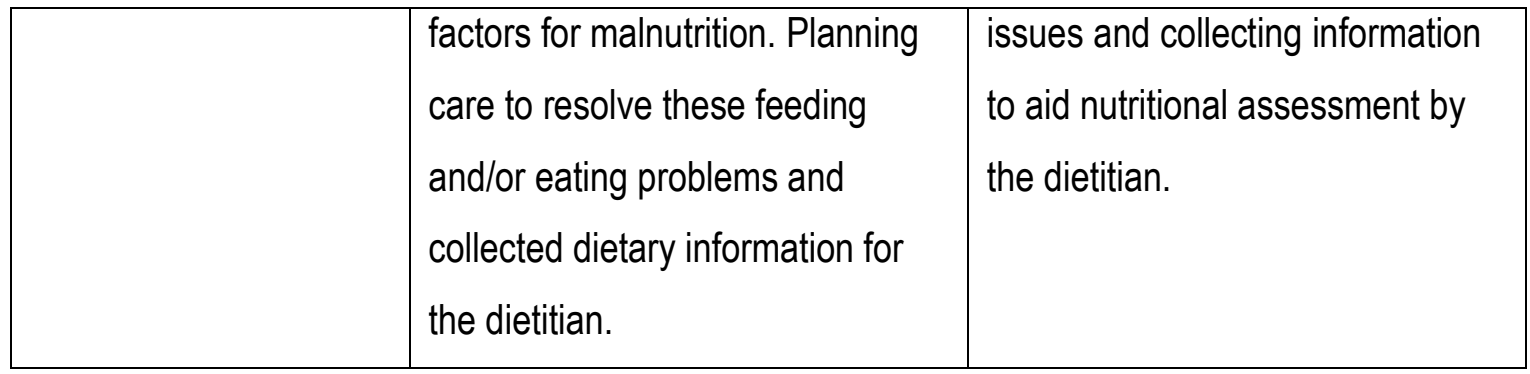

\subsubsection{Effectiveness of trained volunteers}

Volunteers were trained and managed by dietitians in both studies identified examining the effectiveness of volunteers. $(93,99)$ In the study by Walton et al(99) 25 volunteers were trained, however details of the training provided was not reported other than specifying that volunteers were asked to encourage patients to eat the high energy and protein components of their meal first. Volunteer assistance was provided at lunch-time on weekdays, with each volunteer assisting two to three patients within a 45 minute period. In the study by Wright et al(93) the volunteers were three undergraduate nutrition students who were provided with one week training by a dietitian and speech and language therapist prior to the study. Professional experience or background of the volunteers in the study by Walton et al(99) study was not reported on.

The roles and functions of the trained volunteers in the studies by Walton et al(99) and Wright et al (93) are outlined in Table 4.2. Although both of these studies reported on the use of trained volunteers, their role and functions differed. The volunteers in the study by Wright et al(93) performed duties that were similar to that of the employed assistants in the studies by Hickson et al(97) and Duncan et al.(98) These duties were somewhat enhanced when compared to the volunteers in the study by Walton et al,(99) including feeding patients with dysphagia using specific feeding techniques, increased physical contact with patients and developing care plans with nurses. The volunteers in the study by Walton et al(99) had a more limited role and were required to seek assistance from nursing staff to change patient positioning prior to or during mealtimes if indicated in order to facilitate eating, put in dentures and for any patients who exhibited swallowing difficulties. The enhanced role of the volunteers in the study by Wright et al(93) may explain the improvement in both energy and protein intake observed by these authors.

Making comparisons between the two studies is problematic for although both studies used people who were volunteers by nature, their roles and functions were markedly different. Wright et al(93) stated that one of the roles of the trained volunteers was to organise specific patients to eat in the dining room which could be considered to be an additional mealtime intervention in this study that may have further enhanced the outcomes for the intervention group; given that Wright 
et al(100) previously evaluated the effect of eating in a dining room and found that it significantly increased patients energy intake. Wright et al(93) did not reported how many, if any, patients attended the dining room as directed by the volunteers.

Volunteers are known to make a significant contribution in many healthcare settings ${ }^{(108)}$ and the last few decades has seen an increase in the number of volunteers undertaking both clinical and administrative tasks in hospitals.(109) The reasons why people volunteer are not fully understood, ${ }^{(110)}$ with younger people often reported as volunteering to gain work experience ${ }^{(110,}$ 111) as in the study by Wright et al;(93) and older people volunteering for social or personal reasons such as friendship, belonging and self fulfillment. $(109,110)$ Teasdale(111) reported that the profile of hospital volunteers is changing from the altruistic retired woman to a younger person from diverse ethnic communities.(111) The level of assistance volunteers are able to provide to patients in hospital is likely to vary; with support from volunteers typically being available at lunch-times on week day, as in the studies by Walton et al(99) and Manning et al.(112) However, Brown et al(96) reported that at the Chelsea and Westminster Hospital National Health Service Trust, UK students at the neighbouring college undertaking an access to nursing program volunteered to be part of the hospitals dining companion program. Some of these students volunteered to provide assistance in the evenings and at weekends, ${ }^{(96)}$ perhaps marking the beginning of a change in volunteer practices. The volunteers in the study by Wright et al(93) were undergraduate dietetic students and as such, would have had a better understanding of patient nutritional care than other volunteers may have had. In addition to this, the performance of the volunteers in the study by Wright et al(93) may have been enhanced given that they were gaining work experience in the clinical setting which could potentially affect future references and/or employment. This added incentive may also have contributed to an improved volunteer performance and subsequent improved energy intake as seen in the study by Wright et al(93) when compared with the volunteers in the study by Walton et al.(99)

Table 4.2. Comparison of the role and function of trained volunteers in Walton et al(99) and Wright et al.(93)

\begin{tabular}{|l|l|l|}
\hline Role and function & Walton et al.(99) & Wright et al.(93) \\
\hline Food choice & $\begin{array}{l}\text { Encouraging patient to eat high } \\
\text { protein and high energy } \\
\text { components of meal first. }\end{array}$ & $\begin{array}{l}\text { Ensuring correct food is served } \\
\text { and thickened fluids are of the } \\
\text { correct consistency. }\end{array}$ \\
\hline Oral supplements and & No role or function described. & Offering snacks and drink \\
\hline
\end{tabular}




\begin{tabular}{|c|c|c|}
\hline snacks & & $\begin{array}{l}\text { throughout the day. Provide } \\
\text { additional milky drinks and } \\
\text { distribute prescribed supplements. } \\
\text { Offer thickened fluids. }\end{array}$ \\
\hline Mealtime assistance & $\begin{array}{l}\text { Assist patients with meal tray set } \\
\text { up and opening packages. }\end{array}$ & $\begin{array}{l}\text { Ensuring patient is seated } \\
\text { comfortably and in the best } \\
\text { position to eat, meal is within } \\
\text { reach and all packets are opened } \\
\text { and lids removed. Ensure } \\
\text { dentures in place prior to } \\
\text { mealtimes. Assist with cutting up } \\
\text { food. Organise specific patients to } \\
\text { eat in dining room. }\end{array}$ \\
\hline Feeding & No role or function described. & $\begin{array}{l}\text { Ensuring safe patient swallow by } \\
\text { using behavioural techniques } \\
\text { (previous taught) to improve oral } \\
\text { control and swallowing. }\end{array}$ \\
\hline $\begin{array}{l}\text { Patient interacting and } \\
\text { encouragement }\end{array}$ & $\begin{array}{l}\text { Encourage and converse with } \\
\text { patients. }\end{array}$ & $\begin{array}{l}\text { Offering patients verbal prompts } \\
\text { to eat. }\end{array}$ \\
\hline $\begin{array}{l}\text { Data collection and } \\
\text { documentation }\end{array}$ & $\begin{array}{l}\text { Documenting what assistance } \\
\text { was provided and approximately } \\
\text { how much of the meal was eaten. }\end{array}$ & $\begin{array}{l}\text { Monitoring any dietary } \\
\text { modifications. }\end{array}$ \\
\hline $\begin{array}{l}\text { Identification and } \\
\text { resolution of nutritional } \\
\text { issues }\end{array}$ & No role or function described. & $\begin{array}{l}\text { Developing patient nutrition care } \\
\text { plans with nurses. }\end{array}$ \\
\hline
\end{tabular}

\subsubsection{Effectiveness of eating at table or in a dining room}

Studies in healthy community living individuals have found that eating with companions can both enhance and suppress food intake although it is unclear how or why this occurs.(113) Eating in the company of others has been shown to increase the amount of food eaten at mealtimes, $(114,115)$ particularly when eating in the company of family members or friends where food intakes have been found to increase by $18-50 \% .(114-116)$ This social facilitation of food intake is believed to occur in part because companions provide a distraction from thinking about how much is being eaten, enable a relaxed eating environment(116) and because individuals will model the amount eaten on that of their companions; meaning they will increase their food intake to match that of 
their companions. ${ }^{(113)}$ Conversely, companions who merely observe and do not participate in eating have been found to suppress the food intake of those eating.(113) The presence of mealtime assistants or volunteers at mealtimes could be considered to be similar to that of observers who do not participate in eating and if so this could adversely affect food intake. Hetherington et al(116) found that healthy community living individuals who ate alone while watching television had an increased energy intake of $14 \%$. Music has also been found to increase the amount of food eaten in nursing home patients with dementia(117) and in students; ${ }^{(118)}$ suggesting that environmental noise has an impact on mealtime ambience and subsequent food intake.

Encompassing both the effects of the eating environment and companionship at mealtimes in acute care hospitals, two of the included studies $(100,101)$ examined the effectiveness of patients eating in a dining room and around a table as opposed to eating by their bedsides or whilst in bed. The location of the table, how the table was set or the number of patients sitting around the table was not revealed in the study by Edwards et al.(101) In the study by Wright et al(100) a trained nursing assistant supervised the dining room and offered patients encouragement and support as required. Nursing assistants were also available in the ward for the control group of patients who ate by their bedside. It is possible that the presence of nursing assistants who did not participate in eating during mealtimes may have had a suppressive effect on patient food intake as outlined by Herman et al,(113) nevertheless this would have been controlled for given that nursing assistants were present to assist both the intervention and control groups. Details regarding how the dining room was set up or the number of patients in the dining room at any given mealtime were not provided in the study by Wright et al.(100) The authors of these studies ${ }^{(100,101)}$ do not indicate if meal ambience, companionship or both contributed to improved patient energy intake.

Patients who attended the dining room in the study by Wright et al(100) had been encouraged to do so at lunch-time during weekdays. Only patients who were deemed suitable by the physiotherapist and nursing staff to independently attend the dining room were allocated to the intervention group, suggesting a certain level of functionality was required to attend the dining room. Greater physical functionality and younger age in the intervention group may reflect better overall health status, increased appetite and as a result the ability and motivation to eat more which could potentially create bias in the reported results. In the study by Edwards et al,(101) patients self selected whether they would eat around a table, or from meals trays by their bedsides or in their beds. Patients who ate around the table were aged 36-62 years, compared with 49-89 years for those who ate from trays in bed and 60-86 years for those who ate from trays 
in by their bedside. Given that the patients who ate at the table were younger, it is likely that they would have had an overall better health status, functionality and fewer co-morbidities and as a result better appetites than the older patients in the other two groups. Like the study by Wright et al(100) this would potentially create a bias in the subsequent reported results.

\subsection{Limitations of the included studies}

The validity of the studies in this review is mixed primarily due to the varying study designs employed. Two of the studies $(97,98)$ were RCTs with only the study by Duncan et al(98) scoring well enough on appraisal to be considered as being of good quality with a score of $\geq 8$ (Section 3.2, Table 3.1.). If conducted correctly, the RCT study design prevents selection bias.(119) While the study by Hickson et al(97) was an RCT, neither the patients or assessors were blinded, and although patients were randomised to either the intervention or treatment groups it was unclear as to whether the allocator was blinded. This indicates that the study by Hickson et al(97) had the potential for both selection and performance bias, reducing the strength of this study in comparison to the RCT by Duncan et al.(98) Patients in the study by Duncan et al(98) were randomised but not blinded, however both the allocator and assessor were blinded. Nevertheless, the study by Duncan et al.(98) still had a risk of performance bias. A strength of both of these studies $(97,98)$ is that there appeared to be no attrition, detection or reporting bias.

The remaining four included studies(93, 99-101) were considered to have lower validity primarily due to the study designs employed that did not utilise a method of random allocation to assign participants to the intervention or control groups, nor blind allocators or assessors to collect data on outcome measures, creating the risk of selection and performance bias. Three of the included studies(99-101) did not report on withdrawals from their studies creating the potential for attrition bias. The study by Wright et al(93) used two different but valid methods to collect nutritional data over different time periods and then recalculated this data in order to time match the data collection periods, it is unknown whether this was reported correctly and to the fullest extent as errors or omissions could easily be made by the authors. The potential for selection, performance, attrition and reporting bias identified in the included studies ${ }^{(93,97-101)}$ may have influenced the true effects of the interventions examined in these studies.

Furthermore, it should be noted that Hickson et al(97) is an author on both the studies by Wright et al. $(93,100)$ All three studies(93, 97, 100) were conducted between 1998 - 2005 in the same British National Health Service hospital trust. This would have required ongoing collaboration between 
nursing, dietetic and food service staff within the hospital trust and created the potential for contamination bias and for subsequent studies to be influenced by the Hawthorne effect.

\subsubsection{Study population}

Although malnutrition in hospitals had generally been associated with elderly patients the majority of patients at risk of malnutrition are under 65 years of age.(65) With this in mind, most of the included studies $(93,97-100)$ did not fully represent the age range of adult patients who may occupy acute care hospital beds or have nutritional issues. The study participants reported on in this review predominantly comprised of elderly patients with five ${ }^{(93,97-100)}$ of the studies stating that they were conducted in acute medicine for the elderly wards or on patients aged $\geq 65$ years. The study by Edwards et al(101) was the only exception having a patient age range of 36-89 years. Both the studies by Duncan et al(98) and Edwards et al(101) only included female patients which also does not fully represent the acute care hospital population. Three studies were conducted on patients with specific medical conditions with Duncan et al(98) examining patients with nonpathological hip fractures, Wright et al(93) patients who had been diagnosed with dysphagia by a speech and language therapist and Edwards et al(101) employing patients who had undergone gynecological surgical procedures. The other remaining studies $(97,99,100)$ did not report on patient diagnoses or reasons for admission to hospital. Given this limited data on principle diagnoses or co-morbidities it is unclear whether the populations in these studies $(97,99,100)$ truly represents the typical acute care population or whether they had varying degrees of acuity. Low acuity patients are likely to be motivated and able to eat independently, unlike high acuity patients who are likely to require mealtime support. Any acute care population is likely to have a mixture of both types of patients. If the included studies only included one type of patient within the acute care patient population the results of this systematic review would readily only apply to that defined acute care patient group and not the wide acute care population.

In the study investigating volunteer assistants by Wright et al(93) only patients who had been diagnosed with dysphagia by a speech and language therapist and who were on modified texture diets were included in the study. Dysphagia, or impaired swallowing is a common condition associated with advancing age ${ }^{(120)}$ that can occur as a result of wide range of conditions including acute cerebral events, for example stroke, degenerative disorders, brain injuries, and disease of the oro-pharyngo-oesophageal tract.(121) Patients with dysphagia are at risk of aspiration(122, 123) which is associated with pneumonia, malnutrition, dehydration and death.(123) Consequently, patients with dysphagia are likely to require mealtime assistance and/or supervision in order to ensure both an adequate food and fluid intake and safe swallowing. Targeting a group of patients 
who are known to required mealtime assistance provides a good opportunity to examine the effectiveness of the intervention and could be considered a strength of this study. However as the authors note, patients in each arm of the study were not well matched for the level of mealtime assistance and supervision they required(93). Patients in the control group were considered to be more independent at mealtimes and as such would have had increased opportunity and been more likely to eat more. ${ }^{(93)}$ Many patients with dysphagia may be cognitively impaired(124) or have expressive dysphasia where they have impaired expression and comprehension of verbal, written, or sign language ${ }^{(125)}$ creating a barrier to communication. It is unknown whether patients in the study by Wright et al(93) were able to adequately communicate the level of assistance they required. If they were unable to communicate they would have been required to rely upon what assistance they were provided with whether adequate or not.

In the studies by Walton et al(99) and Wright et al(100) patients were required to be referred by staff in order to be part of the intervention. Walton et al(99) referred patients to the volunteer feeding assistance program if the nursing unit manager felt they would benefit from the program. Patients were approved to attend the dining room in the study by Wright et al(100) if nursing and physiotherapy staff felt their medical condition enabled this. In the study by Walton et al(99) patients acted as their own controls with nutritional intake compared for meals with and without volunteer assistance; this is a strength of this study as all other variables that may have influenced nutritional intake such as poor appetite were subsequently controlled for. Conversely, in the study by Wright et al(100) where patients were required to independently walk to the dining room no such controls were in place. It is likely that patients who attended the dining room would have been more medically stable, had a greater degree of functionality and been motivated to do so. These circumstances are likely to have had a positive influence on patients' ability to eat and subsequent nutritional intake.

\subsubsection{Study size and duration}

The studies included in this systematic review varied greatly with regard to both the number of patients included in the study samples and duration of the interventions. Both the studies investigating employed assistants included large numbers of patients with 592 recruited and 509 completing the study by Hickson et al(97) and 302 of the 318 recruited completing the study by Duncan et al.(98) Hickson et al(97) reported that they expected to recruit greater numbers to their study, however unforeseen bed closures due to infection reduced the potential number of patients recruited to the study. In addition to this, 275 eligible patients were not recruited to the study through lack of consent which the authors' state was due to patients not wanting to have 
numerous measurements taken. For this reason the authors changed the recruitment criteria to allow patients to participate in the study without having anthropometric measurements recorded. As a result although 592 patients were randomised to the treatment groups only 484 patients ultimately had anthropometric measures recorded. In addition to this, energy and protein intakes were only measured in a sub-sample of $6 \%$ of patients. Despite the initial number of participants randomised in the study by Hickson et al(97) the outcome measures were only measured in a percentage of the included patients which would have underpowered this study. Duncan et al.(98) reported that 45 patients were excluded from their study either due to lack of consent, ineligibility or being missed by the researchers recruiting to the study.

In contrast to the large numbers of patients in the studies examining the effectiveness of assistants, fewer patients were recruited to the other studies as shown in Table 3.1. Across these studies the number of patients ranged from nine in the study by Walton et al(99) up to 48 in the study by Wright et al.(100) The studies by Hickson et al,(97) Duncan et al(98) and Wright et al(93) used a priori power calculations to guide recruitment in their studies. Despite this, Hickson et al(97) and Duncan et al(98) did not recruit the recommended number of patients leaving these studies underpowered to detect any statistically significant difference. The smaller number of participants in the volunteer study by Walton et al(99) and eating location studies $(100,101)$ will have adversely influenced the statistical power of the analysis performed.

The two studies on employed assistants $(97,98)$ were conducted for periods of 20 months and 36 months respectively. The duration of these studies $(97,98)$ is likely to have contributed to the greater number of participants recruited to these studies in comparison with the other four studies. ${ }^{93,99-}$ 101) Once again, in contrast to the studies on employed assistants the studies on volunteers and eating location were conducted over shorter periods of time ranging from three 24 hour periods in the study by Edwards et al(101) to four months in the study by Wright et al.(93) Although the duration of the studies was reported on, an indication of the intensity of the intervention for individual patients I the treatment groups was only reported in two of the included studies. $(97,100)$

Hickson et al(97) reported that patients received support from healthcare assistants for a median of 16 days with median length of stay in hospital of 21 days for patients in the intervention arm of the study. From this it can be deduced that some patients would not have received the intervention for the entire duration of their admission. Duncan et al(98) clearly acknowledge that it was unknown if all of the patients in the intervention arm of the study actually received the intervention or how many times they received it, as theirs was an intention to treat study. Wright 
et al(100) reported that patients in the intervention arm of their study attended the dining room a mean of four times. Therefore, it is impossible to ascertain from the included studies ${ }^{(93,97-101)}$ the impact of the intensity of the intervention on improving nutritional intake and status.

\subsubsection{Study setting and interventions}

Four of the included studies $(97-99,101)$ used the same ward for both the intervention and control groups. The presence of the assistants, volunteers, and dining tables or rooms in these wards would have brought about the potential for contamination bias ${ }^{(126)}$ in the control groups. Given that ward nurses were not blinded, the visibility of these interventions is likely to have had an impact on their awareness of patient mealtimes and nutritional care which would most likely have a positive influence how they managed mealtimes for the patients in the control groups. All of the included studies have the potential for the Hawthorne effect as they were not double-blinded and nursing staff delivering care to the control groups are likely to have been aware that a study was being conducted which may also have altered their delivery of mealtime care.

In the study by Duncan et al(98) both the intervention and control groups were situated in the same ward. Nursing staff would have previously had the responsibility of providing mealtime assistance to all patients within the ward however, given this study was being conducted; a proportion of patients within the ward would not be requiring usual nursing mealtime care at this time. This could potentially increase the nurse to patient ratio for the control group in this study(98) giving an inaccurate representation of usual care. With competing priorities being cited by nursing staff as reason for not providing mealtime assistance(2) the reduction in the number of patients within the ward requiring usual mealtime care would surely lessen the workload for nursing staff. Duncan et al(98) did not stipulate if nurse to patient ratios were adjusted at mealtimes and if not, there is a risk of performance bias in the control arm of this study.

The study investigating volunteers by Wright et al(93) used a prospective group for the intervention arm of the study and a retrospective group for the control arm of the study. As data from the intervention and control groups were collected two years apart, Wright et al(93) would have been able to control for contamination bias between the two groups. However, as data were collected on two different wards over two different time periods there may have been other uncontrolled variables that may have influenced the outcomes in this study. The study by Wright et al(100) also used two wards, one for the intervention group and another concurrently matched ward for the control group, which would have facilitated in eliminating contamination bias between the groups. 
Duncan et al(98) reported the analysis in their study was on an intention to treat basis. The intention to treat analysis would have analysed all patients randomly allocated to the intervention or control groups within their original groups, whether or not they received the treatment or completed the study or not.(127) Not only would this preserve the original allocation of patients to each group but it would have also provided an unbiased, but conservative estimate of treatment effect and reflect the real clinical situation.(128) In a busy ward it is unlikely that every patient would receive exactly the assistance they require for the duration of their admission unless there was one assistant allocated to each patient. The provision of assistance over the entire seven day week in the study by Duncan et al(98) represents the reality of the need for mealtime assistance in hospitals, even though assistance was available only for six hours per day rather than for all mealtimes. In the study by Hickson(97) the healthcare assistants were available to provide assistance at mealtimes for two meals per day and were involved in other tasks outside of mealtimes.

One of the roles of the volunteers in the volunteer study by Wright et al(93) was to assist patients to attend the dining room making this study multifaceted. It was not reported how many patients in the intervention arm of the study attended the dining room or if improvements in outcomes were a result of volunteer support only or the combination of volunteer support and attending the dining room to eat meals. This is a limitation of this study as the effects of each of these individual interventions are difficult to determine. Patients in the study by Edwards et al(101) self selected where they would eat their meals. This represents the reality of what is likely to occur in hospital with patients making their own choices regardless of what is offered or available to them which increases the applicability of the results beyond the more tightly controlled experimental situations of the remaining studies $(93,97-100)$ in this review.

\subsubsection{Study outcome measures}

Methods used to establish energy and protein intake in the included studies included food charts, weighed and visual estimations of plate waste. These methods are commonly used in healthcare settings to determine nutritional intake. $(55,80)$ Edwards et al $(101)$ obtained nutrition data by weighing plated food using digital scales prior to serving to the patient then weighing plate waste post mealtime. Walton et al(99) also recorded weighed plate waste post mealtime however, these were compared with duplicate meal samples in order to validate the original food portions served rather than comparing with actual food weights before serving the meal. Hickson et al(97) obtained nutritional intake data using a combination of food weights for main meals and food record charts for other food intake including breakfast, snacks and drinks. It was not stated whether this was by 
means of weighed plate wastes compared with hospital standard food serves or food weights calculated from pre- and post-meal food weights. Duncan et al(98) used semi-quantitative food record charts completed by nurses and assistants. Portion sizes were validated on a subset of 27 patients by performing a three day weighed food intake on days three to six post operation and then again on a further 24 patients during the second year of the study. The specific method by which these weighed intakes were obtained was not reported. The researchers collected the nutrition intake data in the study by Wright et al(100) by means of food record charts.

One of the main limitations of the study by Wright et al(93) which is also acknowledged by these authors, is that different methods of collecting nutritional data were used in each arm of the study. The intervention group received mealtime assistance from volunteers and had their nutritional intake data recorded by means of food record charts over a six hour period of the day. Food intake data for the control group on the other hand, were collected from a 24 hour weighed food intake, using a combination of weighed intake for main meals and food record charts for other nutritional intake. The authors state some recalculation of this original data was undertaken in order to time match the two groups ${ }^{(93)}$. The accuracy or impact of this recalculation is difficult to establish. None of the studies reported examining patient fluid balance charts as these are also used in some acute care hospitals to record the intake of oral nutritional supplements and other drinks of nutritional value. More detail could have been reported on the methods used to collect food intake data in the included studies. ${ }^{(93,97-101)}$

Five of the included studies(93, 97, 99-101)indicated the use of commercial nutritional analysis software to calculate nutritional intakes from the amount of food consumed. Two studies $(93,100)$ stated that registered dietitians performed this task who would have knowledge of nutritional analysis methods. None of the studies(93, 97-101) reported on whether the program user had received any training or competency testing on the use of the nutritional analysis software. Nutritional analysis, whether completed by hand using nutrition composition tables or by nutritional analysis software is limited by the competence of the individual who completes the calculations or inputs the data. Given this, there would have been the potential for reporting errors or omissions to occur in all of the included studies.

While improvements were seen in the nutritional intakes of patients in the intervention groups of the included studies, ${ }^{(93,97-101)}$ this did not translate to statistically significant improvements in nutritional status or length of stay in hospital. It is possible that an improved nutritional intake would need to be evident for a longer period of time than demonstrated in these acute care 
studies $^{(93,97-101)}$ before it would follow on to show improvements in the different markers of nutritional status or length of stay. Both of the studies that examined the effectiveness of employed assistants $(97,98)$ reported on length of stay in hospital. While a useful outcome measure that has been reported as having an association with malnutrition, $(7,8,14,66)$ it can also be associated with other clinical and non clinical factors. A systematic review by Campbell et al(129) found that length of stay in hospital was affected by severity of illness, cognition, functionality, polypharmacy, age and gender. Black et al(130) reported that length of stay in acute care hospitals can also be influenced by staff working hours, availability of specific services within a hospital and local social services who provide home supports and nursing home placements for patients. Duncan et al(98) stated that in the dietetic assistant arm of their study, patients may have survived their hospital admission due to enhanced nutritional intake from mealtime support who would have otherwise not survived their admission and that these patients would have been expected to need longer admissions to hospital.

\subsection{Discussion of methods for this Systematic Review}

This systematic review aimed to synthesise the best available evidence at the time of its undertaking. The subject of malnutrition in acute and other care settings is vast and complex and this systematic review set out to examine one specific aspect of the management of malnutrition in one particular care setting with clearly defined inclusion and exclusion criteria. One of the strengths of the current systematic review is the rigour applied to the clinical question, inclusion criteria and clarity of the search strategy. The six included studies $(93,97-101)$ were published in peer reviewed journals and as such would have been subject to vetting prior to publication. In addition to this, the studies pertaining to the acute care setting identified in this current systematic review were also identified in the systematic review by Green et al(92) evaluating the effect of volunteers in a variety of healthcare settings and a literature review by Weekes et al(15) investigating the effect of nutrition care interventions across healthcare settings on clinical outcomes and costs. This further validates the search strategy used in this current systematic review. Since the search and analyses of this current systematic review were completed a further study has been published on mealtime assistance. Manning et al(112) recently published a study that evolved from the pilot study by Walton et al((99) included in this systematic review. As in the study by Walton et al,(99) trained volunteers were used to provide mealtime assistance at lunch-time for 23 patients in an aged care ward in a Sydney hospital who had been specifically referred to the volunteer program. Patients were admitted for a range of clinical conditions including fractures following a fall $(35 \%)$, pneumonia $(13 \%)$ and leg ulcers $(13 \%)$. The mean age of patients was 83.2 years with 
a range of 67-97 years. Patients who were nil by mouth or receiving enteral or parenteral nutrition were excluded from this study. Energy and protein intakes were obtained by means of weighed plate waste and patient intakes compared for meals with and without volunteer assistance as in the study by Walton et al.(99) Manning et al(112) demonstrated an improved mean energy intake of $396 \mathrm{~kJ}(74 \mathrm{kcal})(p=0.005)$ and improved mean protein intake of $4.3 \mathrm{~g}(p=0.009)$ for meals when volunteers supported patients. The authors attempted to measure grip strength in a subset of 13 patients and compare this with standards for age and gender, however physical deformity, fractures and arthritis prevented a complete data set being recorded.

In the current systematic review the scanning of citations and reading of full text papers to determine if inclusion criteria was met was only performed by the primary reviewer creating the potential for errors of omission. Two papers ${ }^{(131,132)}$ were unable to be retrieved from the citation search creating the risk of bias in the reporting of the final systematic review. There is also the risk of publication bias as only a small number of studies were included in this systematic review.

Despite clinical homogeneity in the two studies(97, 98) on employed assistants, Duncan et al(98) reported means for outcome measures whereas Hickson et al(97) reported medians which meant it was not possible to calculate standard deviations and consequently meta-analysis was not undertaken. Meta-analysis was also not possible in the studies that evaluated the effectiveness of trained volunteers ${ }^{(93,99)}$ as these were considered to be clinically heterogeneous due to the differing roles and responsibilities of the volunteers. Likewise, the two studies on eating location $(100,101)$ were also considered to be clinically heterogeneous and consequently meta-analysis was not undertaken. These limitations have inevitably affected the depth of analysis possible for this current systematic review.

\subsection{Implications for practice}

The results of this systematic review indicate that the interventions employed in the included studies(93, 97-101) improve patient nutritional intake although the effects on nutritional status are limited and no effect on length of stay in hospital was demonstrated. The effects of the interventions on outcomes in each of the studies may have been amplified if the interventions had been available at all mealtimes. While employed assistants were effective, many hospitals will be unable to fund staff in this capacity to support patients at mealtimes and may consider volunteers to be a more cost-effective option. Although having volunteers assisting patients at mealtimes may represent a cost saving(133) to hospitals, it should be noted that volunteer programs such as 
those outlined by Manning et al(112), Walton et al(99) and Wright et al(93) are not cost neutral.(134) Managers of hospital volunteer programs would need to ensure that adequate training is available for volunteers and that they are retained in order to ensure an adequate supply of willing volunteers to fulfill the role.(109) Volunteer programs also require the provision of space and resources to enable recruitment, screening, training and management of volunteers. ${ }^{(134)}$ Some hospitals may be unable to provide the additional resources required to operate a volunteer mealtime assistance program.

Many hospitals have turned day or dining rooms into offices or staff rooms. Given that the results of this systematic review support having a designated table or dining room where patients can sit and eat with other patients at mealtimes; consideration should be given to reclaiming these areas. Rooms with tables could be made available at mealtimes in locations which may have other functions at other times of the day, allowing full and effective utilisation of space within a hospital. This is something that should also be explored by the planners and architects of new hospitals.

It should be recognised that even with nutritional screening, the correct nutritional meal plan and a suitable level of mealtime assistance nutritional intake and status will not improve in some patients and may even decline. Other nutritional factors for example poor appetite, early satiety, nausea, constipation and taste alterations may create additional barriers to an adequate nutritional intake particularly if they are not addressed.(135) It is likely that the most effective approach to managing malnutrition in hospital will be a combination of all of the aforementioned measures including the mealtime strategies identified in this systematic review.

\subsection{Implications for research}

Few studies were located and included in this systematic review indicating that currently there is only a small amount of evidence to support mealtime interventions like volunteer assistants, choice of eating environment and the presence of trained personnel to assist patients at mealtimes. This is despite promotion of these interventions by organisations like Age UK(24, 25) and the Council of Europe. (23) In addition to this, overall there appears to be a lack of high quality studies informing these issues. As a result, there appears to be ample scope for future primary research in the area of mealtime interventions in the acute care setting; whether it includes further research on employed assistants, trained volunteers or eating location as examined in this systematic review or the effectiveness of other interventions like protected mealtimes and red tray 
systems. Future studies should ideally consider ways of optimising the study design in order to ensure the studies are robust and ensure that they are adequately powered.

Research on malnutrition in the acute care setting should now look beyond focusing investigation on the identification of patients who are malnourished or at risk of malnutrition, and seek to further explore strategies that may improve patient nutritional intake and/or status. This may include further research on nutritional provision, mealtime environment, how food is served or what supportive assistance is offered. Any acute care hospital looking to implement strategies aimed at improving patient nutritional intake and/or status should do so as part of health research and measure the relevant outcomes so that this can add to the existing but limited body of evidence currently available. While this current systematic review examined quantitative studies, consideration should also be given qualitative research in the field of malnutrition. Dickinson et al(136) demonstrated through action research that it is possible to change nursing practice at patient mealtimes.

Nutrition is an interdisciplinary concern and given this, concerted efforts should be made in acute care hospitals to conduct primary research that includes all relevant disciplines in order to fully explore the barriers to effective nutritional care. One profession conducting a study looking at their individual role is not sufficient and misrepresents the reality of the situation in acute care hospitals. Larger studies involving greater numbers of patients which encompass the full duration of a patient's admission would add greater weight to the evidence base. While improvements in patient nutritional intake have been seen with the interventions examined in this systematic review none of the studies provided the intervention at all mealtimes. It would be worthwhile examining the effects of the interventions outlined in the included studies $\left.{ }^{93,}, 97-101\right)$ if they were available at all mealtimes in order to ascertain if this demonstrates any benefit over and above what has already been shown. This may provide an indication of how much assistant or volunteer input is required to achieve the best outcome for patient nutritional intake and status. In practice, given the complexity of conducting primary nutrition research smaller studies are often undertaken in preference to large scale studies. These studies are still valuable as they potentially provide the opportunity to conduct a meta-analysis which further adds to the depth of analysis of the available evidence.

With targeted mealtime assistance suggested by Wright et al(93) and Walton et al(99) as being more effective, consideration should be given to investigating potential early indicators of the need for mealtime assistance. This could be achieved by examining nursing admission practices 
in the acute care setting or by using a mealtime assistance tool to facilitate the identification of those who require assistance. A systematic review by Chang et al(137) found that several instruments were available to measure feeding difficulties in cognitively impaired adults for example the Edinburgh Feeding Evaluation in Dementia Feeding. The authors(137) note that these instruments are incomplete as they do not necessarily include the antecedents and consequences of patient feeding difficulties. These instruments have been developed for cognitively impaired patients and not for other patient groups and so are unlikely to be suitable for use in the general acute care patient population. Weekes et al(15) reported in their literature review that no studies were found that evaluated the effect of mechanisms for identifying patients who require feeding assistance. If such a mealtime assistance screening tool was developed for the acute care setting there are no guarantees that it would be of benefit to patients, as despite the implementation of nutrition screening tools that also address the issue of malnutrition, studies have shown that not all patients are screened.(41,74,75) Weekes et al(15) concluded from their literature review in relation to nutrition screening that nutrition screening alone may be insufficient to achieve benefits for malnourished patients.

\subsection{Conclusions}

The evidence suggests that the use of dietetic/healthcare assistants, trained volunteers, eating around a table or in a supervised dining room increases energy intake of adult patients in acute care hospitals. Mealtime assistance by volunteers also increases patient protein intake. There is scant evidence to support improvements in nutritional status with no improvements in length of stay in hospital reported. Reduced mortality was demonstrated in one study(98) where patients were supported by dietetic assistants. The findings of this systematic review support the recommendations made by the Council of Europe ${ }^{(23)}$, BAPEN(22) and Age UK ${ }^{24,25)}$ with regard to the use of volunteers, patients having the ability to chose their own eating environment, sitting at a table for main meals and the presence of trained personnel to assist with mealtimes and feeding. This systematic review does not support the recommendations made by Age UK $(24,25)$ and BAPEN(22) with regard to using a red tray system or protected mealtimes in the acute care setting.

The mealtime interventions identified and discussed in this systematic review are clearly just the beginning for this area of clinical nutrition. There is huge potential for further primary research as the effectiveness of these strategies have not been fully explored. It should be noted that not every patient will respond to mealtime interventions as there may be other physical and 
psychological barriers to obtaining optimal nutritional intake and status. The mealtime interventions included in this systematic review have merit for inclusion with other nutritional strategies in the management of malnutrition in acute care hospitals.

Although nutrition research is difficult to undertake and a lack of good quality studies were unearthed, this systematic review represents the synthesis of the best available evidence on the subject of mealtime environment and circumstances of eating for adult patients in the acute care setting at the time of its undertaking. It has provided some guidance with regard to the effectiveness of these mealtime strategies in the acute care setting and indicators for future directions. 


\section{Appendix 1 Systematic Review Protocol}

Title

Effectiveness of mealtime interventions in improving nutritional intake in adult patients in the acute care setting: a systematic review.

\section{Primary Reviewer}

Gail Whitelock BSc, CFJBI, APD12

${ }^{1}$ MSc Clinical Sciences Candidate, The Joanna Briggs Institute, Faculty of Health Sciences, The University of Adelaide, Adelaide SA 5005, Australia.

2Senior Dietitian, Department of Clinical Dietetics, Royal Adelaide Hospital, Adelaide, SA 5000, Australia

Gail.Whitelock@health.sa.gov.au

\section{Secondary Reviewer:}

Mary-Anne Ramis BN13

${ }^{3}$ Research Nurse, Nursing Research Centre, Mater Health Service, South Brisbane, QLD 4101, Australia

Mary-Anne.Ramis4@mater.org.au

\section{Review Objective/Question}

The objective of this review is to identify, assess and synthesise the available evidence on the effectiveness of mealtime interventions that improve nutritional intake in adult patients in the acute care setting. Interventions reviewed will not include nutritional interventions that are related to the actual food or fluids offered or ordered, for or by the patient, but rather will include interventions that evaluate or alter the environment and/or circumstances of the patient's mealtimes. Mealtimes will be taken to mean both designated mealtimes and/or other times when patients may eat or drink.

The review question is: What are the effects of identified mealtime interventions in improving the nutritional intake of adult patients in the acute care setting? 


\section{Background}

Malnutrition has been well documented over the last few decades as being a common problem in acute care hospitals which is often unrecognised and untreated.(1-3) In the acute care setting malnutrition is known to effect between $20-50 \%$ of patients depending on the primary disease state and criteria used to determine nutritional status. ${ }^{(1,2,4)}$ Malnutrition is associated with a number of adverse complications including increased morbidity and mortality, delayed wound healing, increased infection rates, functional decline and increased length of stay in hospital. $(1,4,5)$

Malnutrition can be taken to mean both under- and over-nutrition. However, despite this definition, it is under-nutrition which has been adopted by many healthcare professionals to be the common meaning of malnutrition. Under-nutrition has been defined by Allison as "a state of energy, protein or other specific nutrient deficiency which produces a measurable change in body function and is associated with worse outcome from illness as well as being specifically reversed by nutritional support".(6) For the purposes of this systematic review the term malnutrition will refer to the state of protein energy under-nutrition.

There have been numerous studies addressing the subject of malnutrition in the acute care setting by healthcare professionals from a variety of disciplines. Many focus on aspects of identifying malnutrition and its treatment through nutritional provision like modified menus, oral nutritional supplements or enteral feeding. $(7,8)$ However, despite the development in recent years of validated nutritional screening tools to assist in identifying patients at risk of malnutrition and the technological advances in patient nutritional provision through enteral feeding products, oral nutritional supplements and food service production malnutrition remains an issue in acute care hospitals which is costing healthcare providers and patients alike.(4,9)

Even when diagnosed as being malnourished or identified as being at risk of malnutrition and provided with an individualised tailored meal plan, patients may still have an inadequate nutritional intake due to suboptimal environmental factors, organisational and physical barriers. ${ }^{10}$ The following scenarios may contribute to an inadequate nutritional intake:

- missing meals due to medical and surgical procedures being performed at mealtimes

- extended and/or inappropriate periods of fasting

- food and fluids not being available when required

- food and fluids placed out of reach

- lack of assistance with opening food and fluid packaging

- lack of assistance with feeding and set up for meals 
- disturbances during mealtimes including noise, smells and staff interruptions

- lack of the necessary encouragement to eat

In a bid to better manage malnutrition in hospitals organisations like Age UK, the British Association of Parenteral and Enteral Nutrition (BAPEN) and the Council for Europe have been promoting strategies such as 'protected mealtimes' and the 'red tray system' as supportive nutritional interventions to promote optimal eating and feeding practices in hospitals. ${ }^{(11,12)}$ Given this interest in supportive nutritional practices which relate more to the environment and circumstances of eating, this review proposes to examine those interventions which promote optimal eating and feeding for adult patients in the acute care setting which are not solely nutritional screening or interventions based on the provision of additional energy and protein. It is also envisaged that this review will assist in formulating some guidance with regard to supportive environmental and nutritional practices in acute care.

An initial limited search has been undertaken to ascertain the suitability of the proposed topic and to determine if this or a similar review had already been conducted. The following related articles were found:

- Joanna Briggs Institute (JBI) Systematic Review by Vanderkroft et al(13) in 2007 entitled Minimising under nutrition in the older person. This review was undertaken in the acute care setting and set out to identify best practices to minimise under-nutrition in patients aged 65 years and older. The review included 29 identified studies from 1980 to 2005. The interventions in the included studies related to additional nutritional provision from modified menus, oral nutrition supplementation or enteral feeds. Although conducted in the same setting as the intended review, Vanderkroft et al(13) review was specific to elderly patients and focused on nutritional provision interventions.

- Joanna Briggs Institute Systematic Review Protocol The effectiveness of interventions to reduce under-nutrition and promote eating in older adults with dementia: a systematic review by Jackson et al was registered in 2009.(14) The protocol indicates that the author will be considering both direct nutritional provision and related nursing, food service, dietetic and feeding practices. Although these related practices are also the intended focus of this review the population groups are different in that this protocol indicates that the author intends only to focus on patients with dementia and not other disease states and that a variety of care settings will be reviewed.

- The Cochrane review by Milne et al in 2009 entitled Protein and energy supplementation in elderly people at risk from malnutrition.(8) This review examined 62 randomised and 
quasi-randomised controlled trials conducted with elderly patients who were provided with additional energy and protein primarily from oral nutritional supplements. As this review did not examine supportive nutritional practices and its focus was on elderly patients it is deemed sufficiently different to the intended review.

- Review in the Journal of Clinical Nursing by Jefferies et al(15) in 2011 entitled Nurturing and nourishing: the nurses' role in nutritional care. The aim of this qualitative systematic review was to describe what nurses could do to reduce the incidence of malnutrition in patients in acute care and long term hospitals. The review examined what nurses could do to facilitate access to food, support the mealtime environment and prevent prolonged and repeated periods of nil-by-mouth. The review identified 73 papers from 1998 to 2008 and used JBI appraisal instruments to evaluate the literature. The outcome of this review was used to produce eight nursing standards to form the basis of a hospital policy. This review examined patients in both acute and long term care and was only concerned with exploring the nurses' role and not that of other staff members.

\section{Inclusion Criteria}

\section{Types of Participants}

The review will consider publications that include male and female adults aged 18 years old and over, from any ethnic background, who are inpatients in acute care hospitals with any diagnosis. The review will consider patients who obtain their nutrition by oral route and exclude patients who are enterally or parentally fed.

The review will exclude patients in intensive care or high dependency facilities, palliative care and end of life patients. Other healthcare settings such as rehabilitation, transitional care and residential aged care facilities will not be considered.

\section{Types of Intervention}

Interventions may include but will not be limited to:

- organisational practices;

- food Service practices;

- nursing practices;

- medical practices;

- dietetic practices;

- dietetic/diet/nutrition assistant practices; 
- volunteer practices; and

- family/carer practices.

The following mealtime interventions have been identified as having the potential to influence nutritional intake and therefore will be examined in the first instance:

- Focused or set up for meals practices where a pre-mealtime routine of getting patients ready for mealtimes occurs. This practice may include washing hands, toileting, ensuring space available for meal tray and correct position for eating.

- Meal delivery systems or targeted feeding assistance practices e.g. 'red tray system' where patients previously identified as requiring feeding assistance have their meal delivered on a red tray which acts as a visual cue to all staff that the patient requires feeding assistance.

- Feeding assistance practices where patients are provided with feeding assistance by nursing staff, nursing/dietetic/nutrition assistants or volunteers.

- 'Protected mealtimes' where patients are allowed to eat undisturbed at mealtimes and do not undergo medical procedures during this time.

- Ward dining rooms where patients eat in a designated room or area specifically designed for mealtimes and free from other ward distractions.

- Ward kitchens/pantries which allow patients 24 hour access to food and fluids.

- Nutrition support teams who consider more than just the foods or fluids prescribed for the patient but also the delivery of the above practices.

Interventions which solely relate to the actual food or fluid offered or ordered, for or by the patient, will not be considered. Strategies to promote the identification of malnutrition for example nutritional screening will not be included in this review.

\section{Types of Outcome}

The primary outcomes of interest are measures of improved dietary intake and/or nutritional status. These may include actual or subjective measures of plate waste, documented food intakes, patient weight, Body Mass Index (BMI) and malnutrition status as determined by nutritional screening or assessment tools. Secondary outcome measures of length of stay in hospital and all-cause mortality will also be considered. 


\section{Types of Studies}

This review will consider any experimental studies including Randomised Control Trials (RCTs) and quasi-RCTs. In the absence of these studies or in the event of insufficient data being available the review will extend to other study designs primarily prospective observational studies.

\section{Search Strategy}

The search strategy aims to find published and unpublished studies reported in English language. A three step search strategy will be utilised in this review. An initial limited search of MEDLINE and CINAHL will be undertaken followed by analysis of the text words contained in the title and abstract, and of the index terms used to describe the article.

A second search using all identified keyword and index terms will then be undertaken across all included databases. Thirdly, the reference list of all identified reports and articles will be searched for additional studies.

The following databases will be searched:

MEDLINE;

CINAHL;

EMBASE;

Informit - Health;

Cochrane Clinical Trials Register;

Scopus;

Australian Digital Theses Program;

Index to Theses; and

Proquest Dissertations \& Theses.

The following keywords have been identified for use in the initial search:

Mealtimes

Food service

Dining rooms

Eating

Feeding methods

Eating behaviour

Feeding assistance

Assisted feeding 
Feeding volunteers

Red tray

Protected mealtimes

Focused mealtime

Food

Nutritional intake

Food intake

Dietary intake

Diet records

Plate waste

Body Mass Index

Weight loss

Length of stay

Nutritional status

Malnutrition

Under-nutrition

Adults

Inpatients

Patients

Acute care

Hospitals

Hospitalisation

Exclusion terms will include enteral feeding, tube feeding, PEG feeding and parenteral feeding. In addition, this review will also search the following organisations publications, reports and web sites:

- Australian State and Federal Government Departments of Health;

- National Health Service, UK;

- Age UK;

- Dietitians Association of Australia;

- British Dietetic Association;

- American Dietetic Association;

- Dietitian of Canada /Les diététistes du Canada;

- Australasian Society for Parenteral and Enteral Nutrition; 
- British Association for Parenteral and Enteral Nutrition;

- European Society for Parenteral and Enteral Nutrition;

- Australian Nursing Federation;

- Royal College of Nursing UK;

- American Nurses Association; and

- Canadian Nurses Association.

Selected journals that feature a number of papers from the first, second and third searches will be hand searched to locate any additional papers which may meet the search criteria.

\section{Assessment of Methodological Quality}

Papers selected for retrieval will be assessed by two independent reviewers for methodological validity prior to inclusion in the review using standard critical appraisal instruments from the Joanna Briggs Institute Meta Analysis Statistics Assessment and Review Instrument (JBIMAStARI), (Appendix I; omitted to avoid repetition refer to Appendix 3). Any disagreements that arise between the reviewers will be resolved through discussion, or with a third reviewer experienced in the topic and the systematic review process.

\section{Data Collection}

As this review will focus on quantitative measures, the data will be extracted using the JBI data extraction tool MAStARI, (Appendix II; omitted to avoid repetition refer to Appendix 4). The primary and secondary reviewers will extract the data independently.

\section{Data Synthesis}

Data from the studies will, where possible, be pooled in statistical analysis using JBI-MAStARI, with results displayed in a forest plot. All results will be subject to double data entry. Odds ratio (for categorical data) and weighted mean differences (for continuous data) and their 95\% confidence intervals will be calculated. Heterogeneity will be assessed using the standard Chisquare with a random effects model considered for the presentation of statistics. Methodological differences encountered, for example differences in study design, maybe explored by subanalysis where appropriate. Where statistical pooling is not possible the findings will be presented in narrative form.

\section{Conflicts of Interest}

None. 


\section{Acknowledgements}

As this systematic review forms part of a submission for a Masters of Clinical Science, a secondary reviewer will only be used for critical appraisal and data entry stages of the review. 


\section{References:}

1. Watterson C, Fraser A, Banks M, Isenring E, Miller M, Silvester $C$ et al. Evidence Based Practice Guidelines for Nutritional Management of Malnutrition in Adult Patients Across the Continuum of Care. Journal of Nutrition \& Dietetics. 2009: 66; 3.

2. McWhirter JP, Pennington CR. Incidence and recognition of malnutrition in hospital. British Medical Journal. 1994; 2008: 945-948.

3. Butterworth CE. The Skeleton in the Hospital Closet. Nutrition Today. 1974; 9: 2: 4-8.

4. Stratton RJ, Green CJ and Elia M. Disease-related malnutrition: an evidence-based approach to treatment. Wallingford: CABI Publishing, 2003.

5. Middleton MH, Nazarenko G, Nivison-Smith I, Smerdely P. Prevalence of malnutrition and 12 month incidence of mortality in two Sydney teaching hospitals. Internal Medicine Journal 2008; 31: 455-461.

6. Allison SP. Malnutrition, disease and outcome. Nutrition 2000;16 (7/8):590-593.

7. Jones JM. Nutritional screening and assessment tools. New York: Nova Science Publishers Inc, 2006.

8. Milne AC, Potter J, Vivanti A \& Avenell A. Protein and energy supplementation in elderly people at risk from malnutrition (Review). Cochrane Database of Systematic Reviews. 2009, Issue 2. Art. No.: CD003288.

9. Lennard-Jones JE et al. A Positive Approach to Nutrition as Treatment. Kings Fund Centre. 1992.

10. Naithani S, Whelan K, Thomas J, Gulliford MC \& Morgan M. Hospital inpatients' experiences of access to food: a qualitative interview and observational study. Health Expectations 2008; 11 : 294-303

11. Age Concern. Hungry to be Heard - The scandal of malnourished older people in hospital. London: Age Concern, 2006.

12. Council for Europe - Committee of Ministers. Resolution ResAP(2003)3 on food and nutritional care in hospitals, 2003.

13. Vanderkroft D, Collins CE, Fitzgerald M, Lewis S, Neve M and Capra S Minimising undernutrition in the older inpatient. International Journal of Evidence-Based Healthcare 2007; 5: 3 110-181.

14. Jackson J et al. Systematic Review Protocol - The effectiveness of interventions to reduce undernutrition and promote eating in older adults with dementia: A systematic review. Joanna Briggs Institute Protocol 2009.

15. Jefferies $D$. Johnson $M \&$ Ravens J. Nurturing and nourishing: the nurses' role in nutritional care. Journal of Clinical Nursing 2011; 20: 317-330. 
Appendices have been omitted from the systematic review protocol for ease of referencing and to avoid repetition with Appendices 3-4 used in the conduct of this current systematic review. 


\section{Appendix 2 Search strategy}

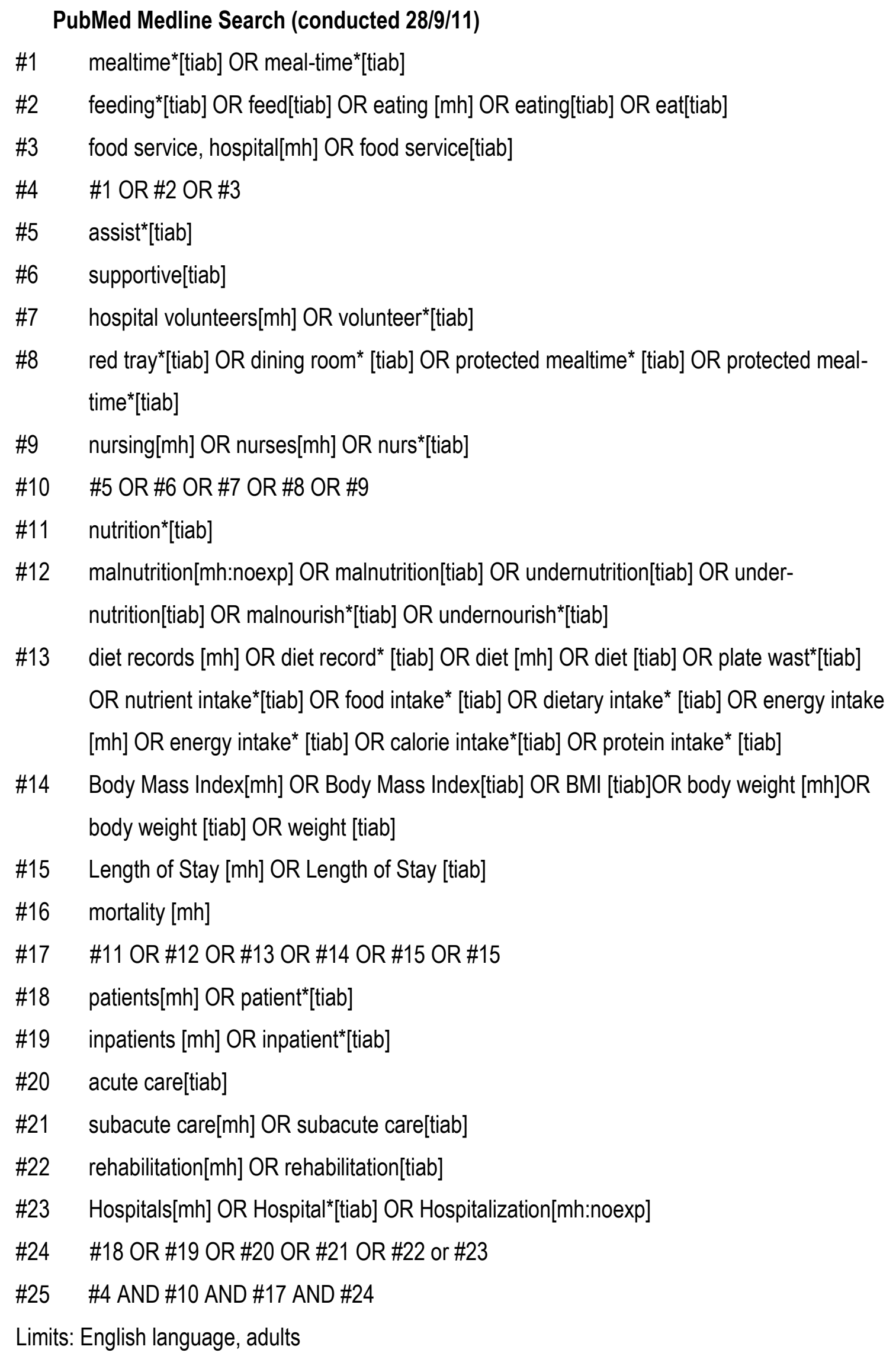




\section{CINAHL Search Strategy (conducted 29/9/11)}

mealtime ${ }^{*}[\mathrm{ti}]$ OR mealtime*[ab] OR meal-time*[ti] OR meal-time*[ab] OR *[t] OR feeding*[ab] OR feed[ti] OR feed[ab] OR eating [mh] OR eating[ti] OR eating[ab] OR eat[ti] OR eat[ab] OR food services [mh] OR food service*[i] OR food service*[ab] assist*[i] OR assist*[ab] OR supportive[ti] OR supportive[ab] OR volunteer workers [mh] OR volunteer*[i] OR volunteer*[ab] OR red tray*[i] OR red tray*[ab] OR dining room* [ti] OR dining room ${ }^{*}[a b]$ OR protected mealtime* [ti] OR protected mealtime*[ab] OR protected meal-time* [ti] OR protected meal-time*[ab] OR nurses [mh] OR nurs* [t] OR nurs*[ab]

\#3 nutrition*[ti] OR nutrition*[ab] OR malnutrition [mh] OR malnutrition[ti] OR malnutrition[ab] OR undernutrition[ti] OR undernutrition[ab] OR under-nutrition[ti] OR under-nutrition[ab] OR malnourish*[ti] OR malnourish*[ab] OR undernourish*[ti] OR undernourish* [ab] OR diet records [mh] OR diet record* [ti] OR diet record*[ab] OR diet[mh] OR diet[ti] OR $\operatorname{diet}[a b]$ OR plate wast*[ti] OR plate wast*[ab] OR nutrient intake*[i] OR nutrient intake*[ab] OR food intake[mh] OR food intake*[t] OR food intake*[ab] OR dietary intake*[ti] OR dietary intake*[ab] OR energy intake[mh] OR energy intake*[ti] OR energy intake* $[a b]$ OR calorie intake*[ti] OR calorie intake*[ab] OR protein intake* [ti] OR protein intake*[ab] OR nutritional status[mh] OR nutritional status[ti] OR nutritional status[ab] OR Body Mass Index [mh] OR Body Mass Index [ti] OR Body Mass Index[ab] OR BMI[ti] OR BMI[ab] OR body weight [mh] OR body weight* [ti] OR body weight*[ab] OR weight loss [ti] OR weight loss [ab] OR length of stay [mh] OR length of stay [ti] OR length of stay [ab] OR mortality [mh] OR mortality[ti] OR mortality[ab]

\#4 patients[mh] OR patient ${ }^{\star}[\mathrm{ti}]$ OR patient ${ }^{\star}[\mathrm{ab}] \mathrm{OR}$ inpatients [mh] OR inpatient*[ti] OR inpatient*[ab] OR acute care [ti] OR acute care[ab] OR sub acute care[ti] OR sub acute care [ab] OR sub-acute care[ti] OR sub-acute care [ab] OR rehabilitation[mh] OR rehabilitation[ti] OR rehabilitation[ab] OR hospitals[mh] OR hospital ${ }^{*}[\mathrm{ti}]$ OR hospital*[ab] OR hospitalization[mh:noexp] \#1 AND \#2 AND \#3 AND \#4

Limits: Humans, English language, adults 
EMBASE Search Strategy (conducted 6/10/11)

\#1 mealtime*:ti,ab

\#2 'meal-time':ti,ab

\#3 'meal-times':ti,ab

\#4 'feeding behaviour'/mj

\#5 feeding:ti,ab

\#6 feed:ti,ab

\#7 eating:ti,ab

\#8 eat:ti,ab

\#9 'food service':ti,ab

\#10 'hospital food service'/mj

\#11 \#1 OR \#2 OR \#3 OR \#4 OR \#5 OR \#6 OR \#7 OR \#8 OR \#9 OR \#10

$\# 12$ assist*:ti,ab

\#13 supportive:ti,ab

\#14 'volunteer worker'/mj

\#15 volunteer*ti,ab

\#16 'red tray':ti,ab

\#17 'red trays':ti,ab

\#18 'dining room':ti,ab

\#19 'dining rooms':ti,ab

\#20 'protected mealtime':ti,ab

\#21 'protected mealtimes':ti,ab

\#22 'protected meal-time':ti,ab

\#23 'protected meal-times':ti,ab

\#24 nurse/mj

\#25 nurs*:ti,ab

\#26 'nursing assistant'/mj

\#27 \#12 OR \#13 OR \#14 OR \#15 OR \#16 OR \#17 OR \#18 OR \#19 OR \#20 OR \#21 OR \#22 OR \#23 OR \#24 OR \#25 OR \#26

\#28 nutrition/mj

\#29 nutrition*.ti,ab

\#30 malnutrition/mj

\#31 malnutrition:ti,ab

\#32 undernutrition:ti,ab

\#33 'under-nutrition':ti,ab 
\#34 malnourish*:ti,ab

\#35 undernourish ${ }^{*}: t i, a b$

\#36 'diet record':ti,ab

\#37 'diet records':ti,ab

\#38 diet/mj

\#39 diet:ti,ab

\#40 'plate waste';ti,ab

\#41 'plate wastage':ti,ab

\#42 'nutrient intake':ti,ab

\#43 'nutrient intakes':ti, ab

\#44 'dietary intake'/mj

\#45 'dietary intake':ti,ab

\#46 'dietary intakes':ti,ab

\#47 'energy intake':ti,ab

\#48 'energy intakes':ti,ab

\#49 'calorie intake'/mj

\#50 'calorie intake':ti,ab

\#51 'calorie intakes':ti,ab

\#52 'protein intake'/mj

\#53 'protein intake':ti,ab

\#54 'protein intakes':ti,ab

\#55 'food intake'/mj

\#56 'food intake':ti,ab

\#57 'food intakes':ti,ab

\#58 'nutritional status'/mh

\#59 'nutritional status':ti,ab

\#60 'Body Mass Index':ti,ab

\#61 BMI:ti,ab

\#62 'body mass'/mj

\#63 'body weight'/mj

\#64 'body weight':ti,ab

\#65 'weight loss':ti,ab

\#66 'length of stay'/mj

\#67 'length of stay':ti,ab

\#68 mortality/mj 
\#69 mortality:ti,ab

\#70 \#28 OR \#29 OR \#30 OR \#31 OR \#32 OR \#33 OR \#34 OR \#35 OR \# 36 OR \#37 OR \#38 OR \#39 OR \#40 OR \#41 OR \#42 OR \# 43 OR \#44 OR \#45 OR \#46 OR \#47 OR \#48 OR \#49 OR \#50 OR \#51 OR \#52 OR \# 53 OR \# 54 OR \#55 OR \#56 OR \#57 OR \#58 OR \#59 OR \#60 OR \#61 OR \#62 OR \#63 OR \#64 OR \#65 OR \#66 OR \#67 OR \#68 OR \#69

\#71 patient/mj

\#72 patient*:ti,ab

\#73 inpatient*:ti,ab

\#74 'in-patient':ti,ab

\#75 'In-patients':ti,ab

\#76 'hospital patient'/mj

\#77 hospital/mj

\#78 hospital*:ti,ab

\#79 hospitalization/mj

\#80 'acute care':ti,ab

\#81 'sub acute care':ti,a

\#82 rehabilitation/mj

\#83 rehabilitation:ti,ab

\#84 \#71 OR \#72 OR \#73 OR \#74 OR \#75 OR \#76 OR \#77 OR \#78 OR \#79 OR \# 80 OR \#81 OR \#82 OR \#83

\#85 \#11 AND \#27 AND \#70 AND \#84

Limits: Humans, English 
Informit - Health Search Strategy (conducted 9/10/11)

\#1 mealtime* TI OR AB

\#2 "meal-time" TI OR AB

\#3 feed TI OR AB

\#4 feeding ${ }^{*}$ TI OR AB

\#5 eat ${ }^{*}$ TI OR AB

\#6 "food service" TI OR AB

\#7 \#3 OR \#2 OR \#3 OR \#4 OR \#5 OR \#6

\#8 assist $^{*}$ TI OR AB

\#9 supportive TI OR AB

\#10 volunteer* ${ }^{\star}$ TI OR AB

\#11 "red tray" ${ }^{*}$ TI OR AB

\#12 "dining room"

$\# 13$ "protected mealtime ${ }^{*}$ TI OR AB

\#14 "protected meal-time ${ }^{*}$ "TI OR AB

\#15 nurs* TI OR AB

\#16 \#8 OR \#9 OR \#10 OR \#11 OR \#12 OR \#13 OR \# 14 OR \#15

\#17 nutrition* TI OR AB

\#18 malnutrition TIOR AB

\#19 malnourish ${ }^{*}$ TI OR AB

\#20 undernutrition TI OR AB

\#21 "under-nutrition" TI OR AB

\#22 "diet record" TI OR AB

\#23 "plate wast" ${ }^{*}$ TI OR AB

\#24 "nutrient intake*" TI OR AB

\#25 "dietary intake" ${ }^{*}$ TI OR AB

\#26 "food intake"

\#27 "energy intake" ${ }^{*}$ TI OR AB

\#28 "calorie intake*" TI OR AB

\#29 "protein intake " TI OR AB

\#30 "nutritional status" TI OR AB

\#31 "Body Mass Index" TI OR AB

\#32 BMI TI OR AB

\#33 weight TI OR AB

\#34 "weight loss" TI OR AB 
\#35 "length of stay" TI OR AB

\#36 mortality TI OR AB

\#37 \#17 OR \#18 OR \#19 OR \#20 OR \#21 OR \#22 OR \#23 OR \#24 OR \#25 OR \#26 OR \#27 OR \#28 OR \#29 OR \#30 OR \#31 OR \#32 OR \#33 OR \#34 OR \#35 OR \#36

\#38 patient* TI OR AB

\#39 inpatient ${ }^{*}$ TI OR AB

\#40 "in-patient"

\#41 "acute care" TI OR AB

\#42 hospital ${ }^{*}$ TI OR AB

\#43 "sub acute care" TI OR AB

\#44 rehabilitation TI OR AB

\#45 \#38 OR \#39 OR \#40 OR \#41 OR \# 42 OR \#43 OR \#44

\#46 \#7 AND \#16 AND \#37 AND \#45 
Scopus Search Strategy (conducted 13/10/11)

\#1 mealtime TITLE OR ABS

\#2 (meal-time) TITLE OR ABS

\#3 feed TITLE OR ABS

\#4 feeding TITLE OR ABS

\#5 eat TITLE OR ABS

\#6 eating TITLE OR ABS

\#7 food service TITLE OR ABS

\#8 food services TITLE OR ABS

\#9 \#1 OR \#2 OR \#3 OR \#4 OR \#5 OR \#6 OR \#7 OR \#8

$\# 10$ assist TITLE OR ABS

\#11 support TITLE OR ABS

\#12 volunteer TITLE OR ABS

\#13 red tray TITLE OR ABS

\#14 red trays TITLE OR ABS

\#15 (dining room) TITLE OR ABS

\#16 (dining rooms) TITLE OR ABS

\#17 (protected mealtimes) TITLE OR ABS

\#18 (protected mealtime) TITLE OR ABS

\#19 nurse TITLE OR ABS

\#20 nursing TITLE OR ABS

\#21 \#10 OR \#11 OR \#12 OR \#13 OR 314 OR\#15 OR \#16 OR \#17 OR \#18 OR \#19 OR \#20

\#22 nutrition TITLE OR ABS

\#23 malnutrition TITLE OR ABS

\#24 malnourish TITLE OR ABS

\#25 undernutrition TITLE OR ABS

\#26 (under-nutrition) TITLE OR ABS

\#27 undernourish TITLE OR ABS

\#28 (diet record) TITLE OR ABS

\#29 (dietary records) TITLE OR ABS

\#30 (plate waste) TITLE OR ABS

\#31 (plate wastage) TITLE OR ABS

\#32 (nutrient intake) TITLE OR ABS

\#33 (dietary intake) TITLE OR ABS

\#34 (food intake) TITLE OR ABS 


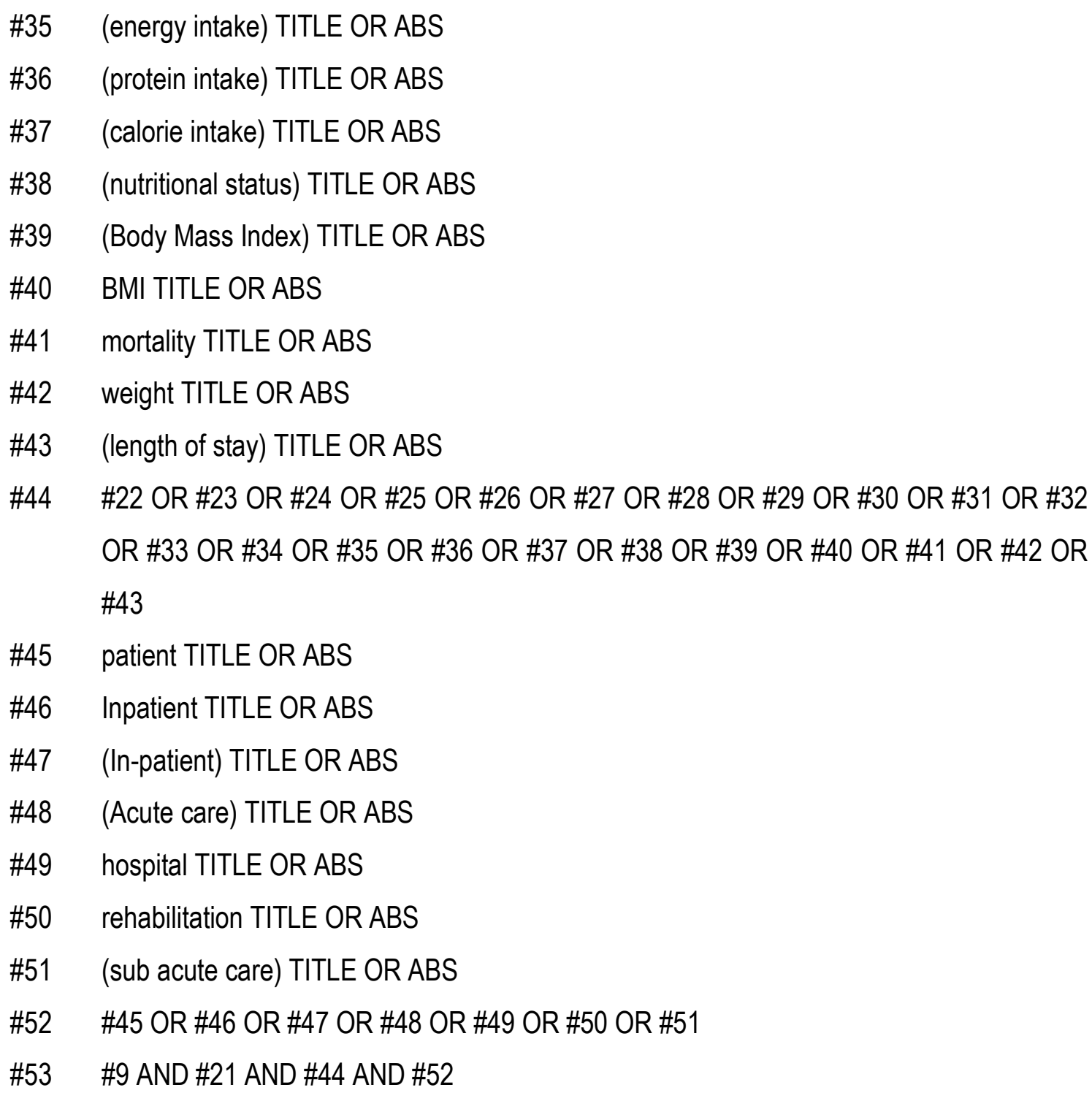

Limits: English 


\section{Appendix 3 Critical appraisal tool}

1. Was the assignment to treatment groups truly random?

\begin{tabular}{|l|l|}
\hline Yes & $\begin{array}{l}\text { Method by which randomisation to mealtime intervention or control group } \\
\text { described by author(s). }\end{array}$ \\
\hline No & $\begin{array}{l}\text { Methods other than randomisation used to allocate patients to mealtime } \\
\text { intervention or control groups. }\end{array}$ \\
\hline Unclear & $\begin{array}{l}\text { General terms like "random" and "randomisation" used but method by which } \\
\text { this was achieve not clearly described. }\end{array}$ \\
\hline
\end{tabular}

Reviewer's response/comment:

\section{Were patients blinded to treatment allocation?}

\begin{tabular}{|l|l|}
\hline Yes & $\begin{array}{l}\text { Patients unaware that they have been allocated to either the mealtime } \\
\text { intervention or control group. }\end{array}$ \\
\hline No & $\begin{array}{l}\text { Patients aware of which group they have been allocated to even although } \\
\text { blinding may have been possible. }\end{array}$ \\
\hline Unclear & Description of above unclear or unsatisfactory. \\
\hline
\end{tabular}

Reviewer's response/comment:

3. Was allocation to treatment groups concealed from the allocator?

\begin{tabular}{|l|l|}
\hline Yes & $\begin{array}{l}\text { Allocator unaware of whether they were allocating patients to mealtime } \\
\text { intervention or control group. }\end{array}$ \\
\hline No & $\begin{array}{l}\text { Allocator aware of which group they were allocating participants (patients) } \\
\text { to. }\end{array}$ \\
\hline Unclear & Description of above unclear or unsatisfactory. \\
\hline
\end{tabular}


4. Were the outcomes of people who withdrew described and included in the results and analysis?

\begin{tabular}{|l|l|}
\hline Yes & $\begin{array}{l}\text { Withdrawal patients reported and reasons for the withdrawal described. } \\
\text { Withdrawal patients analysed in the groups to which they were originally } \\
\text { allocated. } \\
\text { All patients included in final calculations including withdrawal patients, } \\
\text { regardless of whether their final outcomes were measured. }\end{array}$ \\
\hline No & $\begin{array}{l}\text { No explanation of withdrawal patients or the significance of these } \\
\text { withdrawals Withdrawal patients not analysed in the groups to which they } \\
\text { were originally allocated. }\end{array}$ \\
\hline Unclear & $\begin{array}{l}\text { Withdrawal patients incompletely described. } \\
\text { Numbers of withdrawal patients do not match result figures. } \\
\text { Description of above unclear or unsatisfactory. }\end{array}$ \\
\hline
\end{tabular}

Reviewer's response/comment:

5. Were those assessing outcomes blind to the treatment allocation?

\begin{tabular}{|l|l|}
\hline Yes & $\begin{array}{l}\text { Researchers collecting data on outcome measure(s) were unaware of } \\
\text { which group the patient belonged to. }\end{array}$ \\
\hline No & $\begin{array}{l}\text { Researchers collecting data on outcome measure(s) were aware of which } \\
\text { group the patient belonged to. }\end{array}$ \\
\hline Unclear & Description of above unclear or unsatisfactory. \\
\hline
\end{tabular}

Reviewer's response/comment: 


\section{Were the control and treatment groups comparable at entry?}

\begin{tabular}{|l|l|}
\hline Yes & $\begin{array}{l}\text { At a minimum, the following baseline data for the patients was reported: } \\
\text { - }\end{array}$ \\
& $\begin{array}{l}\text { - } \text { Age } \\
\text { - }\end{array}$ \\
\hline No & $\begin{array}{l}\text { No or minimal reporting of baseline data i.e. only age and sex reported } \\
\text { with no indication of individual baseline measurements for intended } \\
\text { outcome measures. }\end{array}$ \\
\hline Unclear & Description of above unclear or unsatisfactory. \\
\hline
\end{tabular}

Reviewer's response/comment:

7. Were groups treated identically other than for the named interventions?

\begin{tabular}{|l|l|}
\hline Yes & $\begin{array}{l}\text { Patients in both the mealtime intervention and control groups were treated } \\
\text { identically for all other aspects of nutritional care. }\end{array}$ \\
\hline No & $\begin{array}{l}\text { Patients in each group were treated differently in respect to other aspects } \\
\text { of nutritional care. }\end{array}$ \\
\hline Unclear & Description of above unclear or unsatisfactory. \\
\hline
\end{tabular}

Reviewer's response/comment:

8. Were outcomes measured in the same way for all groups?

\begin{tabular}{|l|l|}
\hline Yes & $\begin{array}{l}\text { Description of how data were measured and collected. } \\
\text { - }\end{array}$ \\
- Dietary intake obtained using the same method. \\
\\
- Dietary data analysed to obtain energy and protein intakes using the \\
- Weight obtained using the same method.
\end{tabular}




\begin{tabular}{|c|c|}
\hline & $\begin{array}{l}\text { - Height obtained using the same method. } \\
\text { - Nutritional status obtained using the same screening or assessment } \\
\text { tool. }\end{array}$ \\
\hline No & $\begin{array}{l}\text { Description of how outcome data were measured and collected different } \\
\text { for each group. }\end{array}$ \\
\hline Unclear & Description of above unclear or unsatisfactory. \\
\hline
\end{tabular}

Reviewer's response/comment:

\section{Were outcomes measured in a reliable way?}

\begin{tabular}{|c|c|}
\hline Yes & $\begin{array}{l}\text { All outcomes measured using standard methods or instruments. } \\
\text { - } \text { Dietary intake obtained using either subjective visual estimation of } \\
\text { plate waste, weighed plate waste or subjective food intake charts. } \\
\text { - } \quad \text { Dietary intake data were analysed to obtain energy and protein intakes } \\
\text { manually or by using computer program by trained personnel. } \\
\text { - Weight obtained using calibrated scales or weigh bed. } \\
\text { - Height obtained using stadiometer (height rod), ulna length demispan } \\
\text { or knee-height caliper. } \\
\text { - Nutritional status obtained by using screening or assessment tools } \\
\text { validated for the acute care setting. } \\
\text { Screening: } \\
>\text { Malnutrition Screening Tool (MST) } \\
>\text { Malnutrition Universal Screening Tool ('MUST') } \\
>\text { Mini-Nutritional Assessment-Short Form (MNA) } \\
>\text { Nutritional Risk Screening (NRS-2002) } \\
>\text { Simplified Nutritional Assessment Questionnaire } \\
\text { (SNAQ) } \\
>\text { Assessment: } \\
\text { (PG-SGA) }\end{array}$ \\
\hline
\end{tabular}




\begin{tabular}{|l|l|}
\hline \multirow{1}{*}{} & \multicolumn{1}{c|}{$\begin{array}{l}\text { Mini-Nutritional Assessment (MNA) } \\
\text { If alternative methods to the above used to collect outcome measures } \\
\text { author(s) report on the reliability and/or validity of the methods used } \\
\text { including any training provided for data collectors. }\end{array}$} \\
\hline No & $\begin{array}{l}\text { Estimates or self reported outcomes reported. } \\
\text { Incorrect or non standard methods or instruments used. } \\
\text { No reporting on the reliability and/or validity of the methods used for } \\
\text { measuring outcome or training provided for data collectors. }\end{array}$ \\
\hline Unclear & \begin{tabular}{l} 
Description of above unclear or unsatisfactory. \\
\hline
\end{tabular}
\end{tabular}

Reviewer's response/comment:

10. Was appropriate statistical analysis used and reported?

\begin{tabular}{|l|l|}
\hline Yes & $\begin{array}{l}\text { Appropriate statistical methods used, described and reported. } \\
\text { Numbers of patients with missing data reported and description of how this } \\
\text { was dealt with in reporting. }\end{array}$ \\
\hline No & $\begin{array}{l}\text { Statistical methods not described or inappropriate methods used. } \\
\text { Missing patient data not reported or accounted for. }\end{array}$ \\
\hline Unclear & Description of above unclear or unsatisfactory. \\
\hline
\end{tabular}

Reviewer's response/comment: 


\section{Appendix 4 Data extraction tool}

Reviewer: Date:

Author: Year:

Journal: Record Number:

Title:

\section{Study Method}

RCT

Retrospective

Quasi-RCT

Observational

Longitudinal

$\square \quad$ Other

\section{Participants}

Setting:

Population:

\section{Sample size}

Group A: Group B:

Intervention

Intervention 1

Intervention 2

\section{Outcomes}

\begin{tabular}{|l|l|}
\hline Outcome description & Scale/measurement \\
\hline & \\
\hline & \\
\hline & \\
\hline & \\
\hline
\end{tabular}


Study results

Dichotomous data

\begin{tabular}{|l|l|l|}
\hline Outcome & $\begin{array}{c}\text { Intervention ( ) number/total } \\
\text { number }\end{array}$ & $\begin{array}{c}\text { Intervention ( ) number/total } \\
\text { number }\end{array}$ \\
\hline & & \\
\hline & & \\
\hline & & \\
\hline & & \\
\hline
\end{tabular}

Continuous data

\begin{tabular}{|l|l|l|}
\hline Outcome & $\begin{array}{c}\text { Intervention ( ) number/total } \\
\text { number }\end{array}$ & $\begin{array}{c}\text { Intervention ( ) number/total } \\
\text { number }\end{array}$ \\
\hline & & \\
\hline & & \\
\hline & & \\
\hline & & \\
\hline
\end{tabular}

\section{Authors conclusion}


Reviewers comments 


\section{Appendix 5 Excluded studies}

Alford DM. Tips on promoting food and fluid intake in the elderly. Journal of Gerontological Nursing. 1991;17(11):44-46.

Reason for exclusion: Paper could not be retrieved.

Amella EJ. Assessment and management of eating and feeding difficulties for older people: a NICHE protocol. Geriatric Nursing. 1998;19(5):269-274.

Reason for exclusion: Not a study; discussion paper on assessment and strategies for managing eating difficulties in the elderly.

Best C, Summers J. Strategies for nutritional care in acute settings. Nursing older people. 2010;22(6):27-31.

Reason for exclusion: Not a study; discussion paper on factors that influence nutritional intake of elderly patients in hospital.

Caplan GA, Harper EL. Recruitment of volunteers to improve vitality in the elderly: The REVIVE study. Internal Medicine Journal. 2007;37(2):95-100.

Reason for exclusion: Study does not meet inclusion criteria of the systematic review.

Cartwright A. The ward hostess: a quality initiative. Nursing Times. 2000;96(18):37-38.

Reason for exclusion: Intervention study using ward hostess in elderly ward, but no detail regarding participants and limited information regarding outcome measures.

Chang CC, Roberts BL. Strategies for feeding patients with dementia. American Journal of Nursing. 2011;111(4):36-44.

Reason for exclusion: Not a study; discussion paper on assessing and managing feeding difficulties in patients with dementia.

Coxall K, Dawes E, Forsyth E, Lloyd H. Applying the key principles of nutrition to nursing practice. Nursing standard (Royal College of Nursing (Great Britain):1987). 2008;22(36):44-8.

Reason for exclusion: Not a study; discussion paper on good nutrition, screening and mealtimes for adult and paediatric patients.

Davidson A. Protecting Mealtimes. Nursing Management 2005 2005;12(5):32-6.

Reason for exclusion: Study does not meet inclusion criteria of systematic review as an audit of who interrupts patients at mealtimes and reasons for the interruptions.

Davis C. Mealtime solutions. Nursing standard (Royal College of Nursing (Great Britain):1987). 2007;21(41):21-3.

Reason for exclusion: Not a study; discussion paper on implementing 'red trays' and similar identification systems in hospitals. 
Dickinson A, Welch C, Ager L. No longer hungry in hospital: Improving the hospital mealtime experience for older people through action research. Journal of Clinical Nursing. 2008;17(11):1492-502.

Reason for exclusion: Study does not meet inclusion criteria of systematic review as involved changes to nursing practice and the effect on patient mealtime experience.

Dube L, Paquet C, Ma Z, St-Arnaud McKenzie D, Kergoat MJ, Ferland G. Nutritional implications of patient-provider interactions in hospital settings: Evidence from a within-subject assessment of mealtime exchanges and food intake in elderly patients. European Journal of Clinical Nutrition. 2007;61(5):664-72.

Reason for exclusion: Study does not meet inclusion criteria as set in geriatric rehabilitation unit.

Eberhardie C. Assessment and management of eating skills in the older adult. Professional Nurse. 2004 Feb 2004;19(6):318-22.

Reason for exclusion: Not a study; discussion paper on assessing and managing eating in the elderly.

Gibbons MRD, Henry CJK. Does eating environment have an effect on food intake in the elderly? Journal of Nutrition, Health and Aging. 2005;9(1):25-9.

Reason for exclusion: Study does not meet inclusion criteria of the systematic review as conducted on patients in a community setting.

Green SM, Martin HJ, Roberts HC, Sayer AA. A systematic review of the use of volunteers to improve mealtime care of adult patients or residents in institutional settings. Journal of Clinical Nursing. 2011;20(13-14):1810-23.

Reason for exclusion: Not a study; systematic review on the use of volunteers in a variety of care settings.

Hickson M, Nicholl C, Bulpitt C, Fry M, Frost G, Davies L. The Design of the Feeding Support Trial - Does intensive feeding support improved nutritional status and outcome in acutely ill older in-patients? Journal of Human Nutrition and Dietetics. 1999;12(1):53-9.

Reason for exclusion: Not a study; details of a proposed study.

Holmes S. Nutrition and eating difficulties in hospitalised older adults. Nursing standard (Royal College of Nursing (Great Britain): 1987). 2008;22(26):47-57; quiz 8, 60.

Reason for exclusion: Not a study; discussion paper on nutrition for elderly patients in hospital. Jacobsson C, Axelsson K, Norberg A, Asplund K, Wenngren BI. Outcomes of individualized interventions in patients with severe eating difficulties. Clin Nurs Res 1997 Feb 1997;6(1):25-44.

Reason for exclusion: Case studies, does not meet inclusion criteria of systematic review as on deglutition disorders. 
Capra S, Collins C, Lamb M, Vanderkroft D, Chan SW. Effectiveness of interventions for under nourished older inpatients in the hospital setting. Australian Nursing Journal. 2007 Nov 2007;15(5):28-31.

Reason for exclusion: Not a study; discussion paper based on JBI systematic review. Jefferies $D$, Johnson M, Ravens J. Nurturing and nourishing: The nurses' role in nutritional care. Journal of Clinical Nursing. 2011;20(3-4):317-30.

Reason for exclusion: Not a study; qualitative systematic review on nursing strategies to manage malnutrition.

Kondrup J. Can food intake in hospitals be improved? Clinical Nutrition. 2001;20, Supplement 1(0):153-60.

Reason for exclusion: Study does not meet inclusion criteria of systematic review. Summary of a number of implementation projects and studies on nutrition screening, weighing, monitoring dietary intake and menus in hospital.

Kowanko I. The role of the nurse in food service: A literature review and recommendations. International journal of nursing practice. 1997;3:73-8.

Reason for exclusion: Not a study; literature review on the role of nurses in nutrition and food service.

Krondl M, Coleman P, Lau D. Helping understand nutritional gaps in the elderly (HUNGER): A prospective study of patient factors associated with inadequate nutritional intake in older medical inpatients. Journal of Nutrition for the Elderly. 2008;27(3-4):205-20.

Reason for exclusion: Not a study; discussion paper on food provision for elderly living in various locations and their social economic and health status.

Lassen KO, Kruse F, Bjerrum M, Jensen L, Hermansen K. Nutritional care of Danish medical inpatients: Effect on dietary intake and the occupational groups' perspectives of intervention. Nutrition Journal. 2004;3(12).

Reason for exclusion: Study does not meet inclusion criteria of systematic review as examined effect of forms for assessing nutritional status and guidance for hospital staff regarding management of nutritional outcome and subsequent effect on patents intake. Related to nursing procedure rather than mealtime environment.

Lassen K, Grinderslev E, R Nyholm. Effect of changed organisation of nutritional care of Danish medical inpatients. BMC Health Serv Res. 2008 Aug 2008;7(8):168.

Reason for exclusion: Study does not meet inclusion criteria of systematic review as assessed the collective food waste per ward with and without health care assistants for feeding assistance and not individual patient dietary intakes. 
Ledsham J, Gough A. Screening and monitoring patients for malnutrition. Professional Nurse (London, England). 2000;15(11):695-8.

Reason for exclusion: Not a study; discussion paper on nurses awareness of nutrition, nutritional screening and supervision at mealtimes.

Mahoney S, Zulli A, Walton K. Patient satisfaction and energy intakes are enhanced by point of service meal provision. Nutrition and Dietetics. 2009;66(4):212-20.

Reason for exclusion: Not a study; systematic review on effect of meal delivery systems on nutritional intake.

Mamhidir A-G, Karlsson I, Norberg A, Mona K. Weight increase in patients with dementia, and alteration in meal routines and meal environment after integrity promoting care. Journal of Clinical Nursing. 2007;16(5):987-96.

Reason for exclusion: Study does not meet inclusion criteria of systematic review as conducted on long term care wards.

Manthorpe J, Watson R. Poorly served? Eating and dementia. Journal of Advanced Nursing. 2003;41(2):162-9.

Reason for exclusion: Not a study; literature review with discussion on eating difficulties in dementia.

McKevith B. Undernutrition in elderly people. Practice Nurse. 2007;34(8):33.

Reason for exclusion: Not a study; discussion paper on nutrition in the elderly.

Miceli BV. Nursing unit meal management maintenance program. Continuation of safeswallowing and feeding beyond skilled therapeutic intervention. Journal of Gerontological Nursing. 1999;25(8):22-36; quiz 50-1.

Reason for exclusion: Not a study; description of meal management program for dysphagia. Mudge AM, Ross LJ, Young AM, Isenring EA, Banks MD. Helping understand nutritional gaps in the elderly (HUNGER): A prospective study of patient factors associated with inadequate nutritional intake in older medical inpatients. Clinical Nutrition. 2011;30(3):320-5.

Reason for exclusion: Study does not meet inclusion criteria of systematic review. Prospective cohort study on energy intake and resting energy expenditure.

Murray C. Improving nutrition for older people. Nursing older people. 2006;18(6):18-22.

Reason for exclusion: Not a study; discussion paper on protected mealtimes project. Musson ND, Kincaid J, Ryan P, Glussman B, Varone L, Gamarra N, et al. Nature, nurture, nutrition: Interdisciplinary programs to address the prevention of malnutrition and dehydration. Dysphagia. 1990;5(2):96-101.

Reason for exclusion: Study does not meet inclusion criteria of systematic review as conducted in long term care facilities. 
Parker J, Miller L. Using enter-and-view provision to review hospital nutritional care. Nursing Management (Harrow, London, England : 1994). 2011;18(3):26-9.

Reason for exclusion: Not a study; discussion paper on Local Involvement Network volunteers report on hospital nutrition.

Pedersen PU. Nutritional Care: the effectiveness of actively involving older patients. Journal of Clinical Nursing. 2005;14(2):247-55.

Reason for exclusion: Study does not meet inclusion criteria of systematic review as conducted in a dementia assessment and rehabilitation unit.

Ross LJ, Mudge AM, Young AM, Banks M. Everyone's problem but nobody's job: Staff perceptions and explanations for poor nutritional intake in older medical patients. Nutrition and Dietetics. 2011;68(1):41-6.

Reason for exclusion: Study does not meet inclusion criteria of systematic review as discusses outcome of staff focus groups on nutritional care.

Schenker S. Undernutrition in the UK. Nutrition Bulletin. 2003;28(1):87-120.

Reason for exclusion: Not a study; briefing paper on under-nutrition.

Stuckey CM, editor. The effect of a protected mealtime policy on the energy intake and frequency of non-urgent interruptions during mealtimes at the Royal Bournemouth Hospital. Proceedings of the Nutrition Society; 2010.

Reason for exclusion: Abstract; not enough detail provided.

Stuckey CM, O'Malley G, Matthias S, Hawkins A, Geldart S, Weaver SA, et al. The introduction of nullprotected mealtimes null increases nutritional intake in acute medical patients. Gut. 2009;58(S1):A79-A80.

Reason for exclusion: Abstract; not enough detail provided.

Tsang MF. Is there adequate feeding assistance for the hospitalised elderly who are unable to feed themselves? [corrected] [published erratum appears in NUTR DIET 2008 Dec;65(4):243]. Nutrition \& Dietetics. 2008 Sept 2008;65(3):222-8.

Reason for exclusion: Study does not meet inclusion criteria of systematic review as examined amount and type of feeding assistance elderly patient received.

Ward C. Helping Hands meets the nutritional needs of patients. Volunt Leader. 1994 Summer;35(2):1, 3, 9.

Reason for exclusion: Paper could not be retrieved.

Watson R. Undernutrition, weight loss and feeding difficulty in elderly patients with dementia: A nursing perspective. Reviews in Clinical Gerontology. 1997;7(4):317-26.

Reason for exclusion: Not a study; discussion paper on under-nutrition and dementia. 
Watson R, Green S. Feeding and dementia: a systematic literature review. J Adv Nurs. 2006 Apr 2006;54(1):86-93.

Reason for exclusion: Not a study; systematic review on interventions to promote eating in patients with dementia.

Webster J, Healy J, Maud R. Nutrition in hospitalised patients. Nursing Older People. 2009;21(10):31-7.

Reason for exclusion: Not a study; discussion paper on malnutrition in the elderly which included case studies.

Weekes CE, editor. The effect of protected mealtimes on meal interruptions, feeding assistance, energy and protein intake and plate waste. Proceeding of the Nutrition Society 2008.

Reason for exclusion: Abstract; not enough detail provided.

Westergren A, Karlsson S, Andersson P, Ohlsson O, Hallberg IR. Eating difficulties, need for assisted eating, nutritional status and pressure ulcers in patients admitted for stroke rehabilitation. Journal of Clinical Nursing. 2001;10(2):257-69.

Reason for exclusion: Study does not meet inclusion criteria of systematic review as observational study on eating difficulties and nutritional status.

Westergren A, Torfadóttir T, Ulander K, Axelsson C, Lindholm C. Malnutrition prevalence and precision in nutritional care: An intervention study in one teaching hospital in Iceland. Journal of Clinical Nursing. 2010;19(13-14):1830-7.

Reason for exclusion: Study does not meet inclusion criteria of systematic review as intervention study on point of prevalence of malnutrition risk.

Westergren A, Unosson M, Ohlsson O, Lorefalt B, Hallberg IR. Eating difficulties, assisted eating and nutritional status in elderly ( $>$ or $=65$ years) patients in hospital rehabilitation. International Journal of Nursing Studies. 2002;39(3):341-51.

Reason for exclusion: Study does not meet inclusion criteria of systematic review as observational study of eating difficulties and nutritional status in rehabilitation hospital.

Westergren A, Wann-Hansson C, Borgdal EB, Sjolander J, Stromblad R, Klevsgrd R, et al.

Malnutrition prevalence and precision in nutritional care differed in relation to hospital volume ? A cross-sectional survey. Nutrition Journal. 2009;8(1).

Reason for exclusion: Study does not meet inclusion criteria of systematic review as cross sectional study of nine hospitals examining malnutrition risk.

Wong A, Burford S, Wyles CL, Mundy H, Sainsbury R. Evaluation of strategies to improve nutrition in people with dementia in an assessment unit. Journal of Nutrition, Health and Aging. 2008;12(5):309-12. 
Reason for exclusion: Study does not meet inclusion criteria of systematic review as conducted on dementia assessment and rehabilitation unit.

Xia C, McCutcheon H. Mealtimes in hospital - Who does what? Journal of Clinical Nursing. 2006;15(10):1221-7.

Reason for exclusion: Study does not meet inclusion criteria of the systematic review as descriptive observational study on patient mealtimes.

Young A, Banks M, Mudge A, Ross L, Daniels L, editors. Encouraging, assisting and time to eat: improved nutritional intake for elderly inpatients receiving protected mealtimes and/or additional nursing feeding assistance. Clinical Nutrition Supplements. 2011;6(1):15-6

Reason for exclusion: Abstract; not enough detail provided.

Young A, Mudge A, Banks M, Ross L, Daniels L. Increased assistance and reduced interruptions at mealtimes for elderly inpatients using protected mealtimes with and without additional staffing resources. Clinical Nutrition Supplements. 2010;5(2):35.

Reason for exclusion: Abstract, not enough detail provided. 


\section{Appendix 6 Excluded studies following critical appraisal}

Robinson S, Clump D, Weitzel T, Henderson L, Lee K, Schwartz C, et al. The memorial meal mates: A program to improve nutrition in hospitalized older adults. Geriatric Nursing. 2002;23(6):332-5.

Reason for exclusion: Poor scoring on critical appraisal, due to poor study design and unclear reporting of outcome measures.

Wilson A. A comparison of the amount of food served and consumed according to meal service. Journal of Human Nutrition \& Dietetics. 2000;13:271-5.

Reason for exclusion: Poor scoring on critical appraisal, unclear reporting of control and intervention groups characteristics and treatment.

Hickson M, Connolly A, Whelan K. Impact of protected mealtimes on ward mealtime environment, patient experience and nutrient intake in hospitalised patients. Journal of Human Nutrition and Dietetics. 2011;24(4):370-4.

Reason for exclusion: Poor scoring on critical appraisal, unclear reporting of outcomes. 


\section{References}

References

1. Watterson C, Fraser A, Banks M, Isenring E, Miller M, Silvester C, et al. Evidence based practice guidelines for the nutritional management of malnutrition in adult patients across the continuum of care. Nutrition and Dietetics. 2009;66(SUPPL. 3):S1-S34.

2. Ross LJ, Mudge AM, Young AM, Banks M. Everyone's problem but nobody's job: Staff perceptions and explanations for poor nutritional intake in older medical patients. Nutrition and Dietetics. 2011;68(1):41-6.

3. McWhirter JP, Pennington CR. Incidence and recognition of malnutrition in hospital. BMJ. 1994;308(6934):945-8.

4. Elia M, Zellipour L, Stratton RJ. To screen or not to screen for adult malnutrition? Clinical Nutrition. 2005;24(6):867-84.

5. Stratton RJ, Green CJ, Elia M. Disease-related malnutrition: an evidence-based approach to treatment. Wallingford, Oxfordshire: CABI Publishing; 2003.

6. Schenker S. Undernutrition in the UK. Nutrition Bulletin. 2003;28(1):87-120.

7. Braunschweig C, Gomez S, Sheean PM. Impact of declines in nutritional status on outcomes in adult patients hospitalized for more than 7 days. Journal of the American Dietetic Association. 2000;100:1316-22.

8. Norman K, Pichard C, Lochs H, Pirlich M. Prognostic impact of disease-related malnutrition. Clinical Nutrition. 2008;27:5-15.

9. Roubenoff R. Sarcopenia Current Concepts. The Journal of Gerontology. 2000;55(12):716-24.

10. Morley JE. Anorexia, Sarcopenia, and Aging. Nutrition 2001;17:660-3.

11. NICE. Nutrition Support for Adults Oral Nutrition Support, Enteral Tube Feeding and Parenteral Nutrition. National Institute for Health and Clinical Excellence; 2006.

12. Ferguson $\mathrm{M}$, Capra $\mathrm{S}$. Coding for malnutrition enhances reimbursement under casemixbased funding. . Australian Journal of Nutrition \& Dietetics. 1997;54(3):102-8.

13. Gout BS, Barker LA, Crowe TC. Malnutrition identification, diagnosis and dietetic referrals: are we doing a good enough job? Nutrition \& Dietetics. 2009;66(4):206-11.

14. Barker LA. Hospital Malnutrition: Prevalence, Identification and Impact on Patients and the Healthcare System. International Journal of Environmental Res Public Health 2011;8:51427.

15. Weekes CE, Spiro A, Baldwin C, Whelan K, Thomas JE, Parkin D, et al. A review of the evidence for the impact of improving nutritional care on nutritional and clinical outcomes and cost. Journal of Human Nutrition and Dietetics. 2009;22:324-35.

16. Mahoney S, Zulli A, Walton K. Patient satisfaction and energy intakes are enhanced by point of service meal provision. Nutrition and Dietetics. 2009;66(4):212-20.

17. Naithani S, Whelan K, Thomas J, Gulliford MC, Morgan M. Hospital inpatients' experiences of access to food: A qualitative interview and observational study. Health Expectations. 2008;11(3):294-303.

18. Stanga Z, Zurflüh Y, Roselli M, Sterchi AB, Tanner B, Knecht G. Hospital food: a survey of patients' perceptions. Clinical Nutrition. 2003;22(3):241-6.

19. Nightingale F. Notes on Nursing: What It Is, and What It Is Not [eBook]. London, UK: Hanson \& Son; 1859.

20. Hungry in hospital: Association of community health councils for England and Wales 1997.

21. Xia C, McCutcheon H. Mealtimes in hospital - Who does what? Journal of Clinical Nursing. 2006;15(10):1221-7. 
22. BAPEN. Council of Europe Resolution Food and Nutritional Care in Hospitals 10 Key Characteristics of good nutritional care in hospitals.: British Association for Enteral and Parenteral Nutrition 2003.

23. Resolution $\operatorname{ResAP}(2003) 3$ on food and nutritional care in hospitals Committee of Ministers, Council of Europe(2003).

24. Hungry to be heard the scandal of malnourished older people in hospital: Age Concern 2006.

25. Still Hungry to be Heard - The scandal of people in later life becoming malnourished in hospital: Age UK 2010.

26. Pearson A, Fitzgerald M, Nay R. Mealtimes in nursing homes: the role of nursing staff. Journal of gerontological nursing. 2003;29(6):40-7.

27. Kowanko I, Simon S, Wood J. Nutritional care of the patient: nurses' knowledge and attitudes in an acute care setting. Journal of Clinical Nursing. 1999;8(2):217-24.

28. Meijers J. Defining malnutrition: Mission or mission impossible? Nutrition 2010;26:432-

40.

29. Jensen GL, Mirtallo J, Compher C, Dhaliwal R, Forbes A, Grijalba RF, et al. Adult starvation and disease-related malnutrition: A proposal for etiology-based diagnosis in the clinical practice setting from the International Consensus Guideline Committee. Clinical Nutrition. 2010.

30. Allison SP. Malnutrition, disease, and outcome. Nutrition. 2000;16(7-8):590-3.

31. WHO. World Health Organisation 2012; Available from:

http://www.who.int/classifications/icd/en/.

32. ICD-10-AM Seventh edition. Codes for Malnutrition (E40-E46) Patient safety and quality improvement service. Patient safety and quality improvement service, Centre for Healthcare Improvement, Queensland Government; 2012.

33. Todorovic VE, Micklewright A, editors. A Pocket Guide To Clinical Nutrition. Third ed: British Dietetic Association; 2004.

34. Appropriate body-mass index for Asian populations and its implications for policy and intervention strategies. Lancet. [Article]. 2004;363(9403):157-63.

35. Jones JM. Nutritional Screening and assessment tools. New York: Nov Science Publishers Inc; 2006.

36. Naber TH, Schermer T, de Bree A, Nusteling K, Eggink L, Kruimel JW, et al. Prevalence of malnutrition in nonsurgical hospitalized patients and its association with disease complications. Am J Clin Nutr. 1997 1997;66(5):1232-9.

37. Middleton MH, Nazarenko G, Nivison-Smith I, Smerdely P. Prevalence of malnutrition and 12-month incidence of mortality in two Sydney teaching hospitals. Intern Med J. 2001;31(8):455-61.

38. Pirlich M, Schutz T, Norman K. The German hospital malnutrition study. Clinical Nutrition 2006;25:563-72.

39. Banks M, Ash S, Bauer J, Gaskill D. Prevalence of malnutrition in adults in Queensland public hospitals and residential aged care facilities. Nutrition \& Dietetics. [Article]. 2007;64(3):1728.

40. Rasmussen HH, Kondrup J, Staun M, Ladefoged K, Kristensen H, Wengler A. Prevalence of patients at nutritional risk in Danish hospitals. Clinical Nutrition. 2004;23(5):100915.

41. Agarwal E, Ferguson M, Banks M, Batterhamd M, Bauer J, Capra S, et al. Nutrition care practices in hospital wards: Results from the Nutrition Care Day Survey 2010. Clinical Nutrition. 2012.

42. Isabel TD, Correia M, Campos ACL. Prevalence of hospital malnutrition in Latin America: The multicenter ELAN study. Nutrition. 2003;19(10):823-5.

43. Pirlich M, Schütz T, Kemps M, Luhman N, Minko N, Lübke HJ, et al. Social risk factors for hospital malnutrition. Nutrition 2005;21:295-300. 
44. Shiwaku K, Anuurad E, Enkhmaa B, Kitajima K, Yamane Y. Appropriate BMI for Asian populations. [Letter]. 2004;363:1077.

45. Arrowsmith $\mathrm{H}$. Nutrition. Malnutrition in hospital: detection and consequences. British Journal of Nursing (BJN). 1997;6(19):1131-5.

46. Elia M, Stroud MA. Nutrition in acute care. Clinical Medicine 2004;4:405-7.

47. Holmes S. Nutrition and eating difficulties in hospitalised older adults. Nursing standard

(Royal College of Nursing (Great Britain): 1987). 2008;22(26):47-57; quiz 8, 60.

48. Coleman Y. Drug-Nutrient Interactions Favourite Fifty. Hawthorn, Victoria, Australia:

Nutrition Consultants Australia; 2005.

49. Allison SP. Hospital food as treatment. Clinical Nutrition. 2003;22(2):113-4.

50. Allison SP. The management of malnutrition in hospital. Proceedings of the Nutrition Society 1996;55:855-62.

51. Edwards JSA, Nash AHM. The nutritional implications of food wastage in hospital food service management. Nutrition \& Food Science. 1999;99(2):89-98.

52. Gall MJ, Grimble GK, Reeve RJ, Thomas SJ. Effect of providing fortified meals and between meal snacks on energy and protein intake of hospitalised patients. Clinical Nutrition. 1998;17(6):259-64.

53. Kowanko I, Simon S, Wood J. Energy and nutrient intake of patients in acute care. Journal of Clinical Nursing 2001;10:51-7.

54. Almdal T, Viggers L, Beck AM, Jensen K. Food production and wastage in relation to nutritional intake in a general district hospital- wastage is not reduced by training the staff. Clinical Nutrition 2003;22(1):47-51.

55. Williams $P$, Walton K. Plate waste in hospitals and strategies for change. e-SPEN, the European e-Journal of Clinical Nutrition and Metabolism. 2011;6(6):e235-e41.

56. Edwards JSA. Food service management in hospitals. International Journal of Contemporary Hospitality Management. 2000;12(4):262-6.

57. Nijs KAND, de Graaf C, Siebelink E, Blauw YH, Vanneste V, Kok FJ, et al. Effect of Family-Style Meals on Energy Intake and Risk of Malnutrition in Dutch Nursing Home Residents: A Randomized Controlled Trial. Journal of Gerontology. 2006;61A(9):935-42.

58. Nightingale JMD, Reeves J. Knowledge about the assessment and management of undernutrition: A pilot questionnaire in a UK teaching hospital. Clinical Nutrition. 1999;18(1):23-7. 59. Saunders J, Smith T. Malnutrition: causes and consequences. Clinical Medicine, Journal of the Royal College of Physicians. 2010;10(6):624-7.

60. Kubrak $C$, Jensen L. Malnutrition in acute care patients: A narrative review. International Journal of Nursing Studies. 2007;44(6):1036-54.

61. Laurance J. Malnutrition in hospitals more rife than believed The Independent. 2010.

62. AlHW. Australia's hospitals at a glance 2010-112012 29/07/12]: Available from:

http://www.aihw.gov.au/australias-hospitals-at-a-glance-2010-11/.

63. Scott IA. Public hospital bed crisis: too few or too misused? Australian Health Review. 2010;34(3):317-24.

64. Population by Age and Sex, Australian States and Territories. In: Statistics ABo, editor.2010.

65. Elia M, Russell CA. Combating Malnutrition: Recommendations For Action2008.

66. Chima CS, Barco K, Dewitt MLA, Maeda M, Mullen KD, Teran C. Relationship of nutritional status to length of stay, hospital costs, and discharge status of patients hospitalized in the medicine service. Journal of the American Dietetic Association. [Article]. 1997 1997/09//:97(9):975+.

67. Amarala TF, Matosa LC, Tavaresa MM, Subtilb A, Martinsa R, Nazare'a M, et al. The economic impact of disease-related malnutrition at hospital admission. Clinical Nutrition 2007;26:778-84. 
68. Isabel TD, Correia M, Waitzberg DL. The impact of malnutrition on morbidity, mortality, length of hospital stay and costs evaluated through a multivariate model analysis. Clinical Nutrition. 2003;22(3):235-9.

69. Smith AE, Smith PE. High-quality nutritional interventions reduce costs. Healthcare Financial Management. [Article]. 1997 1997/08//;51(8):66+.

70. Beck AM, Balkn UN, FÜRst P, Hasunen K, Jones L, Keller U, et al. Food and nutritional care in hospitals: how to prevent undernutrition-report and guidelines from the Council of Europe. Clinical Nutrition. 2001;20(5):455-60.

71. Kondrup J. Proper hospital nutrition as a human right. Clinical Nutrition. 2004;23(2):1357.

72. Protected Mealtimes Review Findings and Recommendations Report. National Health Service National Patient Safety Agency; 2007. p. 1-19.

73. Brotherton A, Simmonds N, Stroud M. Malnutrition Matters - Meeting Quality Standards in Nutritional Care: A Toolkit for Commissioners and Providers in England 2010.

74. Schindler K, Pernicka E, Laviano A, Howard P, Schütz T, Bauer P, et al. How nutritional risk is assessed and managed in European hospitals: A survey of 21,007 patients findings from the 2007-2008 cross-sectional nutrition day survey. Clinical Nutrition 2010;29(552-559).

75. Kondrup J, Johansen N, Plum LM, Bak L, Hojlund Larsen I, Martinsen A, et al. Incidence of nutritional risk and causes of inadequate nutritional care in hospitals. Clinical Nutrition 2002;21(6):461-8.

76. Tsang MF. Is there adequate feeding assistance for the hospitalised elderly who are unable to feed themselves? [corrected] [published erratum appears in Nutr Diet 2008 Dec;65(4):243]. Nutrition \& Dietetics. 2008 Sept 2008;65(3):222-8.

77. Korner U, Bondolfi A, Buhler E, MacFie J, Meguid MM, Messing B, et al. Ethical and Legal Aspects of Enteral Nutrition. Clinical Nutrition 2006;25(196-202).

78. Merlin T, Weston A, Tooher R. Extending an evidence hierarchy to include topics other than treatment: revising the Australian 'levels of evidence'. BMC Medical Research Methodology. 2009;9(34):1-8.

79. NHMRC. How to use the evidence: assessment and application of scientific evidence. Canberra: Biotext; 2000.

80. Connors PL, Rozell SB. Using a visual plate waste study to monitor menu performance. Journal of the American Dietetic Association. 2004;104(1):94-6.

81. Scognamiglio U, Salvia A, Paolucci S, Garbagnati F, Caltagirone C, Musicco M. Validity of a questionnaire for the semi-quantitative evaluation of dietary intake of hospitalised patients compared to weighed records. Journal of Human Nutrition and Dietetics. 2012.

82. Sherwin AJ, Nowson CA, McPhee J, Alexander JL, Wark JD, Flicker L. Nutrient intake at meals in residential care facilities for the aged: validated visual estimation of plate waste.

Australian Journal of Nutrition \& Dietetics. 1998;55(4):188-93.

83. Vanderkroft D, Collins CE, FitzGerald M, Lewis S, Neve M, Capra S. Minimising undernutrition in the older inpatient. International Journal of Evidence-Based Healthcare. 2007;5(2):110-81.

84. Milne AC, Potter J, Vivanti A, Avenell A. Protein and energy supplementation in elderly people at risk from malnutrition. Cochrane Database of Systematic Reviews. 2009(2).

85. Jackson J. The effectiveness of interventions to reduce undernutrition and promote eating in older adults with dementia: A systematic review. 2011.

86. Westergren A. Eating difficulties, need for assisted eating, nutritional status and pressure ulcers in patients admitted for stroke rehabilitation. Journal of Clinical Nursing. 2001;10(2):25769.

87. Davis C. Mealtime solutions. Nursing standard (Royal College of Nursing (Great Britain) : 1987). 2007;21(41):21-3. 
88. Stuckey CM, O'Malley G, Matthias S, Hawkins A, Geldart S, Weaver SA, et al. The introduction of nullProtected Mealtimesnull increases nutritional intake in acute medical patients. Gut2009. p. A79-A80.

89. Murray C. Improving nutrition for older people. Nursing older people. 2006;18(6):18-22.

90. Protected Mealtimes policy - draft. Victorian Government. p. 1-2. Available from:

http://www.health.vic.gov.au/older/toolkit/05Nutrition/docs/Policy\%20Title\%20\%20Protected\%20 Mealtimes.pdf.

91. Jefferies D, Johnson M, Ravens J. Nurturing and nourishing: The nurses' role in nutritional care. Journal of Clinical Nursing. 2011;20(3-4):317-30.

92. Green SM, Martin HJ, Roberts HC, Sayer AA. A systematic review of the use of volunteers to improve mealtime care of adult patients or residents in institutional settings. Journal of Clinical Nursing. 2011;20(13-14):1810-23.

93. Wright $L$, Cotter $D$, Hickson $M$. The effectiveness of targeted feeding assistance to improve the nutritional intake of elderly dysphagic patients in hospital. Journal of Human Nutrition and Dietetics. 2008;21(6):555-62.

94. Walton K, Williams P, Tapsell L. Improving food services for elderly, long-stay patients in Australian hospitals: Adding food fortification, assistance with packaging and feeding assistance. Nutrition \& Dietetics. 2012;69(2):137-44.

95. Robinson S, Clump D, Weitzel T, Henderson L, Lee K, Schwartz C, et al. The memorial meal mates: A program to improve nutrition in hospitalized older adults. Geriatric Nursing. 2002;23(6):332-5.

96. Brown $\mathrm{H}$, Jones $\mathrm{L}$. The role of dining companions in supporting nursing care. Nursing Standard. 2009;23(41):40-6.

97. Hickson M, Bulpitt C, Nunes M, Peters R, Cooke J, Nicholl C, et al. Does additional feeding support provided by health care assistants improve nutritional status and outcome in acutely ill older in-patients? - A randomised control trial. Clinical Nutrition. 2004;23(1):69-77. 98. Duncan DG. Using dietetic assistants to improve the outcome of hip fracture: a randomised controlled trial of nutritional support in an acute trauma ward. Age and Aging. 2006;35:148-53.

99. Walton K, Williams P, Bracks J, Zhang Q, Pond L, Smoothy R, et al. A volunteer feeding assistance program can improve dietary intakes of elderly patients - A Pilot Study. Appetite. 2008;51(2):244-8.

100. Wright L, Hickson M, Frost G. Eating together is important: Using a dining room in an acute elderly medical ward increases energy intake. Journal of Human Nutrition and Dietetics. 2006;19(1):23-6.

101. Edwards JSA, Hartwell HJ. A comparison of energy intake between eating positions in a NHS hospital-a pilot study. Appetite. 2004;43(3):323-5.

102. Harris AD, Bradham DD, Baumgarten M, Zuckerman IH, Fink JC, Perencevich EN. The Use and Interpretation of Quasi-Experimental Studies in Infectious Diseases. Clinical Infectious Diseases. 2004;38:1586-91.

103. Hickson M, Connolly A, Whelan K. Impact of protected mealtimes on ward mealtime environment, patient experience and nutrient intake in hospitalised patients. Journal of Human Nutrition and Dietetics. 2011;24(4):370-4.

104. Wilson A. A comparison of the amount of food served and consumed according to meal service. Journal of Human Nutrition \& Dietetics. 2000;13:271-5.

105. Wright L, Cotter D, Hickson M, Frost G. Comparison of energy and protein intakes of older people consuming a texture modified diet with a normal hospital diet. Journal of Human Nutrition \& Dietetics. 2005;18:213-9.

106. Dietetic Assistants. Professional Development Committee. Briefing Paper No.10. Birmingham: British Dietetic Association 1999. 
107. Le Cornu KA, Halliday D. A study to investigate perceptions of the role of the dietetic support worker by dietitians and dietetic support workers in the NHS. Journal of Human Nutrition and Dietetics. 2008;21(4):393-4.

108. Faulkner M, Davies S. Social support in the healthcare setting: the role of volunteers. Health \& Social Care in the Community. 2005;13(1):38-45.

109. Skoglund AG. Do Not Forget about Your Volunteers: A Qualitative Analysis of Factors Influencing Volunteer Turnover. Health \& Social Work. 2006;31(3):217-20.

110. Zweigenhaft RLAJFA. The Motivations and Effectiveness of Hospital Volunteers. Journal of Social Psychology. [Article]. 1996;136(1):25-34.

111. Teasdale S. As national Volunteers Week begins today, Simon Teasdale looks at the changing profile of volunteers in the NHS. The Guardian. 20071 June 2007.

112. Manning F, Harris K, Duncan R, Walton K, Bracks J, Larby L, et al. Additional feeding assistance improves the energy and protein intakes of hospitalised elderly patients. A health services evaluation. Appetite. 2012;59(2):471-7.

113. Herman CP, Roth DA, Polivy J. Effects of the Presence of Others on Food Intake: A Normative Interpretation. Psychological Bulletin. 2003;129(6):873-86.

114. de Castro JM. Family and friends produce greater social facilitation of food intake than other companions. Physiology \& Behavior. 1994;56(3):445-55.

115. Clendenen VI, Herman CP, Polivy J. Social Facilitation of Eating Among Friends and Strangers. Appetite. 1994;23(1):1-13.

116. Hetherington MM, Anderson AS, Norton GNM, Newson L. Situational effects on meal intake: A comparison of eating alone and eating with others. Physiology and Behavior. 2006;88(4-5):498-505.

117. Ragneskog H, Brane G, Karlsson I, Kihlgren M. Influence of dinner music on food intake and symptoms common in dementia. Scandinavian Journal of Caring Sciences. 1996;10(1):11-7.

118. Stroebele $\mathrm{N}$, de Castro JM. Listening to music while eating is related to increases in people's food intake and meal duration. Appetite. 2006;47(3):285-9.

119. Higgins JPT, Altman DG. Assessing Risk of Bias in Included Studies. Cochrane Handbook for Systematic Reviews of Interventions: John Wiley \& Sons, Ltd; 2008. p. 187-241.

120. Morris H. Dysphagia in the elderly -- a management challenge for nurses. British Journal of Nursing. 2006;15(10):558-62.

121. Leslie P, Carding PN, Wilson JA. Investigation and management of chronic dysphagia. British Medical Journal. 2003;326:433-6.

122. Finestone HM, Greene-Finestone LS. Rehabilitation medicine: 2. Diagnosis of dysphagia and its nutritional management for stroke patients. CMAJ: Canadian Medical Association Journal. [Article]. 2003;169(10):1041-4.

123. Penman JP, Thomson M. A review of the textured diets developed for the management of dysphagia. Journal of Human Nutrition \& Dietetics. 1998;11(1):51-60.

124. Rosenvinge SK, Starke ID. Improving care for patients with dysphagia. Age and Ageing. 2005 November 2005;34(6):587-93.

125. Guyomard V, Fulcher RA, Redmayne O, Metcalf AK, Potter JF, Myint PK. Effect of dysphasia and dysphagia on inpatient mortality and hospital length of stay: a database study. Journal of the American Geriatrics Society. 2009;57(11):2101-6.

126. Delgado-Rodríguez M, Llorca J. Bias. Journal of Epidemiology and Community Health. 2004 August 1, 2004;58(8):635-41.

127. Newell DJ. Intention-to-Treat Analysis: Implications for Quantitative and Qualitative Research. International Journal of Epidemiology. 1992 October 1, 1992;21(5):837-41.

128. Heritier SR, Gebski VJ, Keech AC. Inclusion of patients in clinical trial analysis: the intention-to-treat principle. Medical Journal of Australia. 200320 October 2003;179.

129. Campbell SE, Seymour DG, Primrose WR. A systematic literature review of factors affecting outcome in older medical patients admitted to hospital. Age and Ageing. 2004 March 1, 2004;33(2):110-5. 
130. Black D, Pearson M. Average length of stay, delayed discharge, and hospital congestion. A combination of medical and managerial skills is needed to solve the problem. British Medical Journal. 2002;325:610-1.

131. Ward C. Helping Hands meets the nutritional needs of patients. Volunt Leader. 1994 Summer;35(2):1, 3, 9.

132. Alford DM. Tips on promoting food and fluid intake in the elderly. Journal of gerontological nursing. 1991;17(11):44-6.

133. Hotchkiss RB, Fottler MD, Unruh L. Valuing volunteers: The impact of volunteerism on hospital performance. Health Care Manage Rev. 2009;34(2):119-28.

134. Handy F, Srinivasan N. The Demand for Volunteer Labor: A Study of Hospital Volunteers. Nonprofit and Voluntary Sector Quarterly. 2005;34(4):491-509.

135. Bauer J, Capra S, Ferguson M. Use of the scored Patient-Generated Subjective Global Assessment (PG-SGA) as a nutrition assessment tool in patients with cancer. European Journal of Clinical Nutrition. [Article]. 2002;56(8):779.

136. Dickinson A, Welch C, Ager L. No longer hungry in hospital: Improving the hospital mealtime experience for older people through action research. Journal of Clinical Nursing. 2008;17(11):1492-502.

137. Chang $\mathrm{C}$, Roberts BL. Feeding difficulty in older adults with dementia. Journal of Clinical Nursing. 2008;17(17):2266-74. 